


\section{Aller Künste Wissenschaft}

Die Sammlung des Johann Friedrich von Uffenbach (1687-1769) 
Bibliografische Information

Die Deutsche Nationalbibliothek verzeichnet diese Publikation in der Deutschen Nationalbibliografie; detaillierte bibliografische Daten sind im Internet über http://dnb.dnb.de abrufbar.

\section{Aller Künste Wissenschaft Die Sammlung des Johann Friedrich von Uffenbach (1687-1769)}

Publikation zur gleichnamigen Ausstellung (6. November 2021 bis 13. Februar 2022) in der Kunstsammlung der Georg-August-Universität Göttingen In Kooperation mit der Niedersächsischen Staats- und Universitätsbibliothek Göttingen

Herausgegeben von

Arwed Arnulf, Christian Fieseler und Anne-Katrin Sors

unter Mitarbeit von

Nadja Kehe und Ines Reiss

Satz, Layout, Bildbearbeitung und Umschlaggestaltung:

Katja Töpfer

\section{Abbildungsnachweise:}

Kunstsammlung: Katharina Anna Haase

Niedersächsische Staats- und Universitätsbibliothek: Martin Liebetruth

Wissenschaftliche Instrumente: Sauer Marketing Göttingen

Dieses Buch ist auch als freie Onlineversion über die Homepage des Verlags sowie über den Göttinger Universitätskatalog (GUK) bei der Niedersächsischen Staatsund Universitätsbibliothek Göttingen (https://www.sub.uni-goettingen.de) erreichbar. Es gelten die Lizenzbestimmungen der Onlineversion.

(C) 2021 Universitätsverlag Göttingen http:/ / univerlag.uni-goettingen.de ISBN: 978-3-86395-515-1 doi:10.17875/gup2021-1777 


\section{Inhalt}

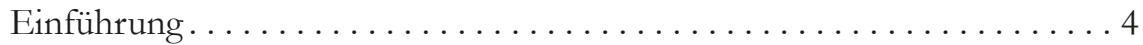

Uffenbachs Sammlung. ............................ 10

Curieuse Dinge................................ 12

Gelehrtes Beisammensein .............................. 14

Wissenschaftliche Kunstwerke . . . . . . . . . . . . . . . . . . . . 16

Reisen im 18. Jahrhundert ........................... 18

Reiseplanung. ................................... 20

Unterwegs in fremden Städten $\ldots \ldots \ldots \ldots \ldots \ldots \ldots \ldots \ldots . \ldots . \ldots . \ldots . \ldots 22$

Reiseerinnerungen in Kupfer. . . . . . . . . . . . . . . . . . . . . . . . . 24

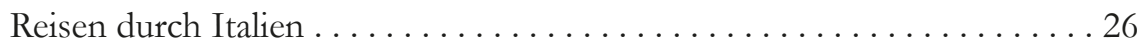

Schlossbesichtigungen ............................. 28

Reisen im heimischen Sessel ........................... 30

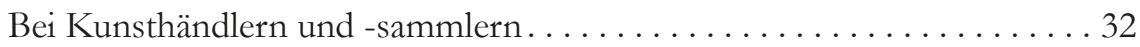

In fremden Bibliotheken ............................. 34

Uffenbach kauft Kunst .............................. 36

Die Wissenschaft der Schönen Künste...................... 38

Theorie und Praxis der Oper.............................. 40

Künstlerviten ................................ 42

Uffenbachs „kleine Bilder-Versammlung“ . ................. 44

Auf der Suche nach dem richtigen Künstlernamen................ 46

Friedrich Brentels Illuminierbücblein. . . . . . . . . . . . . . . . . 48

Systematisierung und Nutzen von Holzarten. . . . . . . . . . . . . 50

Architekturtheorie ................................. 52

Angewandte Mathematik ............................ 54

Unterweisungen in Wissenschaften und Künsten ................ 56

Die Praxis des Exzerpierens . . . . . . . . . . . . . . . . . . . . 58

Das Proportionalinstrument ............................ 60

Uffenbachs Sonnenuhren .............................6 62

Wasserspiele und ihre Maschinerien .......................6 64

Der Weg des Lichts . . . . . . . . . . . . . . . . . . . . . . . . . 66

Verzerrte Bilder .................................. 68

Schriften und Instrumente zum Feldmessen . . . . . . . . . . . . 70

Ingenieurwissenschaften: Artillerie und Festungsbau . . . . . . . . . . . 72

Uffenbach als Feuerwerker ............................. 74

Biografie .................................... 76

Literaturverzeichnis ............................ 78 


\section{Einführung}

Mathematisch-physikalische Instrumente und Modelle, gedruckte Bücher, Manuskripte, Kupferstiche und Handzeichnungen hatte der Frankfurter Privatgelehrte Johann Friedrich von Uffenbach (1687-1769) während seines Lebens zu einem wissenschaftlichen Arbeitsapparat zusammengetragen. Nach seinem Tod vermachte er diese Sammlung der Göttinger Universität. Im Laufe der Zeit und in Folge der modernen Auffächerung der Disziplinen wurden die Teilsammlungen auf verschiedene Institutionen der Universität verteilt und erlebten getrennt weitere Nutzung. So forschte und lehrte Georg Christoph Lichtenberg (1742-1799) physikalisch mit Uffenbachs Instrumenten und begründete Johann Dominik Fiorillo (1748-1821) gestützt auf Uffenbachs Reproduktionsgraphiken und Kunstliteratur die Kunstgeschichte als akademisches Lehrfach. Die Ausstellung Aller Künste Wissenschaft unternimmt den Versuch, sämtliche Stücke der Uffenbachschen Schenkung an die Universität aufzuspüren, um die ursprüngliche Sammlung wieder zusammen zu führen und auf dieser Grundlage ihre Funktionen und die Intentionen ihres ersten Besitzers zu ergründen.

Wer aber war dieser Uffenbach?

Johann Friedrich von Uffenbach war wohlhabender Spross einer Frankfurter Patrizierfamilie, von erblichem Adel und der jüngere Bruder Zacharias Conrads (1683-1734), eines der größten Büchersammler und Handschriftenspezialisten seiner Zeit. Er studierte zunächst bei dem mathematisch-rationalistischen Aufklärer Christian Wolff (1679-1754) in Halle, bevor er 1714 einen Abschluss in Rechtswissenschaften an der Universität Straßburg erwarb. Als Europareisender führte er ausführliche Reisetagebücher und lebte als Privatgelehrter mit technisch-naturkundlichen und künstlerischen Interessen, als Sammler von Büchern, Instrumenten, Gemälden, Zeichnungen und Druckgraphik in Frankfurt. Seine Begeisterung für alles Technische, Messbare und neu Erfundene führten zu experimentierendem Lernen auf unterschiedlichsten Gebieten, doch - da kein Zwang zu Broterwerb vorlag - selten zu langfristiger Beschäftigung. Praktisch umgesetzte Zeugnisse Uffenbachscher Tätigkeiten sind beispielsweise eine erneuerte Mainbrücke, verschiedene Großfeuerwerke, diverse Musiken, eine Oper und verschiedene Kupferstiche. Wissenschaftliche Betätigung belegen handschriftliche Aufzeichnungen: über 8.000 Seiten Reisetagebücher, fünf Bände mit Sitzungsprotokollen seiner in Frankfurt gegründeten wissenschaftlichen Gesellschaft, zahlreiche Briefe und

Bildnis des Johann Friedrich von Uffenbach (Künstler unbekannt), ca. 1745, 41 x 31 cm, Kunstsammlung der Universität Göttingen, Inv. Nr. GG 126. 


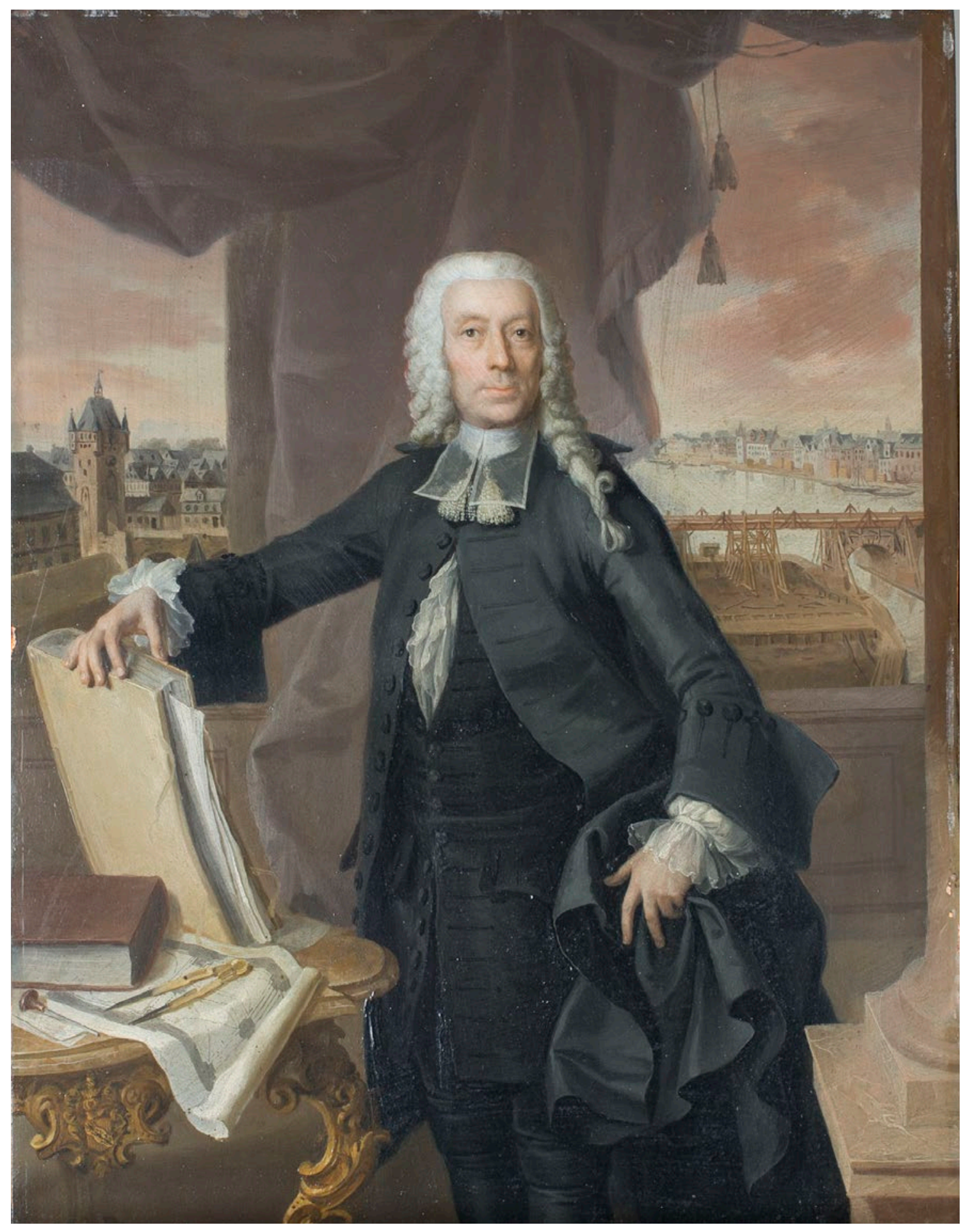


Manuskripte unveröffentlichter Schriften. Uffenbach reiste, lernte, las und erprobte gern, doch war ihm die Breite seiner Studien wichtiger als deren Tiefe. Uffenbachs eigenhändige Kataloge und Verzeichnisse der Sammlungen setzten Handschriftliches mit gedruckten Büchern der Bibliothek, Instrumenten, Modellen, Zeichnungen und Kupferstichen in Beziehung. So entstand ein komplexes, vielteiliges Arbeitsinstrument, das er schon 1736 der neugegründeten Universität vermachte, die es jedoch erst nach dessen Tod 1770 erhielt.

Von Uffenbach selbst gibt es wenige Bildnisse, zwei in Göttingen vorhandene und hier abgebildete umreißen die Spannweite seines Lebens und Wirkens:

Das erste, ein repräsentatives Gemälde, zeigt ihn Mitte der 1740er Jahre in standesgemäßer Kleidung und deutender Pose. Im Hintergrund seine Heimatstadt Frankfurt am Main, links der Sachsenhäuser Torturm, rechts die alte Mainbrücke, an deren Erneuerung Uffenbach 1740 als Architekt entscheidenden Anteil hatte. Die Bücher auf dem Tisch kennzeichnen Gelehrsamkeit und Sammeln, Grundriss und Zirkel architektonische Betätigung, Grabstichel und Kupferstichband seine stechende und sammelnde Begeisterung für Druckgraphik. Das Bildnis wurde von der Witwe des Dargestellten der Schenkung beigefügt.

Dieser offiziellen Darstellung des etablierten Frankfurter Patriziers gegenüber steht das von eigener Hand gezeichnete Abbild im Reisetagebuch von 1712. Es zeigt den Straßburger Studenten, der sich anlässlich eines Maskenballs in einem neapolitanischen (en napolitain) Kostüm verkleidete. Betrachtet man die Zeichnung, so wird klar, dass Uffenbach zwar kein professionell geübter Künstler, wohl aber Absolvent einer damals in seinen Kreisen üblichen Zeichenausbildung war, wie die vielen Zeichnungen sowohl in den Reisetagebüchern als auch in den Protokollbänden seiner wissenschaftlichen Gesellschaft zeigen. Können uns die Bildnisse eine ungefähre Vorstellung vom Aussehen Uffenbachs vermitteln, so begegnet uns in seinen Reisetagebüchern sein neugieriges, kritisch-spöttisches Wesen, wenn er, vom unfreundlichen Wirt über unkundige Bibliothekare bis zum unleidigen Leibniz, Vertreter aller Stände und Funktionen in sprachlicher Schärfe, aber auch mit viel Witz und Verstand beschreibt.

Trotz aller von der Zeit gerissenen Lücken versucht die Ausstellung eine Annäherung an Sammler und Sammlung, an dessen Intentionen und deren Funktionen. Dies herauszuarbeiten erforderte das Zusammenwirken vieler Köpfe und Fähigkeiten. Allen Mitwirkenden sei an dieser Stelle herzlich gedankt. In einem Ausstellungsführer alle namentlich zu nennen, würde das Format sprengen. So danken wir allen beteiligten Mitarbeiterinnen und Mitarbeitern der Niedersächsischen Staats- und Universitätsbibliothek sowie des Kunstgeschichtlichen Semi-

Johann Friedrich von Uffenbach, Selbstbildnis im Kostüm en napolitain anlässlich eines Maskenballs in Straßburg am 28. Februar 1713, Aquarell, Cod. Ms. Uffenbach 29, Bd. I, ad pag. 142. 


$$
1
$$


nars, den Göttinger studentischen sowie wissenschaftlichen Autorinnen und Autoren, vor allem aber den auswärtigen, die hier allein namentlich genannt seien: Valérie Kobi (Hamburg), Stephan Brakensiek (Trier) und Christine Hübner (Leipzig). Gedankt sei ebenso den Praktikantinnen und Praktikanten des Ausstellungsaufbaus sowie allen Personen, die zum Gelingen von Ausstellung und dem hier vorliegenden Ausstellungsführer beigetragen haben. Wurde die Ausstellung vor allem aus den eigenen Beständen von Bibliothek und Kunstsammlung bestückt, bezieht sie ihre besonderen Reize aus exklusiven Leihgaben, deren Besitzern wir herzlich danken: dem Städtischen Museum Göttingen, dem I. Physikalischen Institut der Universität sowie besonders einem privaten Leihgeber aus Hessen.

Die Ausstellung gliedert sich - Uffenbachs Interessen und Sammlung folgend - in die drei Abschnitte Reisen, Kunst und Angewandte Mathematik:

- Uffenbachs außergewöhnlich ausführliche Reisetagbücher, Reisevorbereitungen, Reisepraxis, benutzte Literatur und Kupferstiche des Gesehenen geben ein Bild seiner Gelehrtenreisen.

- Literatur zu Künstlern, Kunst und Kunsttechniken, eine große Kupferstich- und Zeichnungssammlung, Schriften zu Musik sowie Zeugnisse seines gezielten Sammelns bilden Uffenbachs Interessen im Bereich der Künste ab.

- Uffenbachs Leidenschaft für mathematisch-technische Anwendung und Wissenschaft sowie seine Neugierde auf alles Neue stehen hier im Zentrum.

Triebfeder für Uffenbachs Neugier und damit auch Sinn und Zweck seines gelehrten Arbeitsapparates - seiner Sammlung - war das Wissen um die technischen Künste seiner Zeit, oder wie es ein Zeitgenosse Uffenbachs ausdrückte: Aller Künste Wissenschaft.

Die Herausgeber

Johann Friedrich von Uffenbach, Zeichnung einer Pferdesänfte, Cod. Ms. Uffenbach 29, Bd. I, ad pag. 608.

Uffenbachs Unterschrift auf dem Titelblatt seines Katalogs Kurtzes Verzeichnüs derer Mathematischer Physicalischer und Kupffer Bücher, SUB, 8 Cod. Ms. Uffenbach 47. 



\section{Uffenbachs Sammlung}

Uffenbachs Büchersammlung spiegelt seine wissenschaftlich-praktischen Interessen wider: In ihr finden sich überwiegend historische und zeitgenössische Werke zu Mathematik, Physik und Technik sowie zur Kunst- und Architekturgeschichte. Für seine Bibliothek verfasste er einen vollständigen Standortkatalog, „um jedes Buch an seiner eingeräumten Stelle zu finden“, wie er im Vorwort erklärt. Eine Kopie dieses Katalogs schickte Uffenbach 1736 der Göttinger Universität verbunden mit der Ankündigung, ihr diese Sammlung nach seinem Tod zu vermachen.

Allerdings waren für Uffenbach die gedruckten Bücher nur ein Teil seiner Sammlung, zu der ebenfalls eine umfangreiche Kollektion von Kupferstichen und Zeichnungen sowie zahlreiche wissenschaftliche Instrumente gehören. Auch diese Sammlungen sind von Uffenbach in den von ihm verfassten Standortkatalog aufgenommen worden, der dementsprechend den Titel Kurtzes Verzeichnüs derer Mathematischer Physicalischer und Kupffer Bücher wie auch des Vorraths einiger hiezu gehöriger Instrumenten [Uff 47] trägt. Im Zentrum seiner Sammlung steht eine Reihe von eigenen und fremden Handschriften. Uffenbachs eigenhändige Manuskripte sind dabei nicht nur materielle Zeugnisse seiner Beschäftigung mit der gedruckten Literatur, sondern sie sind zugleich auch die Ergebnisse seiner Reisen und praktischen Versuche mit den im Katalog erwähnten Instrumenten.

Nicht wenige seiner Stücke stammen aus den Sammlungen seiner beiden Brüder Zacharias Conrad (1683-1734) und Wilhelm (1689-1735). Mit deren Besitzvermerken (Exlibris) ging Uffenbach recht pragmatisch um und strich nur jeweils die Vornamen durch. Er selbst nutzte kein eigenes Exlibris, ließ aber zahlreiche seiner Bücher in der gleichen Art und Weise binden. Seine eigenen Manuskripte besitzen oft einen typischen grünen Ledereinband mit dem Uffenbachschen Familienwappen als Prägung auf dem Vorderdeckel (Supralibros). Nach Uffenbachs Tod 1769 erhielt die Göttinger Universität wie 1736 vereinbart knapp 2.300 Bände aus seiner Sammlung, darunter mehr als 50 Handschriften und 36 Bände mit Kupferstichen sowie zahlreiche wissenschaftliche Instrumente.

Christian Fieseler

Uffenbachs grün eingebundene Handschriften. Im Vordergrund Kurtzes Verzeichnüs derer Mathematischer Physicalischer und Kupffer Bücher, SUB, 8 Cod. Ms. Uffenbach 47. 


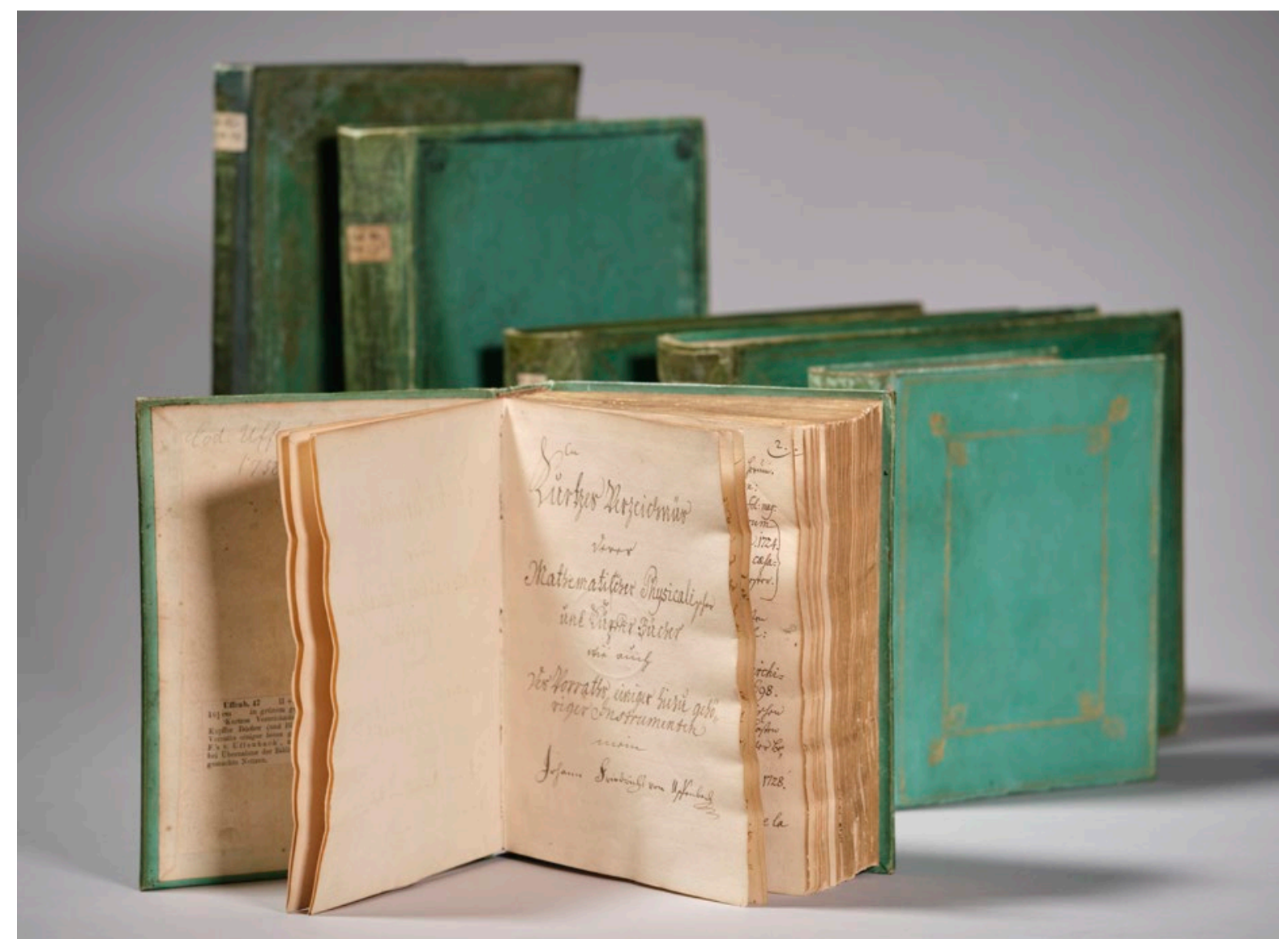




\section{Curieuse Dinge}

„Curieuse Dinge“, im Sprachgebrauch des 18. Jahrhunderts Objekte und Themen, die Interesse verdienen und Aufmerksamkeit auf sich ziehen, faszinierten Uffenbach und seine Zeitgenossen. Ihnen spürte man in Büchern, Sammlungen und auf Reisen nach, strebte nach Erfassung, Einordnung und Verständnis.

Dies konnte auch eine Fliegenfalle betreffen, wie in der 1735 erschienenen Publikation von Franz Ernst Brückmann (1697-1753). Darin wird nicht nur über die Fliegenfalle berichtet, die aus zwei zueinander, unter Spannung stehenden, innenseitig mit Zuckerigem $\mathrm{zu}$ bestreichenden Leisten bestand, deren fliegentötendes Zusammenklappen ein Federmechanismus auslösen sollte. Ungeachtet der fraglichen Effektivität dieser Apparatur erläutert die Schrift die Schädlichkeit des Insekts, nennt abhelfende Hausmittel, gibt einen literaturgeschichtlichen Abriss zur Fliege seit Bibel und antiker Literatur und liefert ein Referat damals moderner insektenkundlicher Literatur, so etwa die Geschichte der gemeinen Stubenfliege (1764) des Wilhelm Friedrich Freiherr von Gleichen-Rußwurm (1717-1783), die einen mikroskopisch erstellten Kupferstich der Fliegenanatomie enthält.

Dürers (1471-1528) Darstellung des Rhinozerus (1515) aus Uffenbachs Besitz dokumentiert ebenso sein Interesse an größeren und exotischeren Lebewesen wie die Elephantographia Curiosa (1723) des Erfurter Mediziners Georg Christoph Petri von Hartenfels (1633-1718). Diese Elefantenmonographie, die literarische Tradition, zeitgenössische Berichte sowie anatomische Studien vereinte und aufwendig mit Kupferstichen illustriert ist, entstand als Reaktion auf die 1698 im Herzogtum Sachsen-Gotha-Altenburg gefundenen fossilen Reste eines voreiszeitlichen Waldelefanten.

Die übliche Spannweite zeittypischer Gelehrtenneugier demonstrieren ebenfalls die Dialogi quatuor de duobus maximis mundi systematibus (1635) des Galileo Galilei (1564-1642), die dessen heliozentrisches Weltbild erklärten, ihren Autor den bekannten Prozess einbrachten und die Uffenbach in einer lateinischen Ausgabe besaß.

Arwed Arnulf

Franz Ernst Brückmann, Die neu-erfundene Curieuse Fliegen-Falle, 1735, SUB, DD2003 A204.

Georg Christoph Petri von Hartenfels, Elephantographia curiosa, Erfurt 1723, SUB, 4 Bibl. Uff 523. 

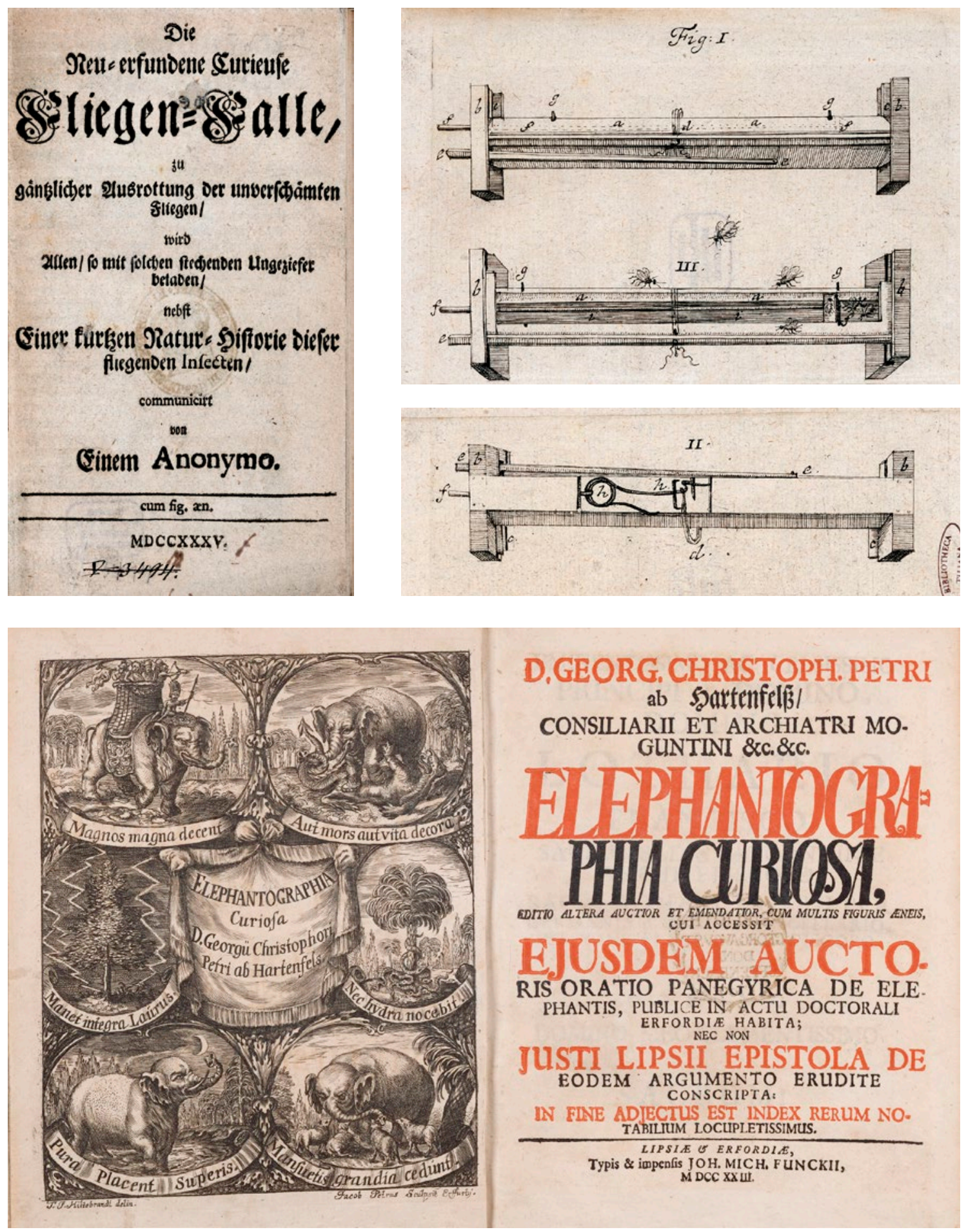

\section{D.GEORG, CHRISTOPH. PETRI ab Sartenfeli} CONSILIARII ET ARCHIATRI MOGUNTINI \&c. \&c.

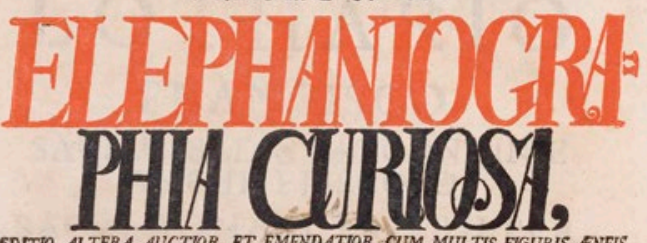

GDITTO ALTERA AUCTIOR ET EMENDATIOR, CUM MULTIS FIGURIS ENEIS,

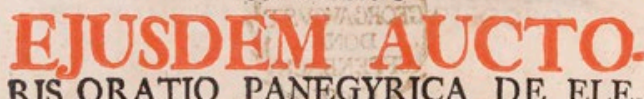

RIS ORATIO PANEGYRICA DE ELE. PHANTIS, PUBLICE IN ACTU DOCTORALI ERFORDIE HABITA;

IUSTI LIPSII EPISTOLA DE EODEM ARGUMENTO ERUDITE CONSCRIPTA:

IN FINE ADIECTUS EST INDEX RERUM NO. TABILIUM LOCUPLETISSIMUS. Typis \& impenfis JOH. MICH. F UNCKII, 


\section{Gelehrtes Beisammensein}

Uffenbachs eigenhändige Zeichnung einer Armillarsphäre - ein astronomisches Lehrinstrument, das Grundlegendes wie Erdachsenneigung, Horizont, Äquator, Tierkreis und Wendekreise veranschaulicht - illustriert einen seiner Vorträge zur Einführung in die Astronomie. Die Erklärungen führen bis hin zum Kopernikanischen heliozentrischen Weltbild, modernsten Beobachtungsinstrumenten und aktuellen Himmelserscheinungen.

Anlass waren die regelmäßigen Sitzungen einer von ihm selbst gegründeten wissenschaftlichen Gesellschaft, deren bis zu sechs Mitglieder einander verschiedene Wissensgebiete, technische Neuerungen, Naturkundliches, Instrumente, Werkzeuge oder Herstellungsverfahren und künstlerische Techniken erklärten. Gerade die astronomischen Erklärungen zeigen, dass es um grundlegende Einführungen für interessierte Laien ging. Als Schriftführer stellte Uffenbach die erhaltenen fünf Bände handschriftlicher Protokolle zusammen. Neben Astronomie waren es etwa Wassertechnik und Pumpsysteme, Bautechnisches und Hebewerke, optische Erkenntnisse aber auch das Linsenschleifen und ebenfalls Techniken graphischer Bilderzeugung wie Holzschnitt, Kupferstich und Radierung, die er seinen Mitstreitern anhand von Beispielen, Instrumenten, Erfahrungsberichten und neuesten internationalen Buchpublikationen erläuterte. So werden zahlreiche Bücher des Uffenbachschen Bestandes in den Protokollen erwähnt, ebenso seine Reiseberichte, Instrumente und Kupferstiche. Neben eher grundsätzlichen Einführungen in Wissensgebiete, wie der Erklärung des gezeichneten Instruments wie der Armillarsphäre, finden sich Darstellungen neuester Technik, so der komplizierten Wasserversorgung der Wasserspiele in Herrenhausen, oder aktuellste Verbesserungen an Mikroskop, Barometer und Feuerspritze.

Arwed Arnulf

Johann Friedrich von Uffenbach, NebenStunden, Frankfurt a. M. 1726-1727, SUB, 2 Cod. Ms. Uffenbach 13, Bd. I, p. 52, Zeichnung einer Armillarsphäre. 


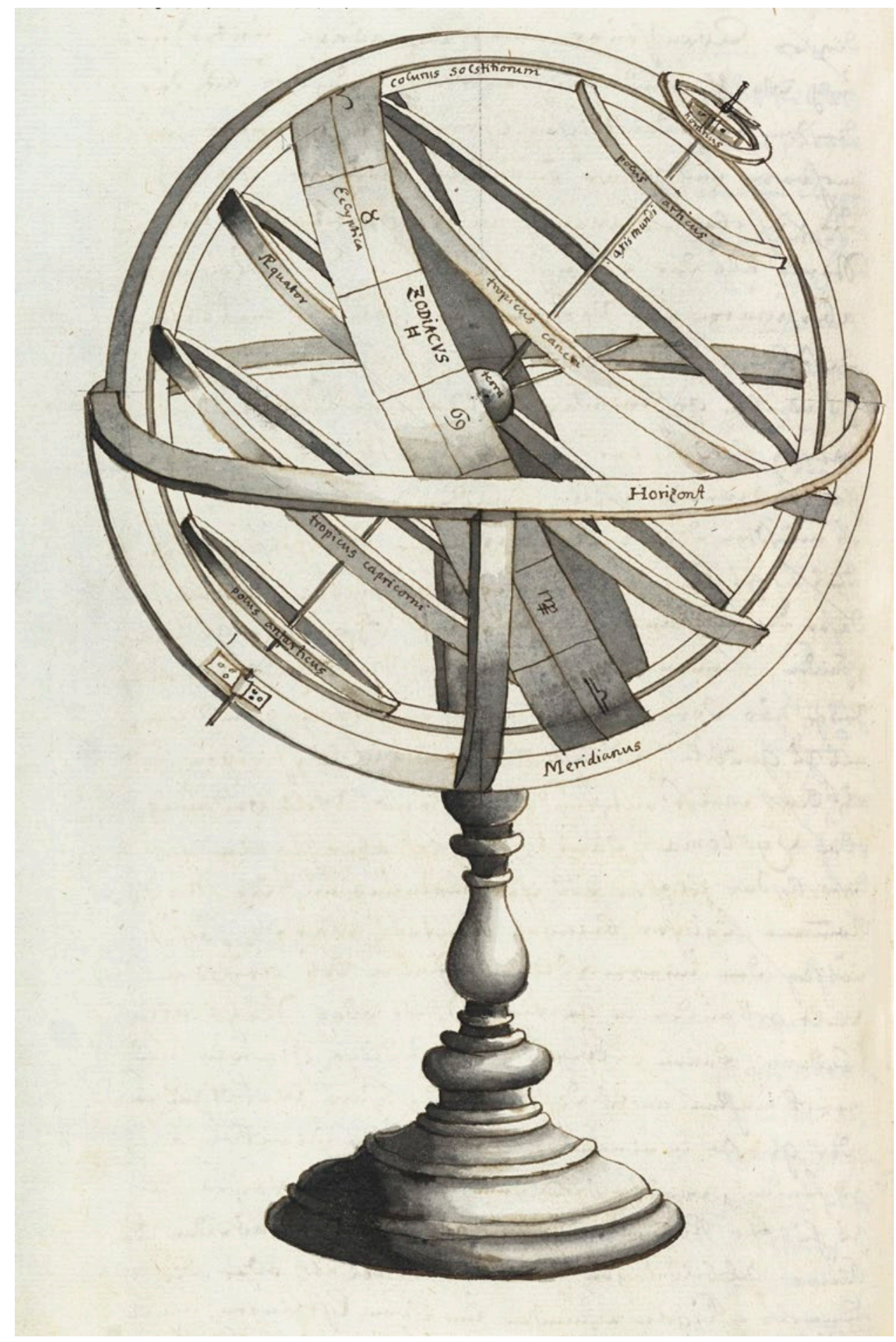




\section{Wissenschaftliche Kunstwerke}

Seefahrer und Expeditionen brachten Berichte über neue Inseln und Meeresstraßen, Gebirgszüge und Flussläufe, wodurch Kontinente und Meere in ihren Umrissen auf Erdgloben zunehmend vervollständigt werden konnten, bis schließlich die letzten „weißen Flecken“ verschwanden. Für die Navigation war die Kenntnis des Firmaments und seiner Sternbilder unabdingbar. Folglich fanden Himmelsgloben, auf denen die Gestirne abgebildet wurden, ihren Einsatz als wesentliches Veranschauungsmittel. Dabei dienen Globen nicht ausschließlich der Orientierung oder wissenschaftlichen Zwecken, sie sind gleichzeitig Modelle von Vorstellungen über die Gestalt der Erde und den Aufbau des Kosmos zur jeweiligen Entstehungszeit.

Seit sich die Architekturlehre Ende des 15. Jahrhunderts mit der idealen Einrichtung von Bibliotheksräumen beschäftigte, gehörte die Ausstattung mit mathematischen Instrumenten und Modellen zur essenziellen Repräsentation von theoretischer Erkenntnis und praktischer Anwendung. Globenpaare - also zusammengehörige Erd- und Himmelsgloben - versinnbildlichten die Einheit von Wissen um irdische und universale Zusammenhänge. Der Besitz dieser wertvollen Stücke wurde zum Attribut eines inszenierten Bildes, das der Eigentümer von sich vermitteln wollte.

Neben zahlreichen Traktaten zu Globen und ihrer Nutzung besaß auch Uffenbach einen Erd- und einen Himmelsglobus, erbaut vom Nürnberger Gelehrten Johann Gabriel Doppelmayr (1677-1750), einem der bedeutendsten Mathematiker und astronomischen Instrumentenbauer. Das Globenpaar repräsentiert die Verbindung von Reisen, Kunst und Wissenschaft - Themen, die ihn sein ganzes Leben begleiteten.

Nadja Kehe

Johann Gabriel Doppelmayr, Himmelsglobus, 1728, SUB, Inv. Nr. 3. Johann Gabriel Doppelmayr, Erdglobus, 1728, SUB, Inv. Nr. 2. Johann Gabriel Doppelmayr, Atlas Coelestis, Nürnberg 1742, SUB, GR 2 Bibl. Uff 472, Taf. 31. 

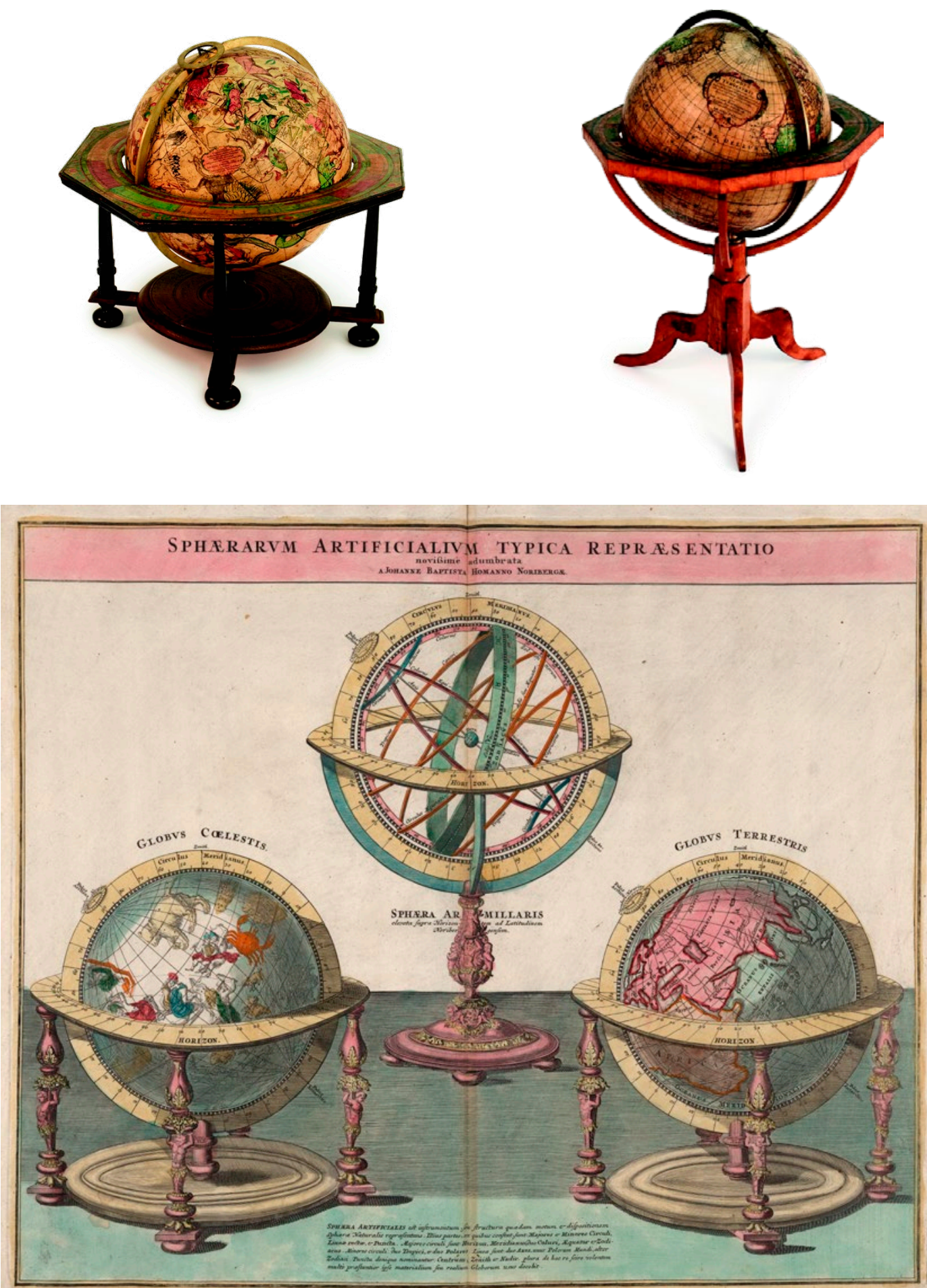


\section{Reisen im 18. Jahrhundert}

Uffenbach reiste viel: Begleitet von seinem älteren Bruder Zacharias Conrad (1683-1734), dem berühmten Gelehrten und Büchersammler, durchreiste der 23-jährige Johann Friedrich 1709 bis 1711 Norddeutschland, die Niederlande und England. Nach seinem Studienabschluss 1712 in Straßburg ging er - der Tradition adliger Grand Tour und gelehrter Bildungsreise folgend - auf eine weitere europaweite Reise, die ihn nach Frankreich und Italien führte. Später besuchte er gezielt Städte und Residenzorte, etwa Hannover, Braunschweig oder Kassel, wobei er von Handwerkern Techniken erlernen, Gelehrte kontaktieren, Residenzen, Gärten, Wasserspiele, Bildergalerien, Graphikkabinette, Münz-, Kunst-, Instrumenten- und Naturaliensammlungen oder auch Opernhäuser besuchen wollte.

Kenntnis dieses gelehrten Reisens vermitteln uns neben den hierzu vor und auf diesen Reisen erworbenen Büchern und Kupferstichen vor allem seine Reisediarien. Dabei handelt es sich um Reisetagebücher, die Wege, Orte, Städte, Schlösser, Kirchen, Bibliotheken, Privathäuser und Sammlungen sowie dort agierende Personen beschreiben. Dies geschah ausführlich in korrigierendem Abgleich mit der zuvor gelesenen Reiseliteratur, kenntnisreich bei der Besichtigung von Architektur und Sammlungen und durchaus kritisch in der Bewertung der jeweiligen Gesprächspartner. All diese Notizen wurden von ihm und engagierten Schreibern in reinschriftliche Prunkbände [Uff 29, I-IV] und Kopien für seinen Bruder [Uff 4, I-IV] gebracht. Zum Druck gab er interessanterweise nur das von seinem Freund Johann Georg Schelhorn (1694-1773) überarbeitete Journal [Uff 25, I-IV] der mit seinem Bruder unternommen ersten Reise, das 1753 erschien.

Neben den wissenschaftlich und technisch motivierten, sehr zweck- und zielorientierten Ausflügen machte die Familie Uffenbach auch Vergnügungsfahrten, so im Juli und August 1718 durch die nördlichen und südlichen Niederlande. Obwohl es sich um ein „Lustreise“ zum Zwecke der „Gemüths-Ergötzung“ handelte, wurde ein Reisejournal geführt, das in der Reinschrift 298 Seiten umfasst [Uff 46]. In Anlage und Ausführung seiner Reisejournale folgte Uffenbach den zu seiner Zeit beliebten Apodemiken, also Reiseanleitungen wie Johann Keilhackers (1667-1708) Der curiöse Hofmeister von 1700 oder Paul Jakob Marpergers (1656-1730) Der kluge und vorsichtige Passagier, oder Unterricht welchergestalt Reisende ibre Reisen zu Wasser u. zu Lande klug anstellen mögen von 1707.

Arwed Arnulf

Johann Friedrich von Uffenbach, Elsaßer und Schweitzer Reis-Diarium von Franckfurt biß Turin exclusive, 1712-1714, SUB, 8 Cod. Ms. Uffenbach 29, Bd. I, ad p. 654: Zeichnung der Alpenüberquerung. 


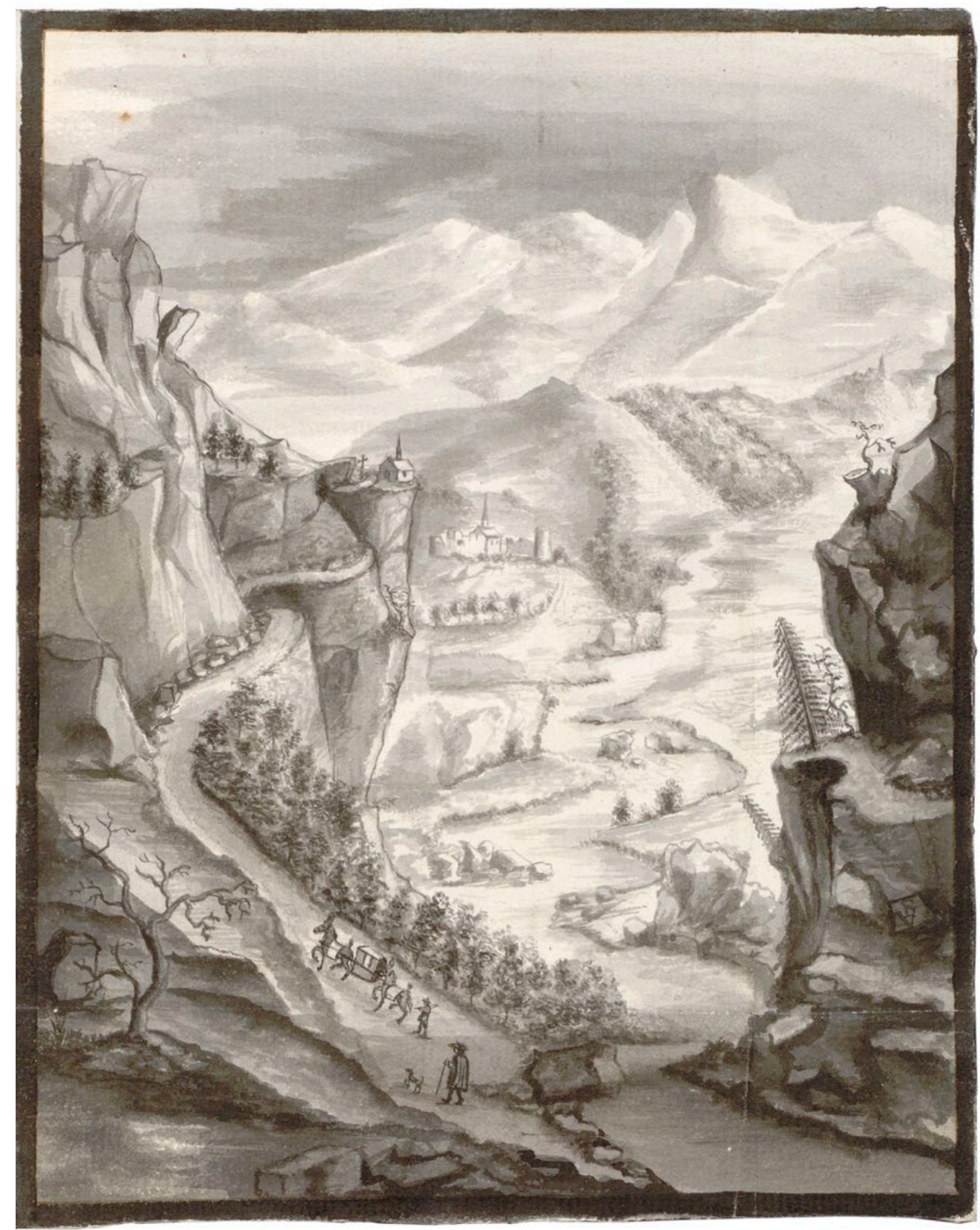




\section{Reiseplanung}

Der Reisende des 17. und 18. Jahrhunderts bedurfte einiger Informationen zur vorausschauenden Planung. Beste Straßen und Routen, dabei berührte Orte und Städte, obrigkeitliche Beschränkungen und Forderungen wie Wegzölle, vor allem aber Postkutschenrouten, Wegstationen, Fahrzeiten und -preise, Wirtshäuser und all jene Dinge, die der Befriedigung alltäglicher Bedürfnisse dienten, waren vorab zu klären. Uffenbach benutzte dafür das gesamte Spektrum der zeitgenössischen Informationsmittel. Neben Postkutschenplänen und diesbezüglichen Karten waren dies vor allem Reisehandbücher, wie Peter Ambrosius Lehmanns (1663-1729) Vornehmste Europaeische Reisen von 1703, das Hauptreiserouten samt Kosten, Reisezeiten und Übernachtungsempfehlungen vorstellte und in vielen aktualisierten Auflagen erschien.

Die erfolgreichsten Reisebücher des 18. Jahrhunderts waren die zahlreichen Ausgaben von Johann Georg Keyßlers (1693-1743) Neuesten Reisen (1740/41). Der Auswahl der Reiseziele dienten Werke wie Leonhard Christoph Sturms (1669-1719) Auflistung berühmter und besuchenswerter Bibliotheken, Kunst- und Naturaliensammlungen. Ähnliches verfasste der Göttinger Historiker Johann David Köhler (1684-1755) mit wissenschaftlichem Anspruch in seinen Anweisungen zur Reiseklugheit junger Gelehrter (1788), worin auch Grundlagenwissen zu Bibliotheken, Naturalien-, Münz-, Gemälde- und Graphiksammlungen vermittelt wird.

Stadtmonographien erläuterten Geschichte, Bedeutung, Infrastruktur und Sehenswürdigkeiten größerer Städte, was Hanse- oder Reichsstädte wie Lübeck, Frankfurt oder Nürnberg ebenso betraf wie Residenzstädte wie Dresden und Paris oder Handelsmetropolen wie Augsburg, Antwerpen und Amsterdam. Der Titel von Joachim Christoph Nemeitz (1679-1753) Paris-Handbuch von 1718 nennt so den Inhalt in Begriffen der Zeit: Séjour de Paris Oder Getreue Anleitung, Welcher gestalt Reisende von Condition sich zu verhalten haben, wenn sie ibre Zeit und Geld nützlich und wohl zu Paris anwenden wollen.

Arwed Arnulf

Peter Ambrosius Lehmann, Die Vornehmsten Europaischen Reisen, Hamburg 1706, SUB, 8 Bibl. Uff 506. 


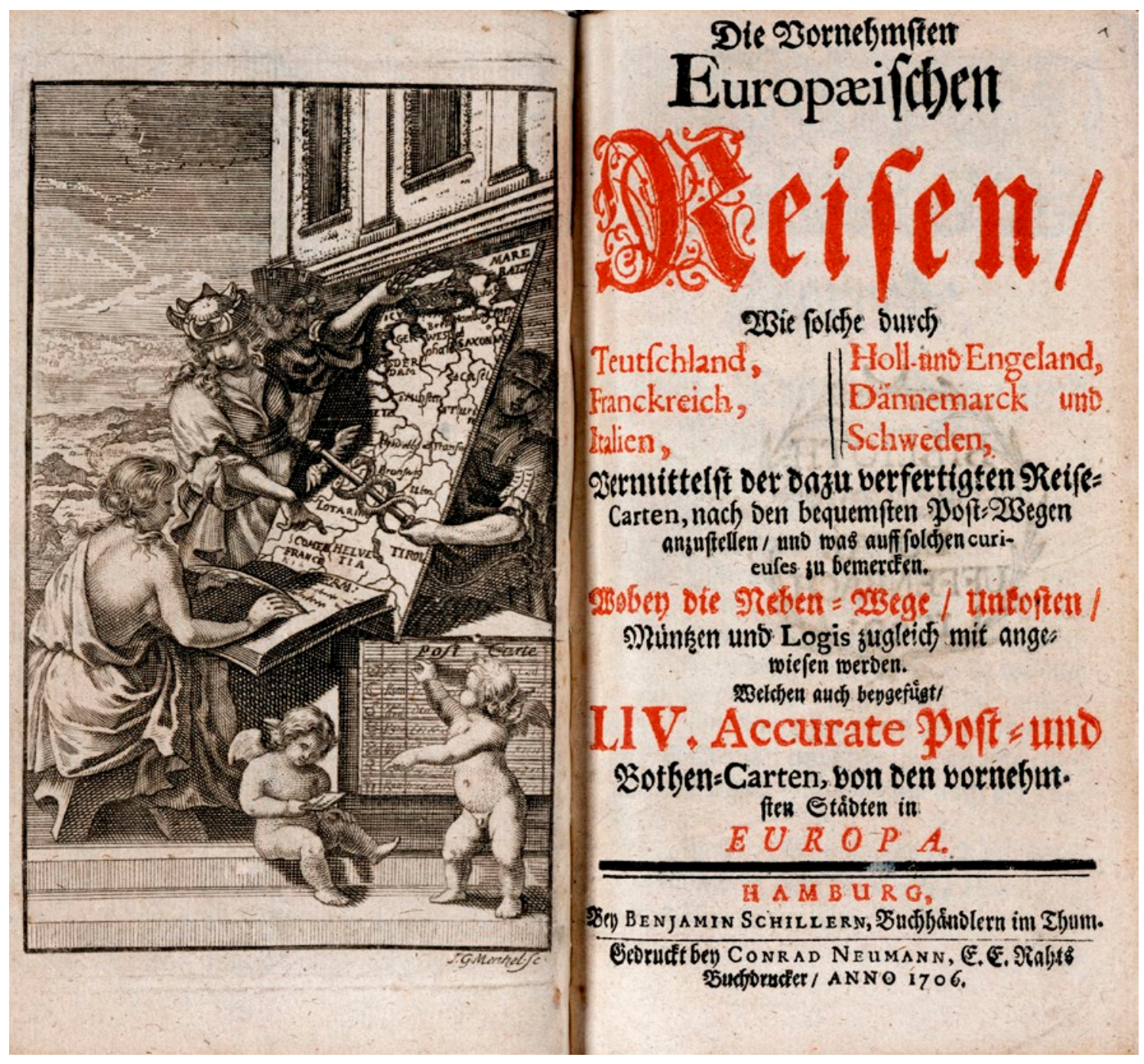




\section{Unterwegs in fremden Städten}

Erreichte Uffenbach eine Stadt per Kutsche, empfahl ihm sein Reisehandbuch meist noch Gasthäuser und Hauptsehenswürdigkeiten. Über Rathäuser, Kirchen, städtische Palais, Börsen, Handelshäuser und vieles andere informierten den Reisenden ausführliche Stadtführer und Stadtbeschreibungen, wie etwa die besonders aufwendig mit Kupferstichen ausgestattete und 1664 erschienene Amsterdam-Beschreibung des Philipp von Zeesen (1619-1689) oder Die beglückte und geschmückte Stadt Lübeck des Johann Gerhard Krüger (tätig 1693-1703) von 1697 - ein Buch, das Uffenbach laut seinen Tagebucheinträgen von 1710 bei sich trug, als er die Lübecker Marienkirche besichtigte. Dort wie auch an anderen Orten korrigierte Uffenbach häufig die Erklärungen dieser Publikationen.

Nicht selten finden sich nicht nur die illustrierten Bücher in seinem Besitz, sondern auch weitere Exemplare der illustrierenden Stiche als Einzelblätter in seiner Sammlung: Das Summum Argentoratensium Templum, eine historische Monographie zum Straßburger Münster, die Oseas Schadaeus (1586-1626) im Zuge des Reformationsjubiläums 1617 auf Veranlassung des städtischen Rats verfasste, bildete in Kupferstichen Isaac Bruns (1596-1657) nicht nur die hochgotische Kirche von innen und außen, sondern auch Hauptausstattungsstücke ab. Den Stich des berühmten Straßburger Südportals, ein bedeutendes Werk gotischer Plastik des 13. Jahrhunderts, besaß Uffenbach auch als Einzelblatt (1617). Daran ist vielerlei bemerkenswert und lehrreich: So schuf man um 1600 Kupferstiche nach gotischen Kunstwerken, erläuterte diese in einem Kirchenführer für Besucher und noch um 1700 fand ein gebildeter Reisender dies so bedeutsam, dass er zum Buch noch den Stich erwarb.

Dass im 17. und 18. Jahrhundert für fast alle größeren europäischen Städte derartige Führer erschienen, zeigt die Reisepraxis der Zeit: Gelehrte und wohlhabende Reisende bereiteten sich mit der vorab erworbenen Literatur vor, lasen und prüften diese vor Ort und sammelten Führer und Kupferstiche als Reiseerinnerungen.

Arwed Arnulf

Philipp von Zesen, Beschreibung der Stadt Amsterdam, Amsterdam 1664, SUB, 8 Bibl. Uff 519, nach S. 134, Ansicht des Alten Rathauses von Amsterdam.

Isaac Brun, Das Südquerbausportal [Straßburger Münster], 1617, Kupferstich, KS, D 988. Aus: Oseas Schadeaus, Summum Argentoratensium Templum, Straßburg 1617. 

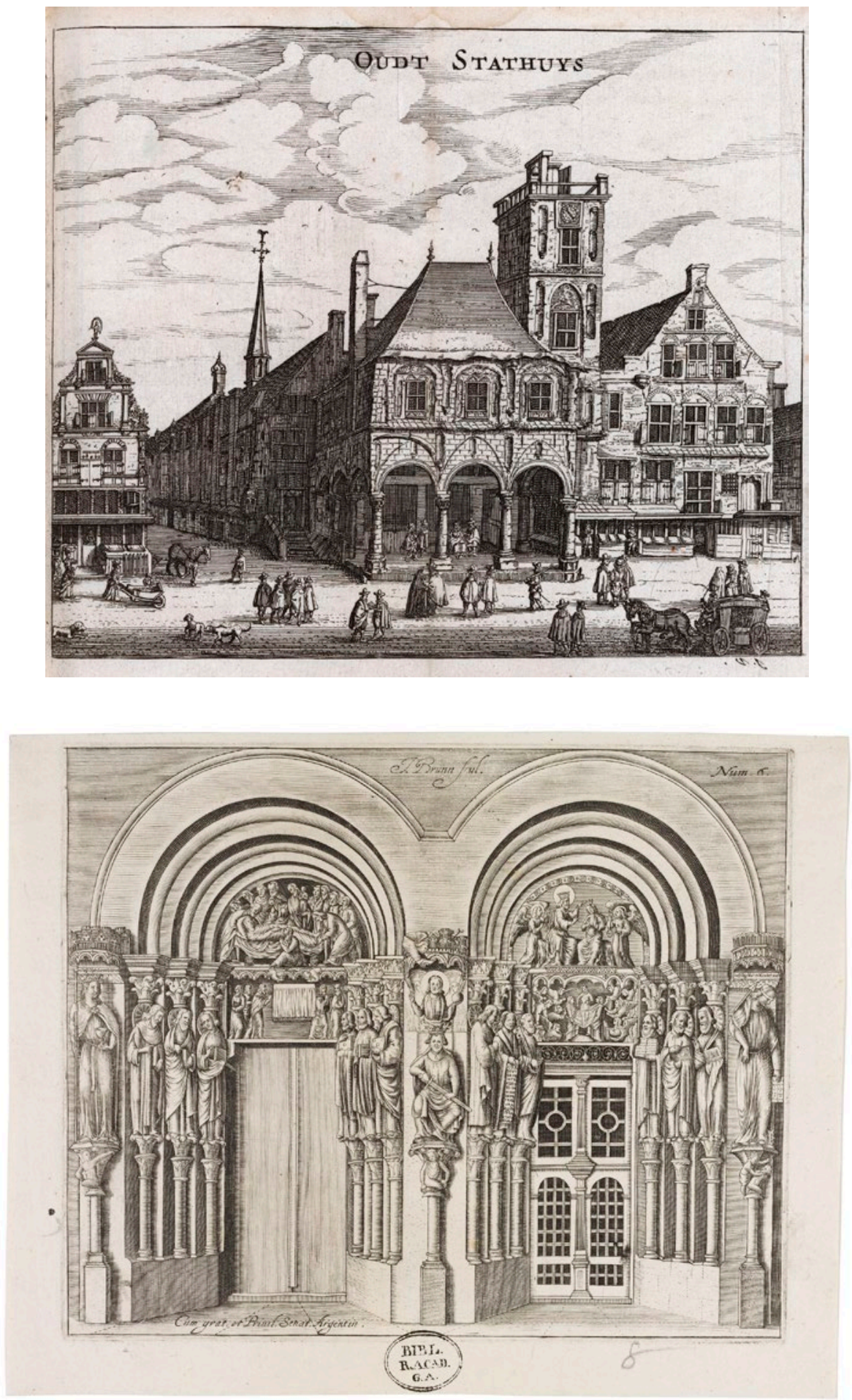


\section{Reiseerinnerungen in Kupfer}

Bevor die Fotografie, in jüngster Zeit in Form des Handyfotos, es ermöglichte, Reiseeindrücke zu konservieren, bedurfte es anderer Medien, um Bilderinnerungen mit nach Hause zu bringen. Uffenbachs Sammlungen zeigen uns die vormodernen Möglichkeiten: Neben eigenhändigen Zeichnungen sind es vor allem Kupferstiche, die in unterschiedlichster Form diesem Zweck dienten. Klein-, mittel- und großformatige Ansichten von Landschaften, Städten, Häfen, Gebäuden, Gärten, aber auch von diversen alten und neuen Kunstwerken unterschiedlichster Funktion wurden als Einzelblatt, Serie sowie in Mappen- oder Buchform angeboten.

Auf Reisen kaufte man diese Werke gern vor Ort: Als Uffenbach am 17. Oktober 1714 in Basel den berühmten Totentan₹, ein spätmittelalterliches Fresko auf der Friedhofsmauer der Predigerkirche besichtigte, vermerkte er dessen jüngste Restaurierung und erwarb bei einem örtlichen Buchhändler eine gebundene Kupferstichpublikation des Werks, herausgegeben vom Frankfurter Verlegers Matthäus Merian d. Ä. (1593-1650) von 1696. Auch der Riesenkupferstich des Rheinfalls, den Uffenbach gut eine Woche später in Schaffhausen bei dem Kunsthändler Johann Georg Seiler (1663-1740) kaufte, fand Erwähnung in den Reiseaufzeichnungen. In den Niederlanden erstand er 1718 ein großformatiges Kupferstichwerk zu Schlössern und Gärten: Afbeeldzels der vermaerdeste Lusthoven in de nederlandse provinzien. Auf dem Frontispiz des Buches notierte Uffenbach Ort und Datum des Ankaufs. Einen ausführlichen Plan von Paris erwarb Uffenbach 1715 bei dem Landkartenmacher Nicolas de Fer (1646-1720), den er gezielt aufsuchte. Der ausführlich beschriftete Plan, den Uffenbach nach eigener Aussage zur Orientierung nutzte, ist ebenso wie der Totentanz und der Riesenkupferstich erhalten.

Für sehr viele ähnliche Werke in Uffenbachs Sammlung, darunter einige großformatige Stiche mit Stadtansichten, Plänen, Schlössern, Gemäldezyklen, berühmten Gebäuden bis hin zu Leuchttürmen ist der Erwerb nicht bezeugt. So etwa für den Großkupferstich des Eddystone-Leuchturmes, der 1698 vor der Küste Cornwalls errichtet, bereits 1703 Opfer einer Sturmflut wurde, dessen Konstruktion aber im Kupferstich gefeiert wurde. All diese Darstellungen dürften als Reiseerinnerung, als bildliche Nachschlagemöglichkeit, als Bildspeicher des Gesehenen, vermutlich auch als Demonstrationsmittel in Gesellschaft gedient haben.

Anne-Katrin Sors

Henry Winstanley, Eddystone-Leuchtturm, Littlebury 1699, Kupfer Vol. zu allen Theilen der Reisz Diariorum, SUB, 2 Cod. Ms. Uffenbach 8, 14. 


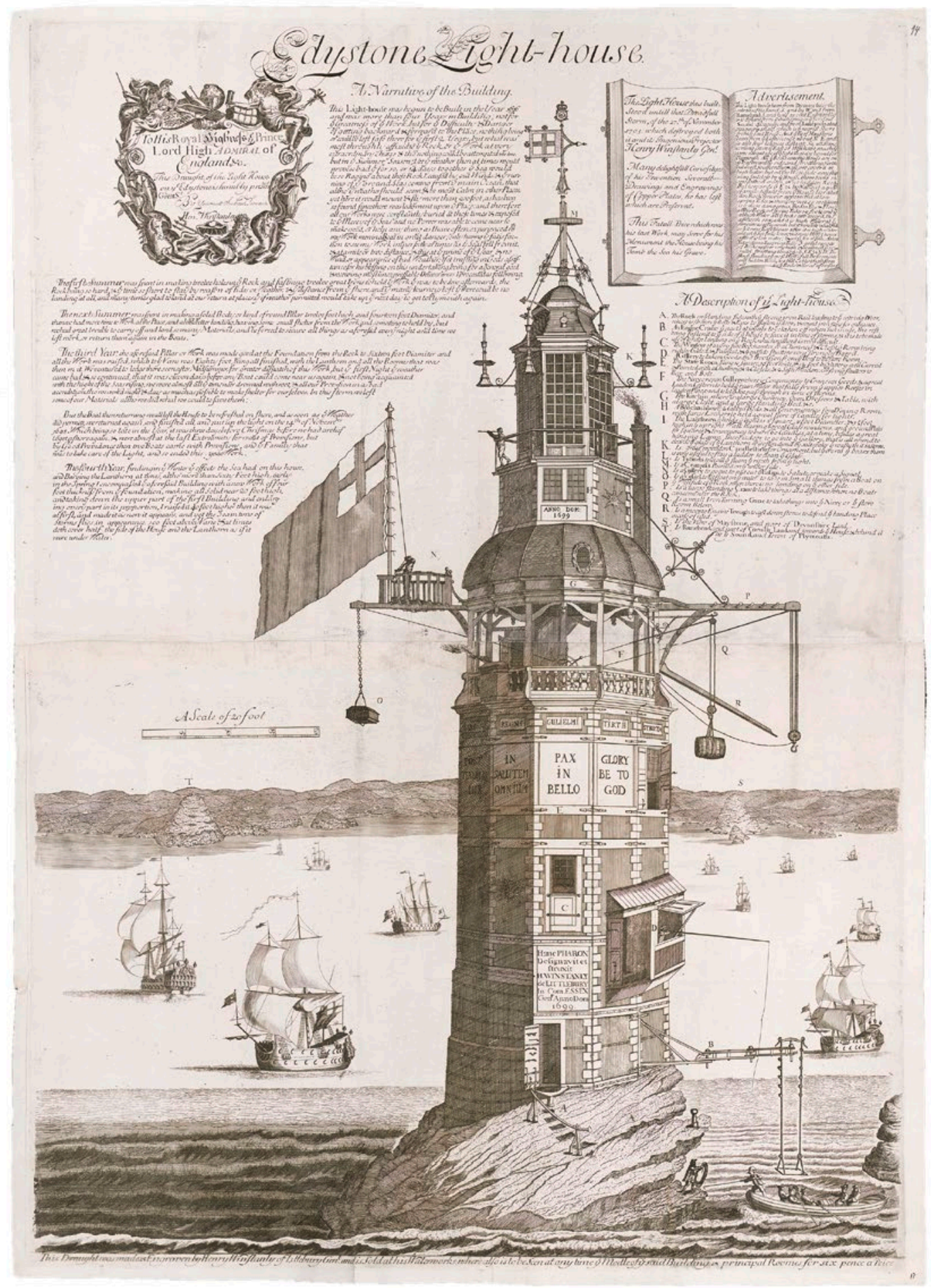




\section{Reisen durch Italien}

Das sonnige Land der Antike und der Künste war im 18. Jahrhundert eine beliebte Etappe auf den Kavalierstouren der Adeligen und reichen Bürgersöhne. Auf der Basis seiner Notizen verfasst Uffenbach nach Rückkehr von der Reise durch das Elsass, die Schweiz, Italien, Frankreich und die Niederlande zwischen 1712 und 1716 ein vierbändiges Tagebuch [Uff 29]: Die Reise durch Italien füllt die Bände II und III und umfasst über 1400 Seiten. Seine Reiseerlebnisse reichert Uffenbach mit Informationen aus der Literatur an, wie die zahlreichen Literaturverweise in seinem Text belegen. Viele Kupferstiche und eigenhändige Zeichnungen sowie Druckwerke, Guiden und Pläne ergänzen sein Diarium.

Im zweiten Band des Tagebuchs reisen wir mit Uffenbach von Turin über Mailand, Venedig und Rom bis nach Neapel. Der dritte Band schildert unter anderem seine Erlebnisse und Begegnungen in Rom, Florenz und Pisa, Genua und Turin. Wir wandeln mit ihm durch die italienischen Städte, lauschen Opern und Konzerten, besuchen Palazzi, antike Stätten und Sakralbauten sowie Werkstätten von Instrumentenmachern, Mechanikern und Glasschleifern. Stadt für Stadt durchzieht er Bibliotheken und die Läden der Buchhändler und erwirbt zahlreiche Bücher, Kunstwerke und Souvenirs. Die Glanzstunden verbringt er in den Bibliotheken und Kunst- und Wunderkammern. Im Gespräch mit den Sammlern über artificialia und naturalia, über Astronomie und Optik zeigt sich Uffenbach als Teil einer Wissensgemeinschaft, die für sein weiteres Sammeln und Denken richtungsweisend werden sollte.

Isabella Augart

Giovanni Battista Falda, Petersplatz, um 1670, Kupfer Vol. zu allen Theilen der Reisz Diariorum, SUB, 2 Cod. Ms. Uffenbach 8, 36.

Giuseppe Tiburzio Vergelli, Kolosseum Rom, 1691, Kupfer Vol. zu allen Theilen der Reisz Diariorum, SUB, 2 Cod. Ms. Uffenbach 8, 60. 

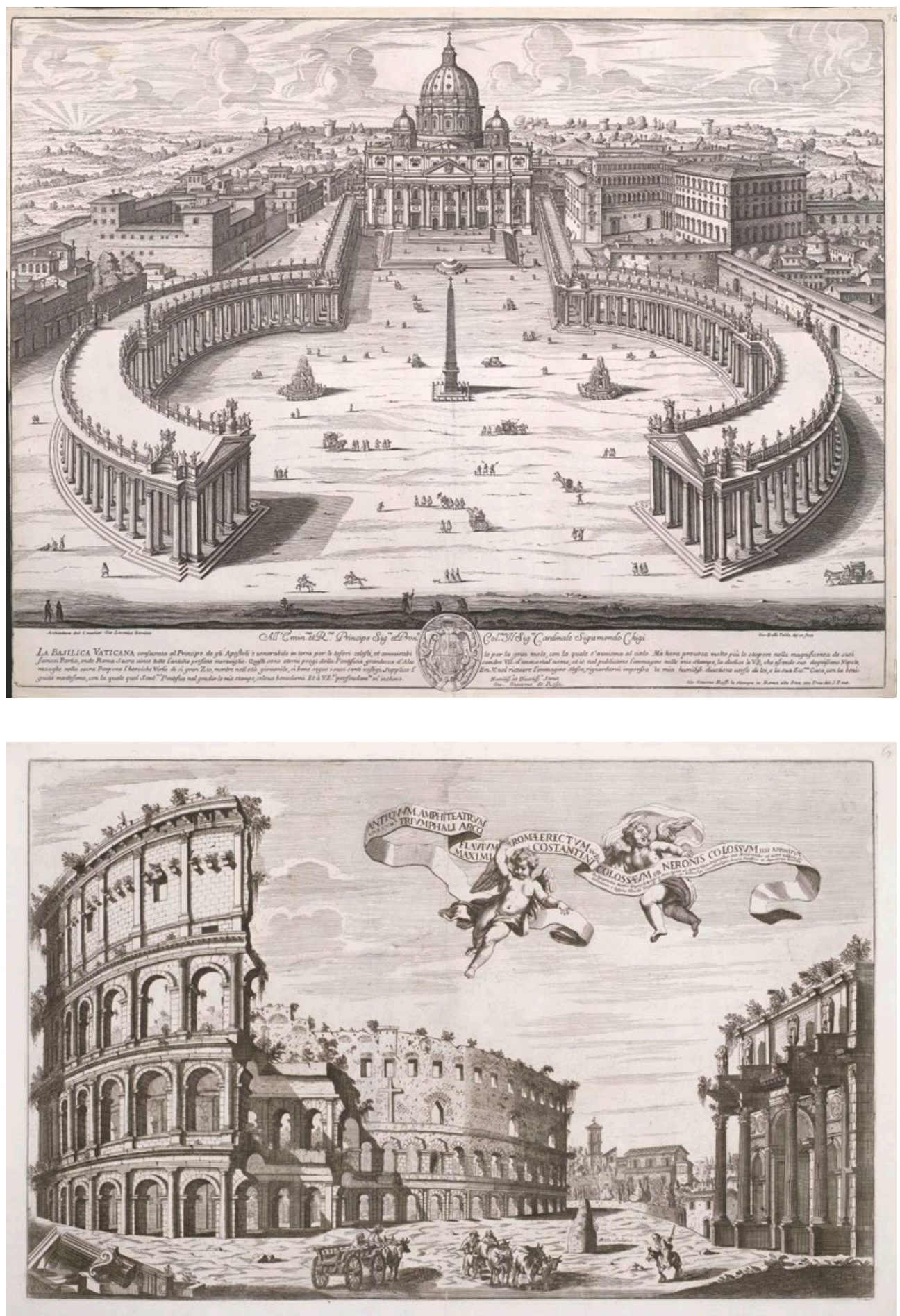


\section{Schlossbesichtigungen}

Neben Städten und Kirchen gehörte der Besuch von Herrschaftssitzen zum üblichen Reiseverhalten des 18. Jahrhunderts. Zacharias Conrad von Uffenbachs Merkwürdige Reisen Uff 25] zeigen die Vorbereitung der Brüder: Vorab und unterwegs erwarben sie Publikationen wie die Kurtze Beschreibung Des Fürstl. Lust-Schlosses Saltzdablum [Uff 33] Tobias Querfurts (um 1660-1734). Meist vermittelt durch private Kontakte führten Angestellte der Hausherren die Gäste durch die Residenzen - also durch die Schlösser und deren Anlagen.

Der Gärtner geleitete die Brüder Uffenbach durch das heute zerstörte Schloss des Landgrafen Karls von Hessen-Kassel (1654-1730): Sie bewunderten die Privatgemächer, die Orangerie sowie die Parkanlage der Karlsaue - die beiden letzteren noch im Bau.

Im Schloss Salzdahlum führte der für die textile Ausstattung des Hofes zuständige Bettmeister durch die Kunstsammlungen. Besonderen Gefallen fanden die Brüder am herzoglichen Rollstuhl, dessen Doppelräder Antrieb per Hand ohne deren Beschmutzung erlaubten. Hervor stachen die Gemäldegalerie, die Kupferstichsammlung mit über 1000 Bänden sowie die Majolikasammlung mit mehr als 600 farbig bemalten zinnglasierten Keramiken nach Raffael (1483-1520). Im Vergleich wirken die Gemächer des Herzogs bescheiden. Zacharias bemerkte wohlgefällig eine Ausgabe der Gelehrtenzeitschrift Nouvelles de la Republique de Lettres auf dem Nachttisch als Hinweis auf dessen Belesenheit.

Aufgrund des schlechten Verhältnisses zu Gottfried Wilhelm Leibniz (1646-1716) fiel der Besuch im Schloss Herrenhausen zu Hannover und dessen bekannten Gärten der Kurfürstin Sophie (1630-1714) führungslos und kurz aus.

Die Beispiele offenbaren die Abhängigkeit zwischen Intensität der Besichtigungen und Qualität der sozialen Kontakte. Das voyeuristische Interesse an Privaträumen Regierender avancierte zu einem internationalen Sport, den nicht nur die Uffenbachs gerne ausübten.

Jana Schulz

Romeyn de Hooghe, Salzdablum, 1688, Kupfer Vol. zu allen Theilen der Reisz Diariorum, SUB, 2 Cod. Ms. Uffenbach 8, 2. 


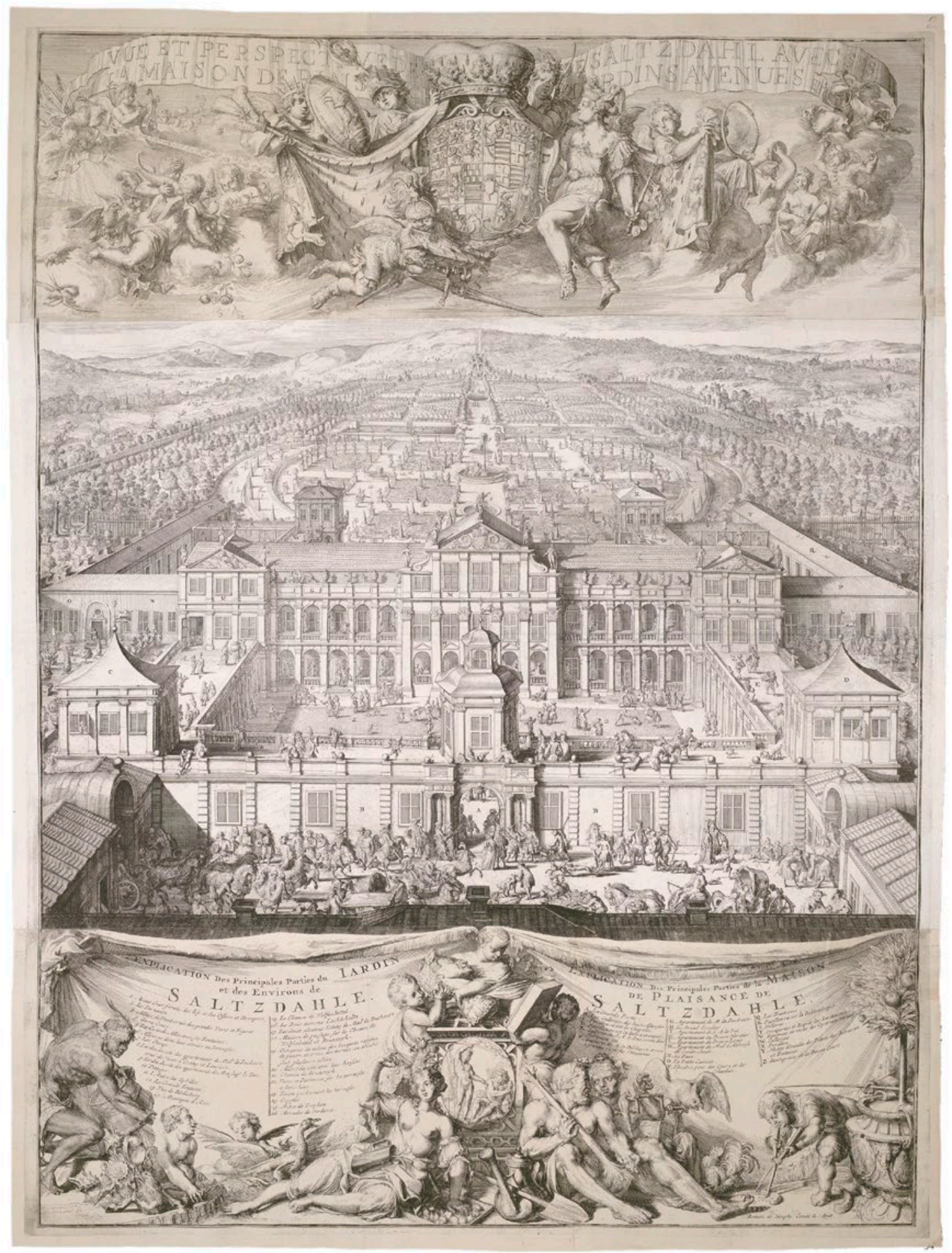




\section{Reisen im heimischen Sessel}

Angesichts des städtischen, höfischen und fürstlichen Baubooms im 18. Jahrhundert war es Uffenbach schlichtweg unmöglich alle Orte, Residenzen und Lustschlösser zu bereisen und zu besichtigen. Auch aus diesem Grund sammelte er großformatige Ansichtswerke - die darin enthaltenen detaillierten und pittoresken Kupferstiche und die dazu gehörenden Beschreibungen ermöglichten ihm durchaus eine Reise im heimischen Sessel.

Ein Großteil der Publikationen in Uffenbachs Besitz, insgesamt 20 gebundene Folianten, stammen von dem Augsburger Architekturzeichner und Kupferstecher Salomon Kleiner (1700-1761), der seinen Ruhm mitunter den Stichserien im Auftrag des Mainzer Erzbischofs und kurfürstlichen Kanzlers Franz Lothar Schönborn (1655-1729) verdankte. Dieser ernannte Kleiner 1724 zum „Churfürstlichen Hoff-Ingenieur“ und beauftragte ihn seine gesamten Besitzungen in Kupfer zu stechen. Dem Bauherrn dienten die Stichfolgen zur höfischen und politischen Selbstdarstellung sowie überregionalen Zurschaustellung der Bautätigkeit und der hierfür aufgewendeten Mittel.

Der umfangreichste Ansichtsband der Schönbornschen Anlagen aus Kleiners Hand, den Uffenbach besaß, ist die Wabrhafte Vorstellung beyder Hoch=Gräfl. Schlösser (1728) mit 27 Kupferstichen, wobei dem Schloss Weissenstein bei Pommersfelden allein 20 Prospekte gewidmet sind. Auf den Gesamtgrundriss der Anlage folgen zwei spektakuläre Vogelschauen, die dem Betrachter mittels perspektivischer Manipulation erlauben, das Schloss mitsamt dazugehörigen Gartenterrassen, Kaskaden, Baumalleen, Orangerien und Menagerien zu erfassen. Ein Anblick, der sich in der Realität niemals darbieten würde. Die nachfolgenden Einzelansichten widmen sich den architektonischen Glanzstücken der Anlage: dem imperialen Treppenhauspavillon und den prachtvoll ausgestalteten Räumen des Lustschlosses. Besonders die dortige Gemäldegalerie dürfte Uffenbachs Interesse geweckt haben, die er dank der Galerieansichten Kleiners in seiner eigenen Bibliothek bewundern konnte.

Ines Reiss

Salomon Kleiner, Wahrhafte Vorstellung beyder Hoch=Gräfl. Schlösser Weissenstein ob Pommersfeld und Geibach [...], 1728, 2 Bibl. Uff 3. 

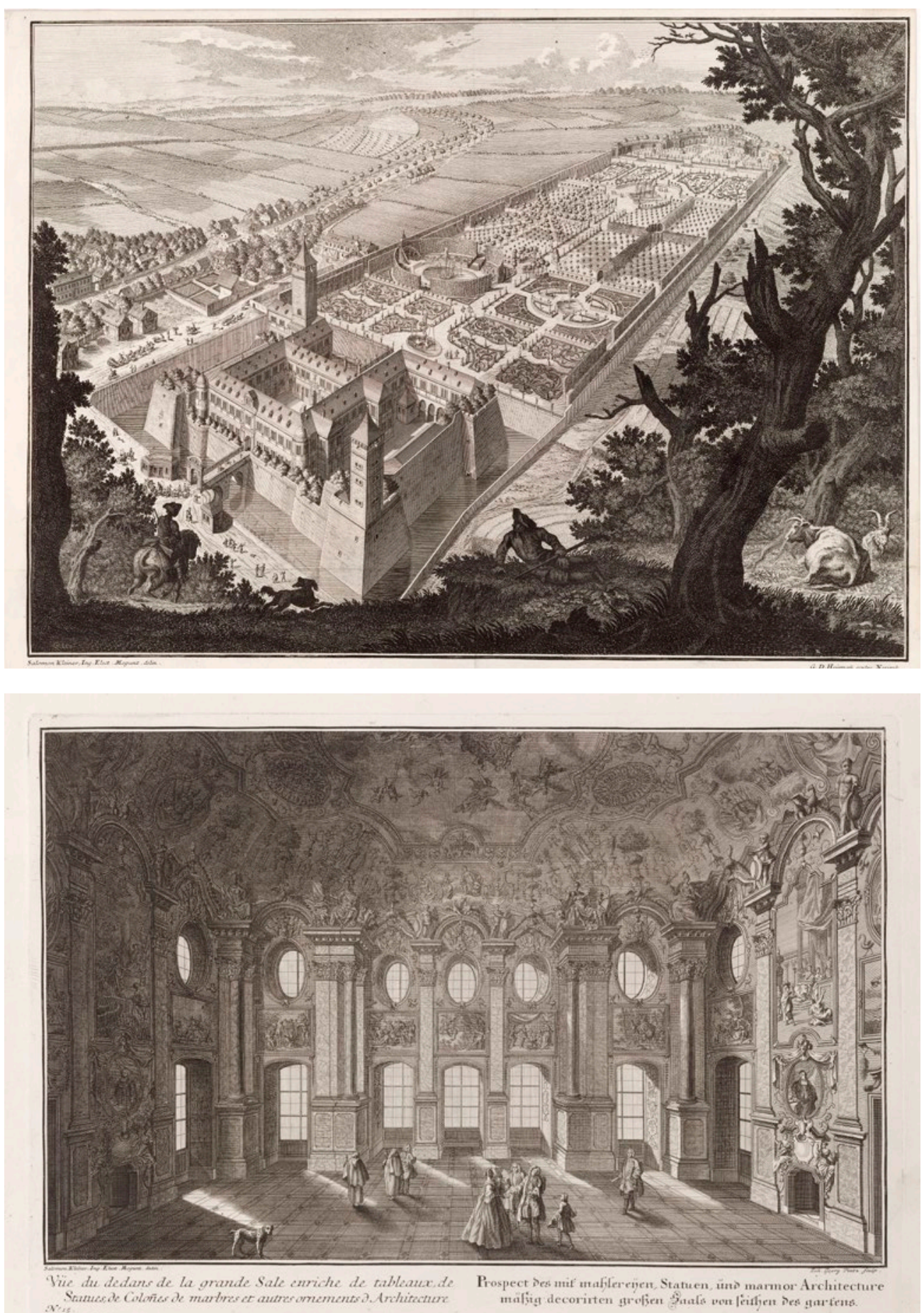

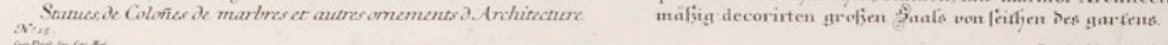




\section{Bei Kunsthändlern und -sammlern}

Im 17. Jahrhundert erlebten die nördlichen Niederlande eine besondere wirtschaftliche Blütezeit, der Ostindienhandel brachte enormen Reichtum, die inländische Produktion von Luxusgütern florierte. Maler und Graphiker machten die Niederlande zur mit Abstand größten Bilderwerkstatt Europas. Entsprechend boomte der Kunsthandel, der sich bereits im 16. Jahrhundert entwickelte und im 17. Jahrhundert entfaltete. Zentrum der Produktion und des Handels war Amsterdam. Spezialisierte Malwerkstätten und Händler, die gezielt die Gemäldeproduktion in Sparten wie Porträt, Landschaft und Stillleben steuerten und dabei selbst in großer Zahl Kopien beliebter Motive herstellen ließen, beherrschten den Markt. So gelangte etwa auch Rembrandt (1606-1669) als Porträtspezialist und zugleich als Schwiegersohn eines der bedeutendsten Amsterdamer Kunsthändler zu frühem Ruhm und Reichtum.

Neben Amsterdam blühte der Kunsthandel in weiteren niederländischen Städten, die Johann Friedrich und Zacharias Conrad ebenso wie die Kunstzentren in Italien, Frankreich und England besuchten. Dort besahen sie kostbare Bücher, Manuskripte, Münzen, Gemälde, Druckgraphik, aber auch kunstgewerbliche Objekte, Instrumente und naturalia wie exotische Muscheln. Uffenbachs Tagebucheinträge zeigen, dass sie das gezeigte meist als zu teuer einstuften und nur sehr gezielt kauften. Kunstobjekte wurden aber nicht nur bei Händlern erworben, sondern auch bei Sammlern, die den Brüdern ihre Objekte präsentierten. Häufig waren diese auch zum Tausch bereit.

Beim Amsterdamer Porzellanhändler Roede wurden ihnen diverse Kunstgegenstände und zahlreiche Druckgraphiken von Rembrandt gezeigt. Dieser Händler schien wenig von deren schon damals hohen Wert zu verstehen und verkaufte Uffenbach Rembrandts sogenanntes Hundertguldenblatt (ca. 1647-1649) für nur einen Gulden. Das Exemplar befindet sich noch heute in der Göttinger Kunstsammlung.

Anna-Lena Sinning / Arwed Arnulf

Johann Friedrich von Uffenbach, Zacharias Conrad von Uffenbach, Register über die

Drey Theile des Reis Diarii durch Nieder Sachsen, Holl- und Engelland, 1680-1720, SUB, 8 Cod. Ms. Uffenbach 25, 4, 374r, Zeichnung des Sammlungsscbrankes des Jacob de Wilde in Amsterdam.

Nicolas Chevalier, Representation de la gallerie de S. Girardon a Paris, SUB, GR 2 Bibl. Uff 467. 

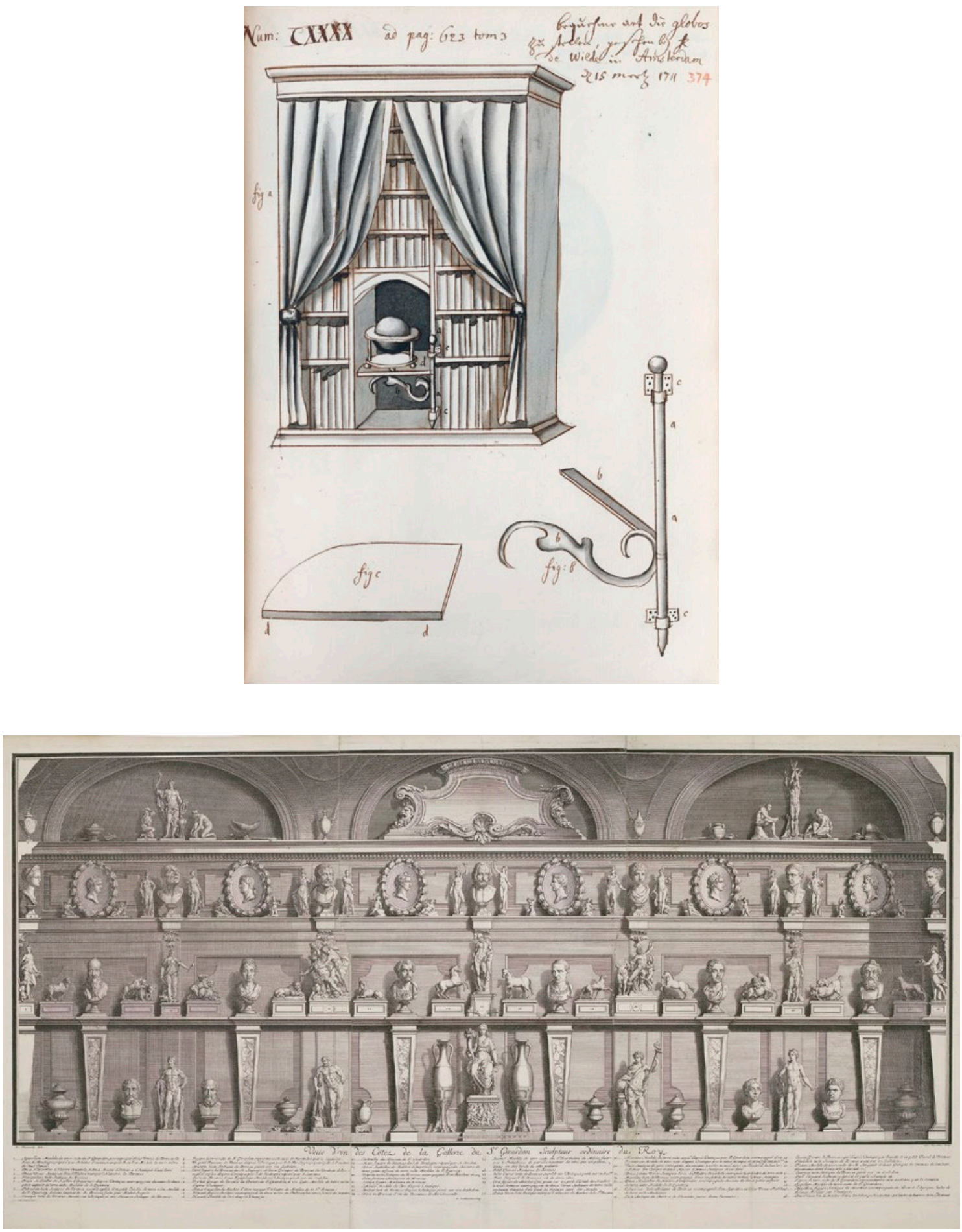


\section{In fremden Bibliotheken}

„Bücher zu kennen ist allen Gelehrten unentberlich. Daher denn auf Reisen die Bibliothecken zuerst zu besuchen sind.“ Was Johann David Köhler (1684-1755) in seiner 1762 postum erschienenen Anweisung für reisende Gelehrte [...] formuliert, beschreibt die vornehmste Aufgabe gelehrten Reisens, wie sie im 18. Jahrhundert gesehen wurde. Schon seit dem 17. Jahrhundert waren Bibliotheksbesuche auf Reisen unter Gelehrten in Europa verbreitet. Sie galten als „,nothwendige[r] Bestandtheil akademischer Bildung“ (Tholuck 1853).

Ganz in dieser Tradition besuchte Uffenbach auf seinen Reisen unter anderem zahlreiche Bibliotheken und füllte insgesamt mehr als 7.500 Manuskriptseiten mit tagebuchartigen Notizen, Sammlungsbeschreibungen und Exzerpten aus den Katalogen der von ihm besichtigten Buchbestände sowie den jeweils dort in kritischen Augenschein genommenen seltenen Handschriften.

Uffenbachs Bibliotheksbeschreibungen sind in der Regel kritisch wertend, selten nur neutral gehalten. Er bemängelt Unordnung und weist diese bestimmten Bibliothekstypen als charakteristisch zu, kritisiert mangelndes Interesse auf Seiten der Bibliothekare sowie den schlechten Zustand der Bibliotheksräume oder mangelhafte Katalogisierung. Allerdings spart er aber auch nicht an Lob, wenn die Büchersammlungen seinen hohen Ansprüchen genügen.

Insgesamt enthalten die Diarien dieser „peregrinatio academica“ - also seiner beiden groBen Reisen - wertvolle Nachrichten über die Spezialbestände der besuchten Bibliotheken, die Uffenbach vor Ort teilweise auf abenteuerlichem Wege dokumentierte. Sie zeigen ihn als einen polyhistorisch orientierten Gelehrten, der sich neben den Buch- und Manuskriptbeständen auch für Architektur, Musik, technische Instrumente und die bildenden Künste interessierte.

Stephan Brakensiek

Johann Friedrich von Uffenbach, NebenStunden, Frankfurt a. M. 1726-1727, SUB, 2 Cod. Ms. Uffenbach 13, Bd. III, p. 210, Zeichnung einer Büchermaschine.

Johann Friedrich von Uffenbach, Spazierfahrt durch die Hessische in die Braunschweig Lüneburgische Lande, Frankfurt a. M. [u. a.] 1728,

SUB, 8 Cod. Ms. Uffenbach 33, nach p. 67, Grund-Riß von Der Hertroglich-Wolffenbüttelschen Bibliothec. Michael Burghers, Queens College Library in Oxford, Kupfer Vol. zu allen Theilen der Reisz Diariorum, o. O. ca. 1680-1720, SUB, 2 Cod. Ms. Uffenbach 8, 9. 

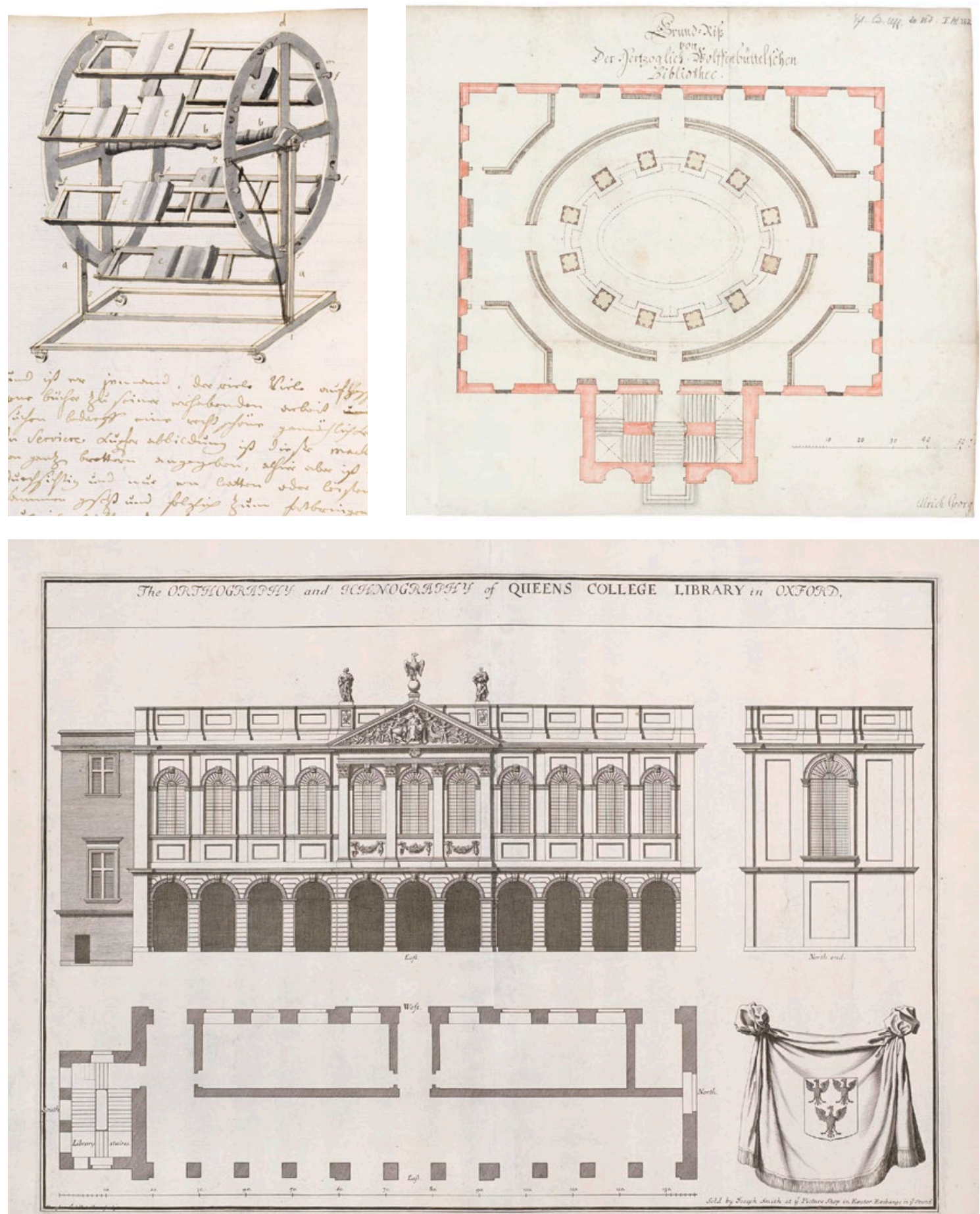


\section{Uffenbach kauft Kunst}

Neben Büchern und Instrumenten ist es vor allem Kunst, die Uffenbach kaufte, nicht nur auf Reisen, sondern auch von Frankfurt aus über Kunsthändler und Agenten, die das europaweite Angebot beschaffen konnten. So erwarb er über Johann Christian Kaller (1725-1794) in Amsterdam die 58 Kupferstiche des Odysseus-Zyklus Theodoor van Thuldens (1606-1669), die 52 Blätter mit Illustrationen der Metamorphosen des Ovid nach Hendrik Goltzius (1558-1616) sowie Jacques Callots (1592-1635) illustrierten Heiligenkalender von 1636. Besonders bedeutsam sind diese bezeugten Ankäufe, da die Werke sich noch heute in Göttingen befinden.

Aus Uffenbachs Reisetagebüchern geht hervor, dass er zu vielen Händlern, Malern, Kupferstechern und Instrumentenbauern schon vor seinen Besuchen Briefkontakt hatte. Viele der Händler waren selbst Sammler: Bereits während des Studiums hatten die Uffenbach-Brüder den berühmten Buchhändler Johann Friedrich Spoor (1641-1709) in seiner Niederlassung im ehemaligen Straßburger Dominikanerkloster besucht, dort etwas erworben und wohl besonders dessen Bestände bestaunt. Nach Spoors Tod wurde ihnen dessen Kunstkammer angeboten, ein sehr umfangreiches Beispiel jenes vormodernen Sammlungstyps, der versuchte, alle Wissensbereiche von den Naturalien bis zu Instrumenten, Modellen, Münzen, Graphik, Gemälden und vieles mehr zu erfassen. Ein Auktionskatalog überliefert die Fülle der Sammlung. Im Uffenbach-Nachlass findet sich auch eine Kopie des Inventars der Spoorschen Graphikund Gemäldesammlung mit Preisen. Von den Erben Spoors erwarb Uffenbach ebenfalls den zeichnerischen und schriftlichen Nachlass des Straßburger Münsterbaumeisters Johann Jacob Arhard (1616-1674), worin sich etwa Zeichnungen für eine geplante Kupferstichpublikation zum Straßburger Münster befinden.

Manche Anschaffungen erscheinen dagegen eher ungewöhnlich: In London kaufte Uffenbach bei Thomas Smith, einem darauf spezialisierten Hersteller und Händler von Glasaugen ,so den seinigen accurat gleich kamen, um sie zu seinem in Wachs abgeformten Porträt zu gebrauchen." Bemerkenswert ist nicht nur der Einkauf bei einem ausgesprochenen Spezialisten selbst, sondern auch der Zweck: Der Leser erfährt hier nebenbei, dass Johann Friedrich bereits im Alter von 23 Jahren ein Wachsportrait von sich anfertigen ließ - eine aufgrund ihrer „Lebhaftigkeit“ sehr beliebte Art sich abbilden zu lassen, bis diese Mode im Laufe des 18. Jahrhunderts verebbte.

Anne-Katrin Sors

Johann Jakob Thurneysen, Toilette der Venus, 1678, Kupferstich, KS, D 2642.

Johann Ulrich Kraus, Der Große Rheinfall bei Schaffhausen, Augsburg 1681, Kupfer Vol. zu allen Theilen der Reisz Diariorum, SUB, 2 Cod. Ms. Uffenbach 8, 19. 

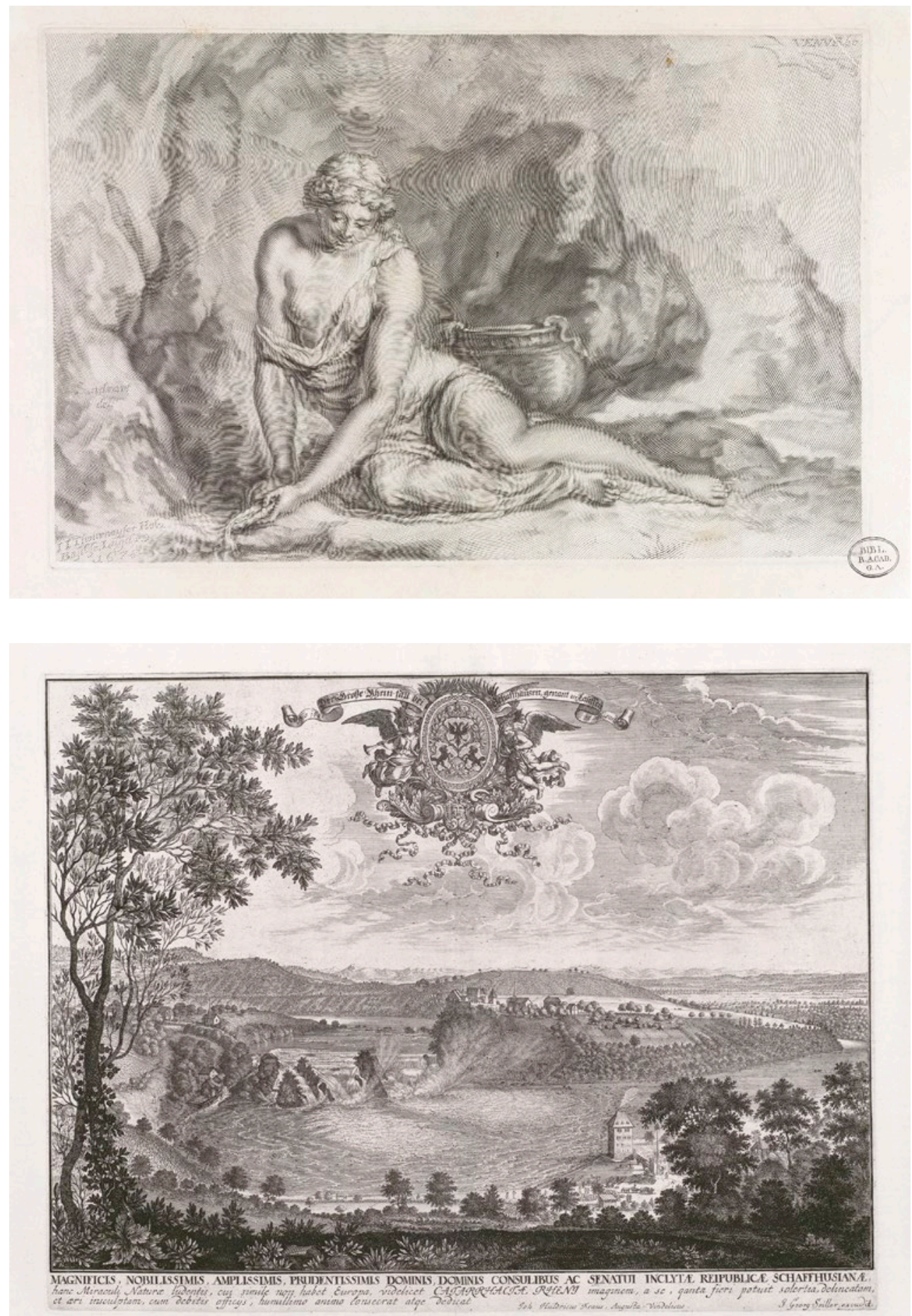


\section{Die Wissenschaft der Schönen Künste}

Obwohl Uffenbach in Straßburg sein Studium in Jura abschloss, bei Christian Wolff (1679_ 1745) in Halle vor allem das aufklärerische Konzept der angewandten Mathematik als Grundlage aller naturwissenschaftlich-technischen Disziplinen kennen und schätzen gelernt hatte, als Ingenieur bei Brückenbau und Großfeuerwerken tätig war, selbst musizierte und komponierte, interessierte er sich in besonders hohem Maß für die Bildkünste. Dies zeigt seine umfangreiche graphische Sammlung, die besondere Konzentration auf technische Aspekte des Zeichnens und der graphischen Reproduktionstechniken belegt: Neben Werken großer Meister von Botticelli, Lucas van Leyden über Dürer bis Rembrandt, sind es technische Besonderheiten, hochkomplexe Verfahren wie das Mezzotinto, einem Druckverfahren, das malerische Halbtöne zu erzeugen vermag, die in seiner großen Sammlung prominent vertreten sind. Das unpubliziert gebliebene Manuskript [Uff 20 II] einer Geschichte der druckgraphischen Techniken befindet sich im Nachlass.

Auch das Sammeln fand seine Aufmerksamkeit. So führte er Kataloge, verzeichnete Ankäufe, sammelte Signaturen und plante ein Lexikon der Künstlersignaturkürzel. Graphische Blätter, vor allem Kupferstiche, dienten wie bei vielen seiner Zeitgenossen aber nicht nur als ästhetisches Erbauungsmittel, sondern waren das Bildmedium der Zeit. Porträts berühmter Personen, Ansichten von Städten, Kirchen und Palästen, Gärten und Landschaften, aber auch von Kunstgegenständen, Möbeln und technischen Gerätschaften gehörten ebenfalls zu diesem Versuch, die Welt in graphischen Abbildungen in sein Studierzimmer zu bringen.

Neben den etwa 10.000 Blatt Druckgraphik finden sich Kupferstiche in ähnlicher GröBenordnung in seinen Büchern unterschiedlichster Thematik. Sein Nachlassinventar verrät, dass Uffenbach neben diesen nach Göttingen gelangten Sammlungsbeständen auch eine wertvolle Gemäldesammlung besaß, die er seit seiner Straßburger Studienzeit zusammengetragen hatte, von ihm nie zur Schenkung nach Göttingen vorgesehen war und nach seinem Tod von der Witwe zum Verkauf gegeben wurde. Da Uffenbach auch selbst Zeichnungen und Druckgraphiken von erstaunlicher Fertigkeit hinterließ, lässt sich feststellen, dass er den Bildkünsten einen erheblichen Teil seiner Zeit und seiner Mittel widmete.

Arwed Arnulf 


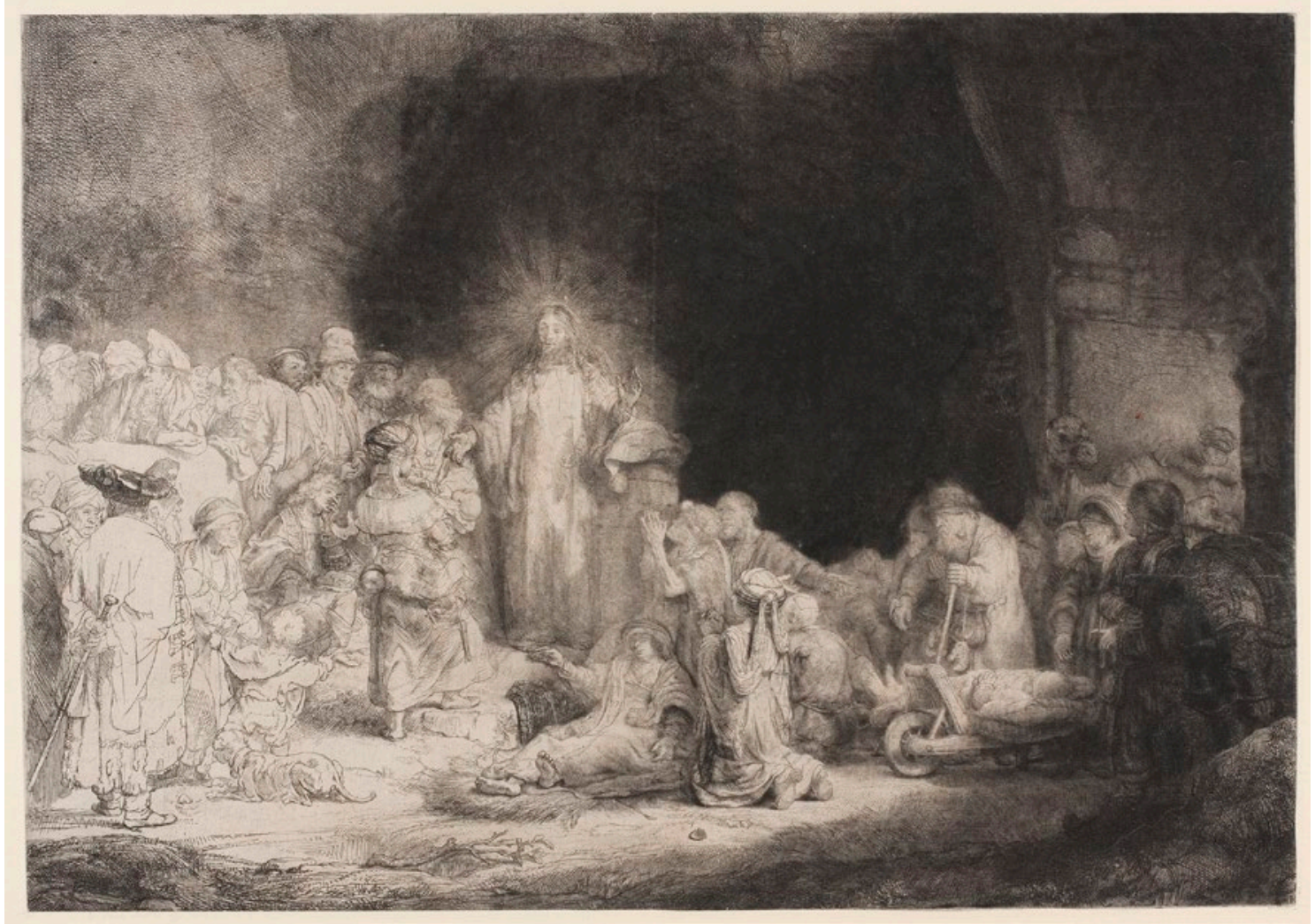




\section{Theorie und Praxis der Oper}

Im Schlussbild von Uffenbachs handgeschriebenem Opernlibretto Pharasmanes [Uff 18] öffnet sich der Blick in die Galerie des Palasts von Pharasmanes, König von Iberien (1. Jh. nach Chr.) und Hauptperson des Stücks. Dieser sitzt rechts mit verhülltem Angesicht unter dem Baldachin seines Throns. Ein „Ballett des Iberischen Adels“ sowie alle weiteren Personen der Handlung haben sich versammelt und werden Zeugen, wie Pharasmanes seiner Geliebten Londina seine wahre Identität offenbart.

Der Stoff der Oper basiert auf einer Episode der Römischen Octavia, dem Romanprojekt von Herzog Anton Ulrich von Braunschweig-Wolfenbüttel (1633-1714). König Pharasmanes soll Prinzessin Londina von Colchis heiraten. Als Gesandter begleitet er inkognito die Delegation, die die Braut aus ihrer Heimat abholt. Verwicklungen nehmen ihren Lauf, als sich der Verkleidete in Londina verliebt, seine Liebe von ihr erwidert wird und sie ihm gesteht, sie sei bereit, ihn dem König vorzuziehen. Eifersüchtig auf sich selbst wird er zum „,von Londinen zugleich geliebte und ungeliebte Pharasmanes“.

Uffenbach besuchte auf seinen Reisen Theateraufführungen und sammelte Informationen über Bühnenmaschinerien und Dekorationen. In einem Klebealbum trug er Druckgraphiken von Theaterbauten und Szenenbildern zusammen, auf die er in seinem Opernprojekt als Vorlagen zurückgriff. Die fünfzehn zum Teil auf farbigen Papieren ausgeführten und fein gerahmten architektonischen Dekorationen sind sorgfältig in Feder gezeichnet, laviert und teilweise weiß gehöht: ihr Hochformat ist für die Bühne ungewöhnlich. Das repräsentativ gestaltete Libretto sandte Uffenbach im Frühjahr 1726 an den Braunschweiger Komponisten und Hofkapellmeister Georg Caspar Schürmann (1672-1751), der es vertonen und eine Aufführung am Braunschweiger Hof im Sommer 1727 vorbereiten sollte. Da Uffenbach das ihm wertvolle Manuskript zurückverlangte, ließ Schürmann den Text abschreiben und die Zeichnungen von Theatermalern kopieren. Trotz aller Vorbereitungen kam es jedoch nie zu einer Vertonung oder Aufführung des Pharasmanes.

Christine Hübner

Johann Friedrich von Uffenbach, Der von Londinen zugleich geliebte und ungeliebte Pharasmanes König von Iberien in einem Sing-Spiel, 1720, SUB, 2 Cod. Ms. Uffenbach 18, p. 37. 


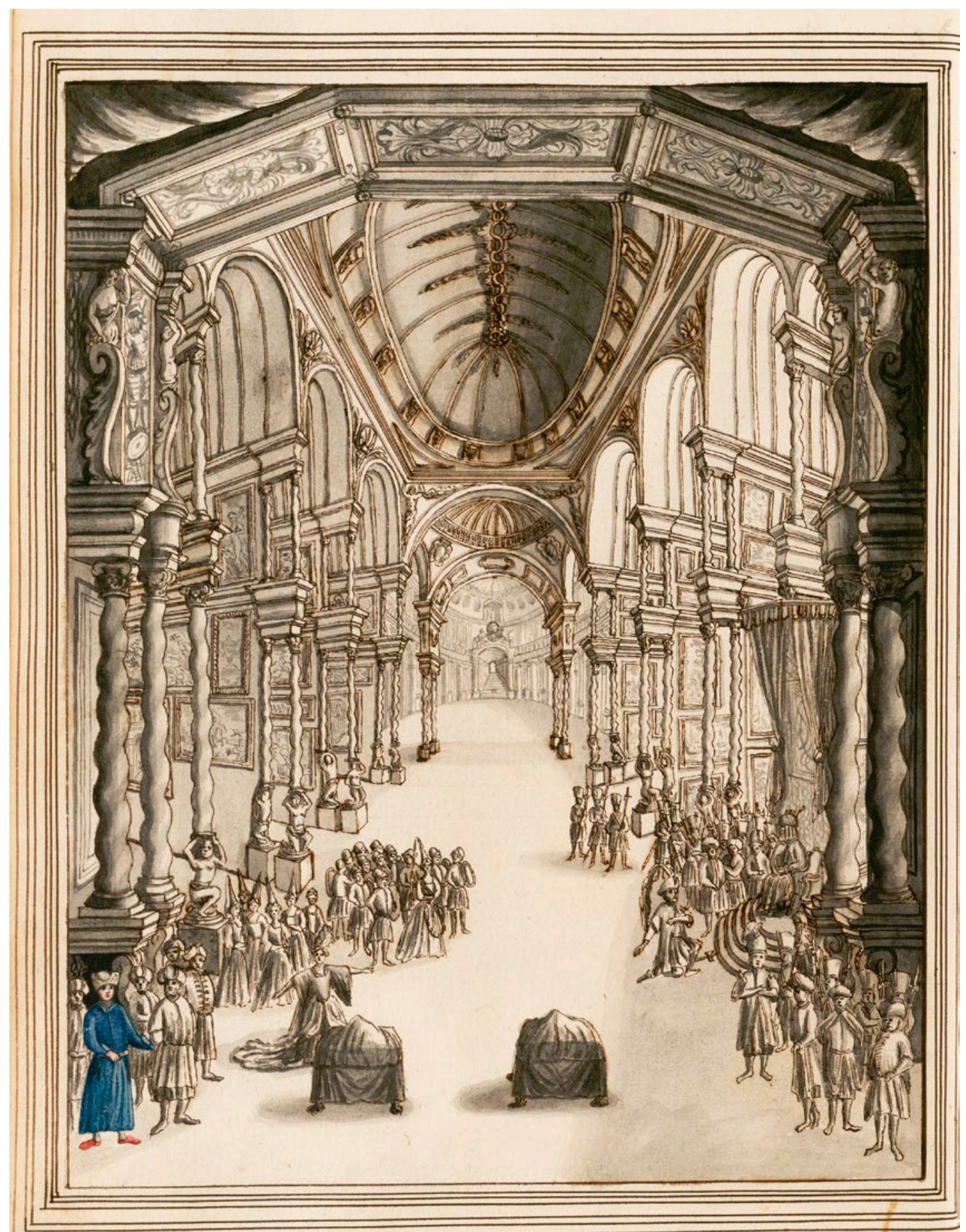




\section{Künstlerviten}

Historisch und geographisch sortierte Lebens- und Werkbeschreibungen von Architekten, Bildhauern und Malern - Künstlerviten -, besaß Uffenbach in großer Zahl. Neben den klassischen Hauptwerken der Gattung wie Giorgio Vasaris (1511-1574) Vite (1550/1568), Joachim von Sandrarts (1606-1688) Teutsche Akademie (ab 1675), Karel van Manders (1548-1606) Schilderboek (1604) oder Arnold Houbrakens (1660-1719) Groote Schouburgh (1718), besaß Uffenbach auch weniger bekannte und spezialisierte Werke, so Johann Caspar Füsslis (17061782) Geschichte und Abbildung der besten Mabler in der Schweitz. (1755). Darin sind den Viten Porträts der Künstler vorangestellt. Auch Maria Sybille Merian (1647-1717), die Tochter des bekannten Verlegers und Kupferstechers Mathäus Merian (1593-1650), ist enthalten. Diese besuchte Uffenbach mit seinem älteren Bruder 1711 in Amsterdam, bewunderte deren Werke und erwarb zahlreiche farbige Zeichnungen und Stiche der für ihre Pflanzendarstellungen berühmten Künstlerin.

Ein weiteres Beispiel heute kaum bekannter Künstler-Literatur aus Uffenbachs Besitz ist das Alchimedon genannte Werk des Johann Christian Schumann (1634-1705), das 1680 in Dresden erschien. Es liefert neben den Viten von 16 deutschen Graphikkünstlern eine frühe Anleitung zum Sammeln von Kupferstichen - kombiniert demnach Uffenbachs Interessen an Künstlerviten, verschiedenen druckgraphischen Verfahren sowie dem Sammeln der Blätter.

Künstlerviten, aber auch Gelehrtenkataloge, in der Sprache der Zeit etwa „Viten der derzeit lebenden Gelehrten”, und aktuelle Künsterlexika mit Verzeichnissen besuchenswerter Sammlungen waren es, die Reisende wie Uffenbach zu den Orten ihres Interesses führten.

Anna-Lena Sinning / Arwed Arnulf

Joachim von Sandrart, Teutsche Academie der Edlen Bau-Bild- und Mablerey-Künste, Nürnberg, Frankfurt a. M. 1675, SUB, 2 Bibl. Uff 345, 1. 


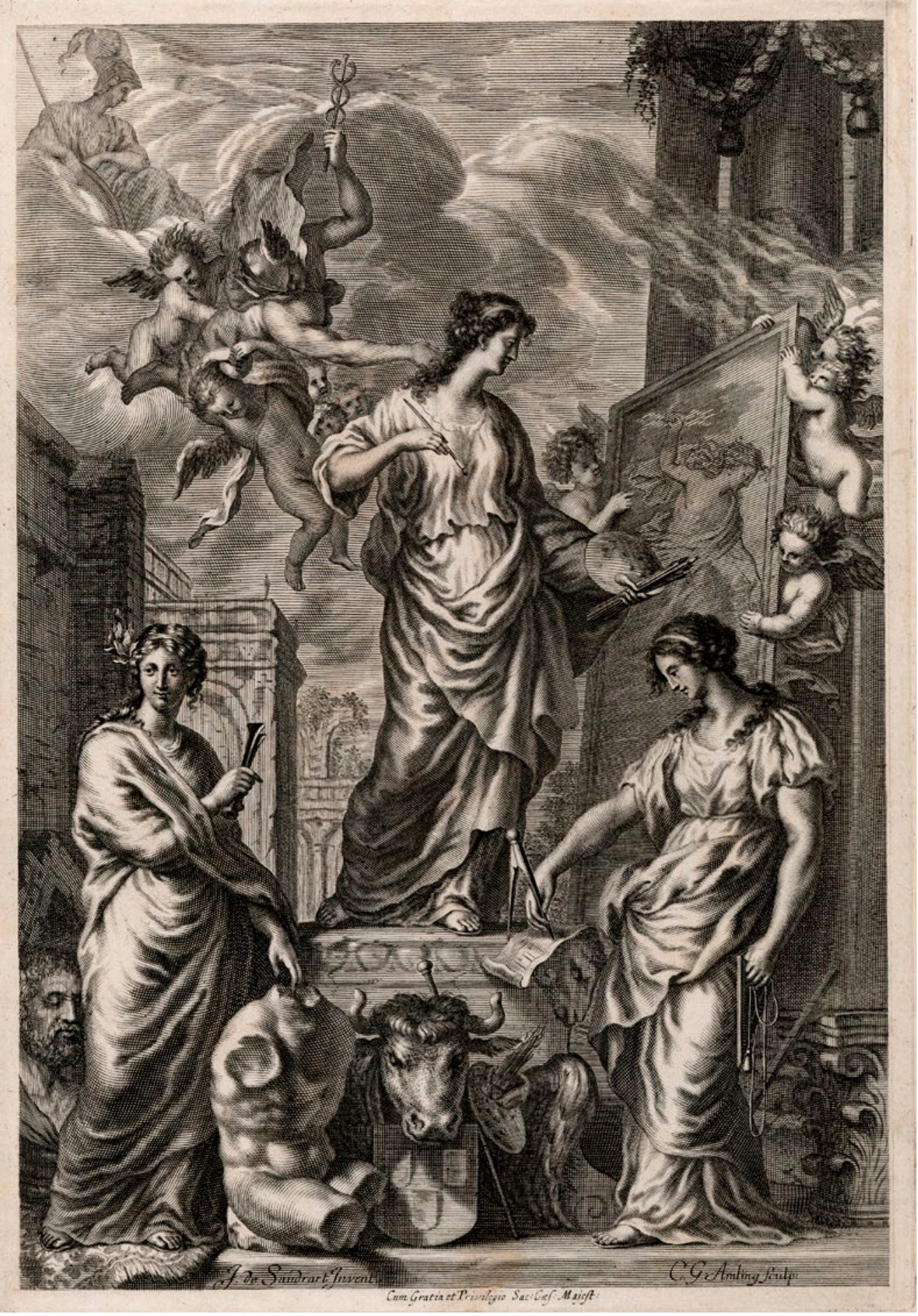




\section{Uffenbachs „kleine Bilder-Versammlung“}

In seinem etwa 10.000 Blatt umfassenden Graphikkabinett - die „kleine Bilder-Versammlung“" [Uff 13 IV] - das Uffenbach mit dem handschriftlichen Verzeichnis Index Titulorum / sive Artificum / Pictorum vel Caelatorum Iconothecae / insertorum (Index der Titel sowohl der Künstler, der Maler wie auch der Kupferstecher, die zu der Bildersammlung gehören) verwaltete, bewahrte er auf hellblauen Kartons aufgeklebte Blätter nach Künstlernamen alphabetisch sortiert in Mappen auf. Auffällig an Uffenbachs Sortierung ist, dass er die Blätter nicht nach Kunstlandschaften ordnete, sondern lediglich fortlaufend nach Künstlernamen.

Dieser Ordnung vorangestellt war eine nach Drucktechniken geordnete Auswahl von Blättern in gesonderten Mappen, die Holzschnitte, Kupferstiche, Radierungen und Mezzotinto-Blätter enthielten. Darunter fanden sich auch in ungewöhnlichen und besonders aufwendigen Verfahren hergestellte Exemplare, wie Hans Burgkmairs (1473-1531) Der Tod überfällt ein Liebespaar von 1510, ein besonders frühes Beispiel des Farbholzschnitts. Dessen Herstellungsprozeß ist kompliziert und langwierig: Man benötigte für jede der hier verwendeten drei Farben eine eigene Holzplatte, die passgenau nacheinander auf das Papier zu drucken waren.

Albrecht Dürers (1471-1528) Die Kanone von 1518 ist ein Beispiel des seltenen Radierens auf einer Eisenplatte. Dürer gehörte zu den Künstlern, die Uffenbach besonders schätzte, laut Verzeichnis besaß er 205 Blätter des Künstlers.

Uffenbachs technische Mustersammlung enthielt sämtliche Spielarten von Holzschnitten als linearem Hochdruck und alle Arten von Tiefdrucktechniken, wie Kupferstichen und Radierungen. Neben diesen Strichverfahren weist sie auch viele Blätter in dem besonders aufwendigen Mezzotinto auf, bei der auf einer mechanisch aufgerauten Platte durch Werkzeuge verschiedene Glättungsgrade erzielt werden, woraus im Druck tonige Darstellungen abgestufter Grautöne entstehen.

Dietrich Meyerhöfer

Hans Burgkmair, Der Tod überfällt ein Liebespaar, 1510, Clair-obscur-Holzschnitt, KS, D 24. Hendrick Goltzius, Phaeton, 1588, Kupferstich, KS, D 5209. Albrecht Dürer, Die Kanone, 1518, Eisenradierung, KS, D 924. 

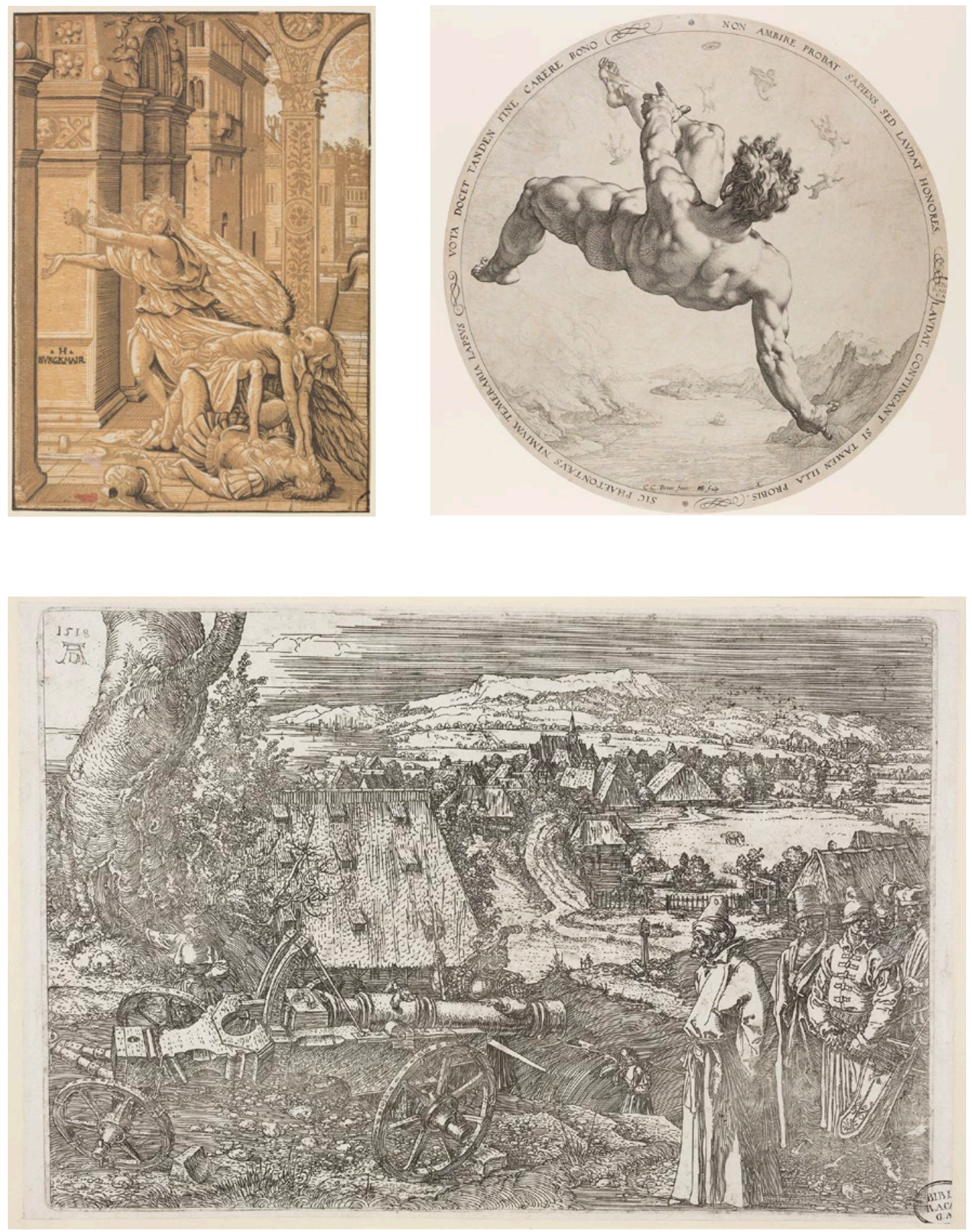


\section{Auf der Suche nach dem richtigen Künstlernamen}

Eines der großen Sammelgebiete Uffenbachs war die Druckgraphik. Auf diesen in großer Zahl gedruckten Blättern hatten die Künstler und Stecher häufig ihre Signatur als ligierte also ineinander verschlungene - Buchstaben hinterlassen. In der internationalen Literatur zu diesem Thema, die Uffenbach zum großen Teil besaß, wurden diese Ligaturen nicht selten falsch entschlüsselt, was den Sammler dazu veranlasste, ein eigenes Verzeichnis mit dem Titel Monogrammata oder Zeichen derer Mahler und Kupferstecher so noch ungedeutet oder unbekant sind [Uff 50] anzulegen. Uffenbach hatte dazu aus Büchern und bei Kabinettbesuchen während seiner Reisen die Monogramme mit der jeweiligen Quelle notiert und wenn möglich den identifizierten Namen des Künstlers davor oder dahinter gesetzt.

Allerdings legte er das Verzeichnis nicht nur für den eigenen Gebrauch an, sondern verfolgte von vornherein die Absicht, seine Erkenntnisse zu veröffentlichen. Dazu kam es jedoch nicht, da der Braunschweiger Maler Anton Friedrich Harms (1695-1745) und besonders der Leipziger Professor und Graphiksammler Johann Friedrich Christ (1701-1756) ihm mit ihren publizierten Monogrammlexika zuvorkamen.

Uffenbach führte bis mindestens 1763 sein Manuskript fort und hatte weiterhin eine Veröffentlichung im Sinn. Aus dieser Zeit stammt das separat gebundene lateinische Vorwort [Uff 36a], in dem er sein Vorhaben nochmals begründet. In einer einleitenden Geschichte der Druckgraphik [Uff 20 II] diskutiert er unter anderem die Entstehungsorte der einzelnen Techniken, da viele Autoren die Erfindung dieser Methoden in „landsmännischen Prahlerey“ jeweils ihrem Heimatland zusprachen.

Dietrich Meyerhöfer

Johann Friedrich von Uffenbach, Monogrammata, o. O. 1730-1735, SUB, 8 Cod. Ms. Uffenbach 50, Titelblatt und 27v/28r. 

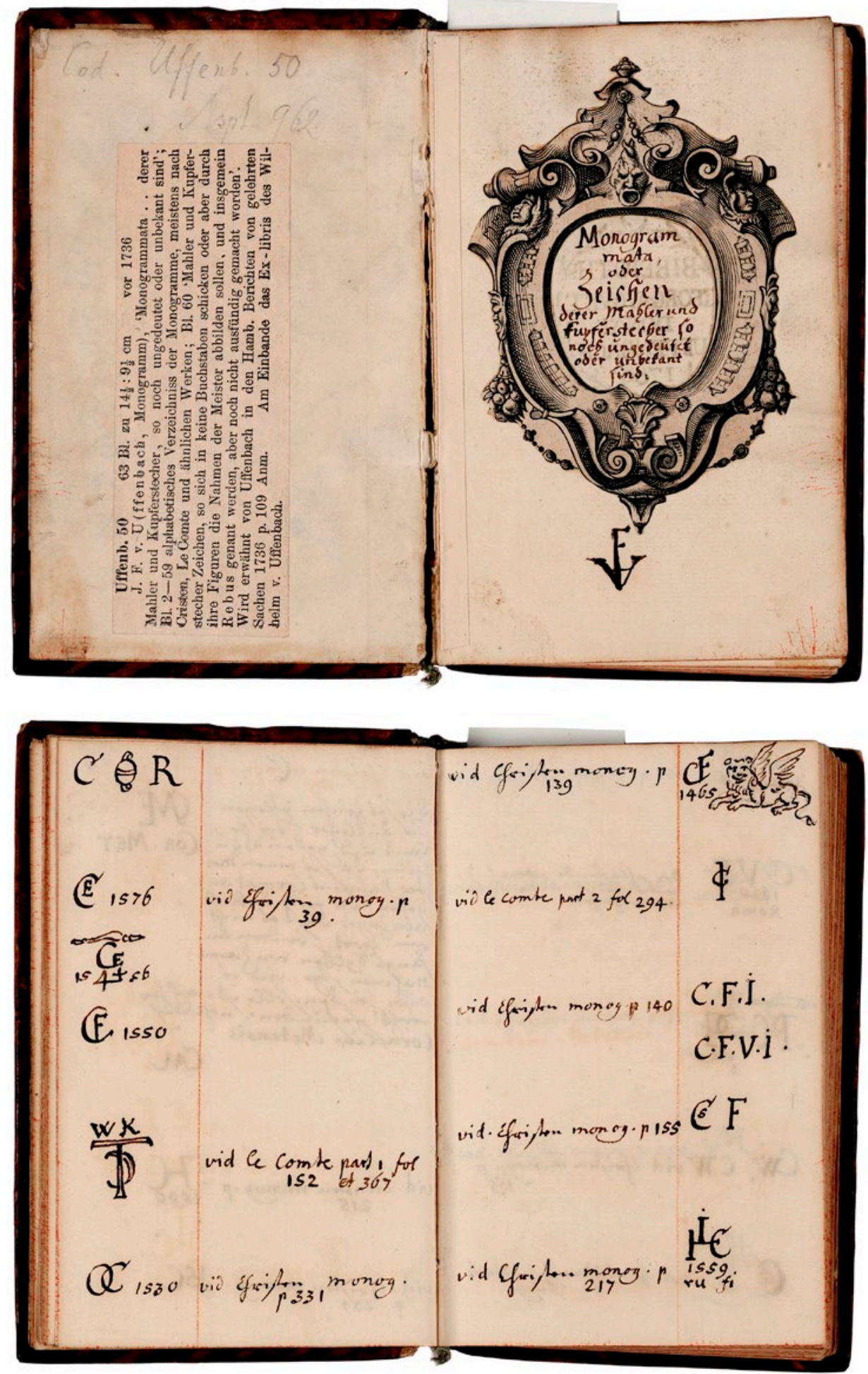


\section{Friedrich Brentels Illuminierbüchlein}

Malereilehrbücher mit Anweisungen und Farbrezepten stellten im 17. und 18. Jahrhundert keine Seltenheit dar. Uffenbach besaß eine ganze Reihe dieser Traktate, die nicht nur allein zur praktischen Anleitung erfahrener Maler dienten, sondern auch zur theoretischen Beschäftigung gelehrter Leser gedacht waren, die der Entstehung bestimmter visueller Effekte nachgehen wollten. Ein Werk zur Encaustischen Mahlerey [Uff 39] von Johann Heinrich Müntz (1727-1798) übersetzte Uffenbach sogar aus dem Englischen, da er von dessen ausführlichen Technikbeschreibungen sehr angetan war.

Das Illuminierbüchlein [Uff 49] von 1642, ein äußerlich unscheinbares Manuskript, ist die bisher einzige bekannte deutschsprachige, vom Künstler selbst verfasste Schrift dieser Zeit, deren thematisch geordneter Inhalt ganz auf kunsttechnische Aspekte fokussiert ist. Der Straßburger Maler, Zeichner und Radierer Friedrich Brentel d. Ä. (1580-1651) beschreibt darin ausgehend von 33 Farbmitteln Anweisungen zur Miniaturmalerei und der Kolorierung von Drucken mit Gummifarben. Neben der Verarbeitung von Farben und Bindemitteln werden maltechnische Hinweise zur Verträglichkeit mit anderen Materialien sowie die Auswahl und Verwendung der Farbmittel in der Malerei ausgeführt. Damit liegt eine Quelle vor, von dessen Verfasser sich zahlreiche malerische Ausführungen erhalten haben, die sich mit den Inhalten seines Manuskripts vergleichen lassen.

Aus Uffenbachs Sammlung gelangte die Federzeichnung Bankett des Markgrafen Wilhelm von Baden-Baden nach Göttingen. Die Zeichnung enthält Beischriften Brentels zu Farben und stofflichen Qualitäten - für den Künstler waren sie Anhaltspunkte für ein späteres, nicht erhaltenes Gemälde, heute erlauben sie wichtige Rückschlüsse auf den Werkprozess, also die Art und Weise, wie Künstler arbeiten.

Nadja Kehe

Friedrich Brentel, Mablen und Illuminir Büchlein, 1642, SUB, 8 Cod. Ms. Uffenbach 49, 12v.

Friedrich Brentel, Bankett des Markgrafen Wilhelm von Baden-Baden in den Auen an der Oos, ca. 1630, Rötel- und Federzeichnung, laviert und weiß gehöht, KS, H 428. 

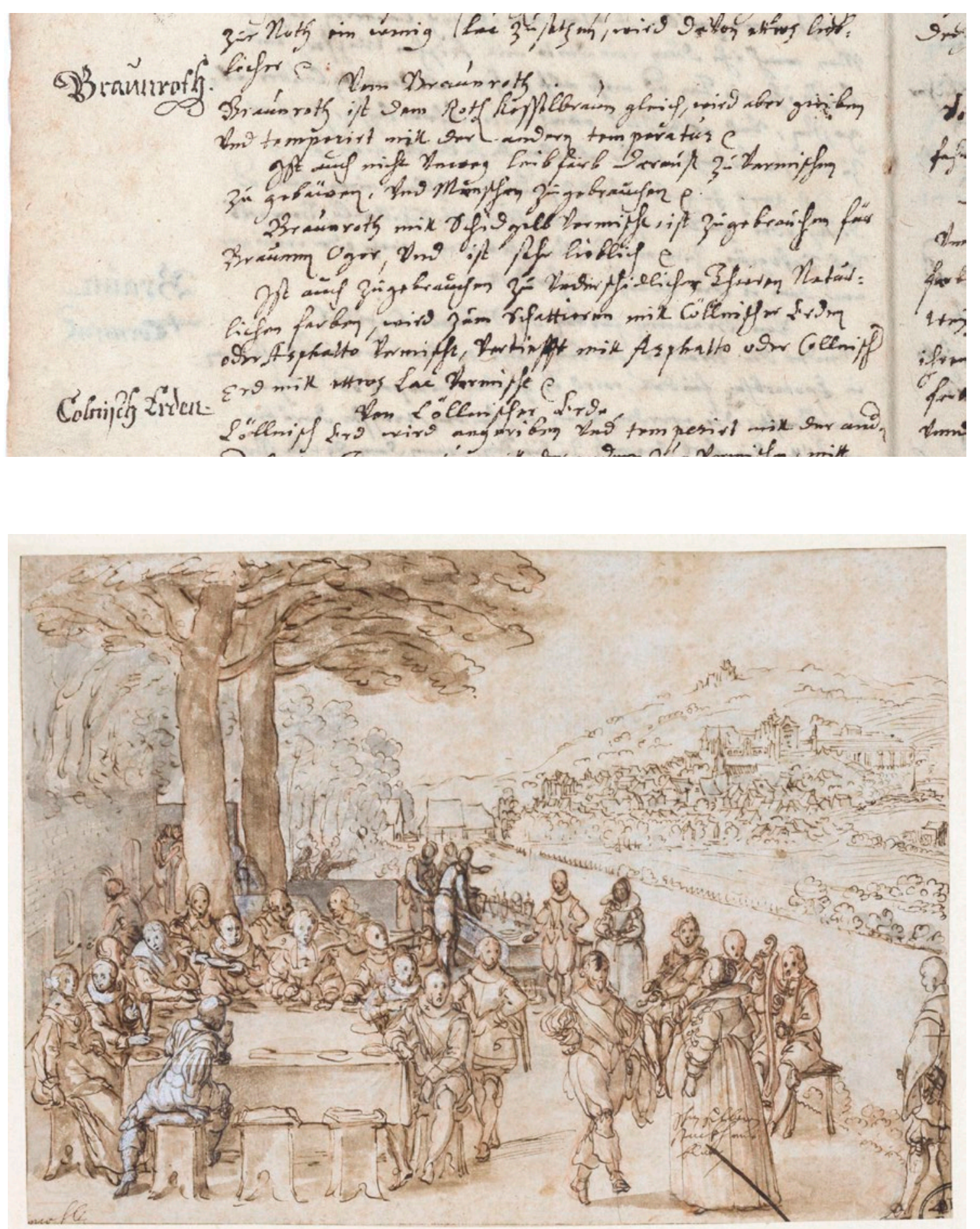


\section{Systematisierung und Nutzen von Holzarten}

Uffenbachs Alphabetisches Verzeichnis derer ausländischen Bäume und Hölzer von allerley Arten aus Asien, Afrika und Amerika [Uff 40] ist eine handschriftliche Zusammenstellung vor allem exotischer Bäume und Hölzer, die er selbst auf Grundlage von botanischer Literatur verfasste. Er sortierte es nach Eigenschaften der Hölzer, etwa Farbe, Dichte, Härte, aber auch des Geruches und pharmakologischer Nutzung. Die Bäume selbst ordnete er nach formalen Kriterien, also Wuchs-, Blatt-, Blüten- und Fruchtform.

Trotz dieses systematisierenden Ansatzes war Uffenbach damit weit von der bis heute wirkenden botanischen Klassifizierung des nur wenig jüngeren Carl von Linné (1707-1778) entfernt, dessen grundlegende Texte, wie Fundamenta Botanica und das irdische Lebensformen klassifizierendes Systema naturae ab 1735 erschienen. Uffenbach, in dessen Besitz Linnés Werke zumindest nicht mehr nachweisbar sind, stütze sich auf eine Handvoll älterer Werke, vor allem das Holz-Kabinet des Christian Clodius (1694-1775) von 1729, das er mit seiner Kompilation ausdrücklich zu verbessern und vervollständigen beabsichtigte. Seine zusammenstellende Arbeit sah er als „keine große kunst aber eine beträchtliche mühe, und nur denen bekannt ist, welche jemahlen hand an dergleichen geleget."

Welchen Nutzen er diesem Unternehmen beimaß, wird verständlich, wenn man Uffenbachs Interesse an technisch-handwerklichen und damit auch wirtschaftlichen Nutzungen von Hölzern in den Blick nimmt, die zahlreiche Werke seiner Bibliothek zu Schreiner-, Tischler- und Sammelarbeit belegen. So etwa die als Vorlagenwerke und Anleitungen konzipierten Bücher und Stichfolgen des Johann Jacob Schüblers (1689-1741), der ebenso Handbücher der Holzverbindungen wie Musterentwürfe modernster französischer Luxusbetten publizierte.

Anne-Lena Dreikluft / Arwed Arnulf

Johann Friedrich von Uffenbach, Alphabetisches Verzeichnis derer ausländischen Bäume und Hölzer, SUB, 8 Cod. Ms. Uffenbach 40, Titelblatt.

Johann Jacob Schübler, Neu-inventiert sehr curieusen Frantzö̈sischen Betten, Augsburg um 1735, SUB, 4 Bibl. Uff 442, 1.

Johann Jacob Schübler, Sciagraphia Artis Tignaria, Oder nutzliche Eröffnung zu der sichern fundamentalen Holtz-Verbindung, Nürnberg 1736, SUB, 2 Bibl. Uff 439. 

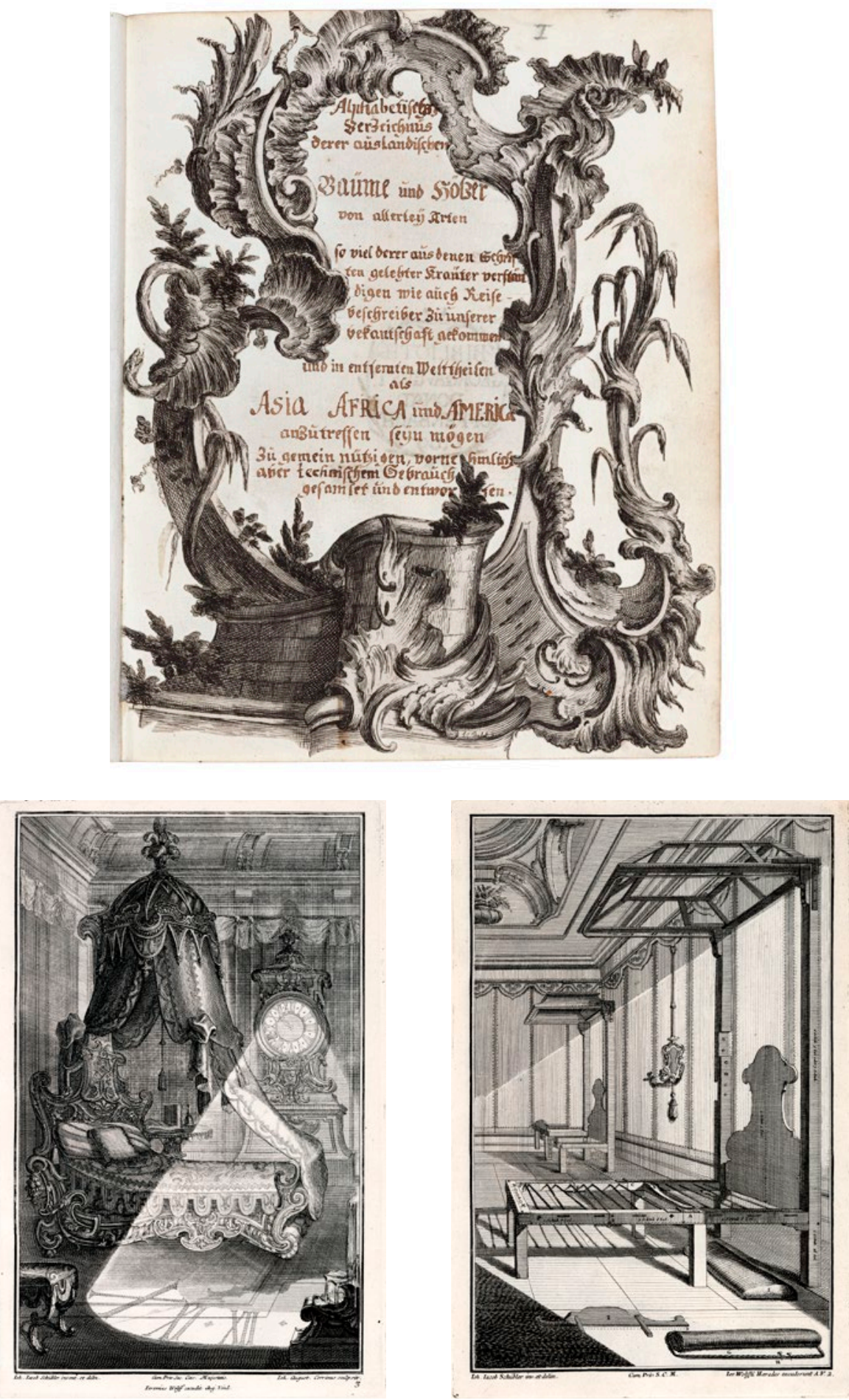


\section{Architekturtheorie}

Uffenbach äußerte sich gern über Architektur in seinen Reisetagebüchern: Kirchen, Schlösser, Rat- und Wohnhäuser, Plätze und Straßenzüge waren Gegenstand seiner Beschreibungen und Einschätzungen. Während Stadthäuser und Kirchen hinsichtlich ihres Alters und Baustils Einordnung finden, ist Uffenbach bei Schlössern und anderen Residenzbauten meist streng. Alter, Bauzustand, Konzeption, Anlage, Stil und die Frage der Angemessenheit für den jeweiligen Bauherren spielen für ihn eine große Rolle, so dass manches Schloss aufgrund seiner Anlage, Fassade oder Innenausstattung schlechte Beurteilung erfuhr.

Den notwendigen Kenntnisstand für derartig kennerschaftliche Einschätzungen hatte sich Uffenbach in seiner Bibliothek erarbeitet. Architekturtheoretische Handbücher, wie das besonders prominente Werk des Sebastiano Serlio (1475-um 1554), spätere Werke wie das von Vincenzo Scamozi (1548-1616) oder die Lehrbücher der Furttenbachs - Joseph d. Ä. (1591-1667) und Joseph d. J. (1632-1655) - fanden sich in seinem Besitz. Grundlagen wie die fünf Säulenordnungen, zugehörige Ornamentik und der Kanon prägender antiker und moderner Bauten, aber auch praktische Erwägungen der Konzeption, Grundrissgestaltung und Nutzung wurden darin behandelt. Überregionale Kenntnis etwa von Schlossbauten, wie Salzdahlum oder Versailles, erwarb Uffenbach durch Publikationen, die in der Frühen Neuzeit üblicherweise Neubauten in Verbindung von Text und Kupferstich vorstellten und damit den repräsentativen Anspruch solcher Bauten auch in die Ferne trugen.

Arwed Arnulf

Sebastiano Serlio, Tutte l'opere d'architettura, Venedig 1584, SUB, 4 Bibl. Uff 36. 


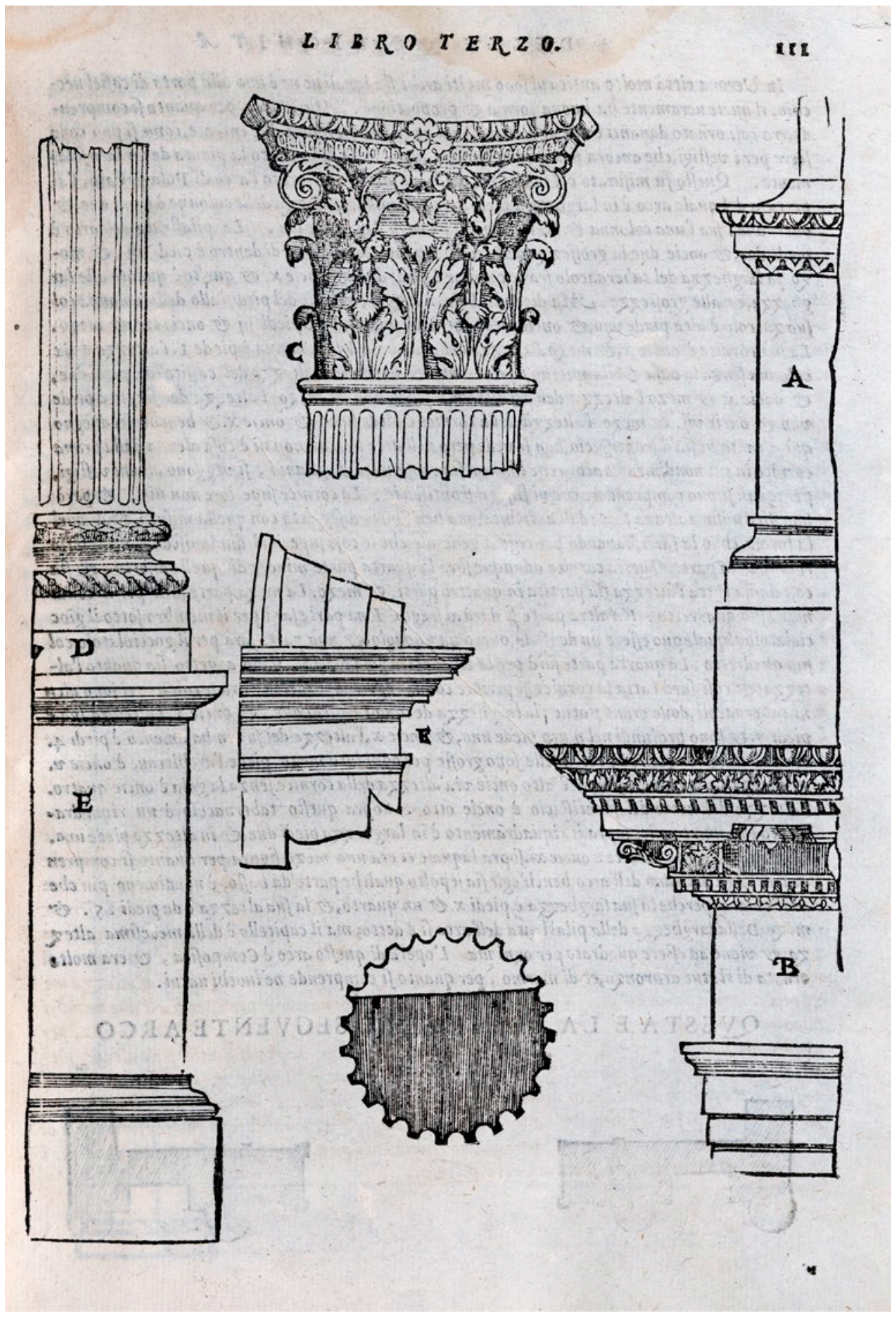




\section{Angewandte Mathematik}

Während seiner Studienzeit in Halle lernte Uffenbach Christian Wolff (1679-1754) kennen, Professor für Mathematik und Philosophie und Vorreiter jener neuen Weltsicht und Bildungsmode, für die sich bald der Begriff Aufklärung etablieren sollte. Wolff bemühte sich um eine Erklärung der Welt und menschlicher Tätigkeiten im Sinn eindeutiger mathematisch begründeter Analyse und Darstellung. Dies betraf Natur- und Ingenieurwissenschaftliches ebenso wie geisteswissenschaftliche Themen. Selbst sprachliche Aussagen und theologische Ausführungen sollten mit gleichsam mathematischer Klarheit und Eindeutigkeit formuliert werden. Neben dieser mathematisch-philosophischen Wirksamkeit übte Wolff auch als Theoretiker des Naturrechts großen Einfluss auf die Rechtswissenschaft aus. Obwohl wissenschaftlich international geschätzt, erzwangen die Hallenser Pietisten, radikalprotestantische und antiaufklärerische Eiferer, Wolffs Vertreibung aufgrund des Atheismusvorwurfs. Uffenbachs auffallend distanzierte Haltung zu Glauben und religiöser Praxis mag damit zusammenhängen. Vor allem aber folgte er der Idee einer mathematisch erklärbaren Welt.

In Uffenbachs Besitz befinden sich die Elementa matheseos universalis, Wolffs umfassendes, die wichtigsten Disziplinen und Künste mathematisch erläuterndes Lehrwerk, zuerst 1713 in Latein, später in deutscher Übersetzung erschienen. Wolffs Werk lieferte theoretische Grundlagen für Uffenbachs Interessen, die sich alle auch als angewandte Mathematik verstehen lassen. Dies betrifft Astronomie, Geographie und deren praktische Ableger wie Messkunst, mechanische Künste wie Architektur, Holz- und Metallverarbeitung, Wassertechnik und Wasserkunst bis hin zu Artillerie- und Befestigungswesen aber auch Musik, Feuerwerkerei oder Drucktechnik und Bildkünste.

Arwed Arnulf 


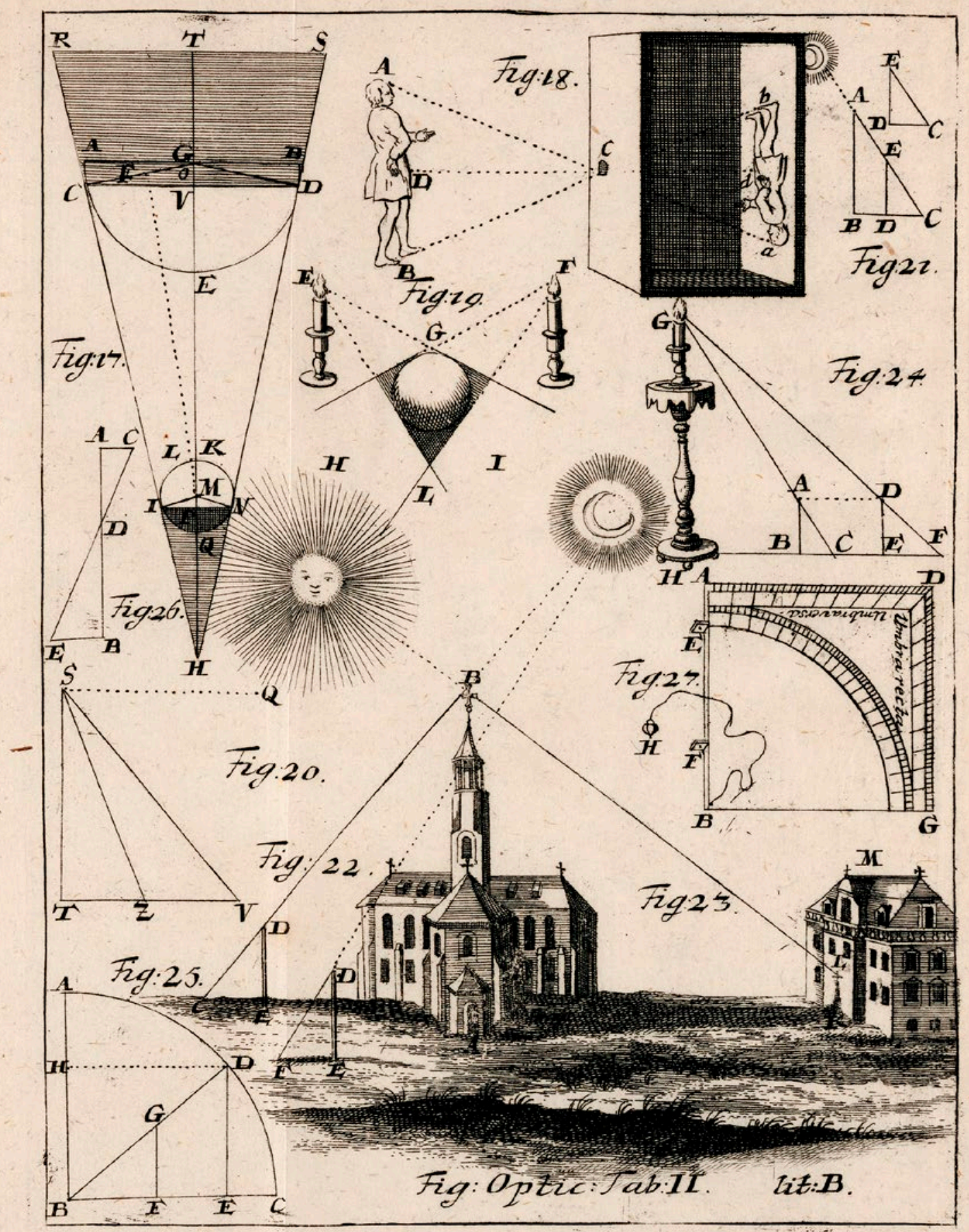




\section{Unterweisungen in Wissenschaften und Künsten}

Einige der ältesten und inhaltlich bereits antiquerten Druckwerke in der Sammlung Uffenbachs sind mehrere Traktate von Joseph Furttenbach (1591-1667) und seinem gleichnamigen Sohn (1632-1655). Der in Italien zum Kaufmann ausgebildete und später zum Bauherrn der Stadt Ulm ernannte Architekturtheoretiker Furttenbach d. Ä. behandelt in seinen ab 1627 erschienenen Schriften neben der Architektur von Privat-, Stadt- und Wohnhäusern auch den Schiffs-, Wehr- und Gartenbau. Er bezieht hierbei zusätzlich zu der formalen Gestaltung auch die Einrichtung und Funktion mit ein und beschränkt sich nicht nur auf Bauten mit repräsentativem Charakter.

Das gesamte Spektrum der mechanischen Künste wird in den Furttenbachschen Werken ausgebreitet: Mechanik, Navigation, Geographie, Perspektive, Astronomie, Geometrie, Planimetrie und Arithmetik, mit denen technische Anwendungen wie Feuerwerk, Grottenwerk, Büchsenmeisterei, Wasserleitung, Zivil-, Schiffs- und Militärarchitektur zu meistern waren. Gesamtkonzept und Texte stammten meist vom Vater, während viele der Stiche später vom Sohn angefertigt wurden. Furttenbach war kein Spezialist auf einem bestimmten Gebiet, sondern war in verschiedensten Gebieten ausgebildet, im Sprachgebrauch des 17. Jahrhunderts Polyhistor genannt, ein Gelehrter, der über das gesamte Wissenspektrum der Zeit publizierte, veröffentlichte Furttenbach d. J. mehrere eigene Traktate.

Da die Werke bereits lange vor den Schul- und Studienzeiten Uffenbachs veraltet waren, erbte er sie möglicherweise vom älteren Bruder Zacharias Conrad als Einführungsliteratur in die unterschiedlichen Wissensbereiche. Johann Friedrichs Interessengebiete deckten sich Zeit seines Lebens stark mit denen der Furttenbachs. Über dessen Werke hinaus bezeugen zahlreiche Drucke der Sammlung das starke Interesse Uffenbachs an dieser Art von Handbuch-Literatur, wie auch damals aktuelle Werke von dem Mathematiker, Architekten und Architekturtheoretiker Leonhard Christoph Sturm (1669-1719).

Lea Gröne / Arwed Arnulf

Joseph Furttenbach d. Ä., Architectura navalis, Ulm 1629, 2 Bibl. Uff 180, 1, Tafel 12. Joseph Furttenbach d. Ä., Mechanische ReißLaden, Augsburg 1644, 4 Bibl. Uff 268. 

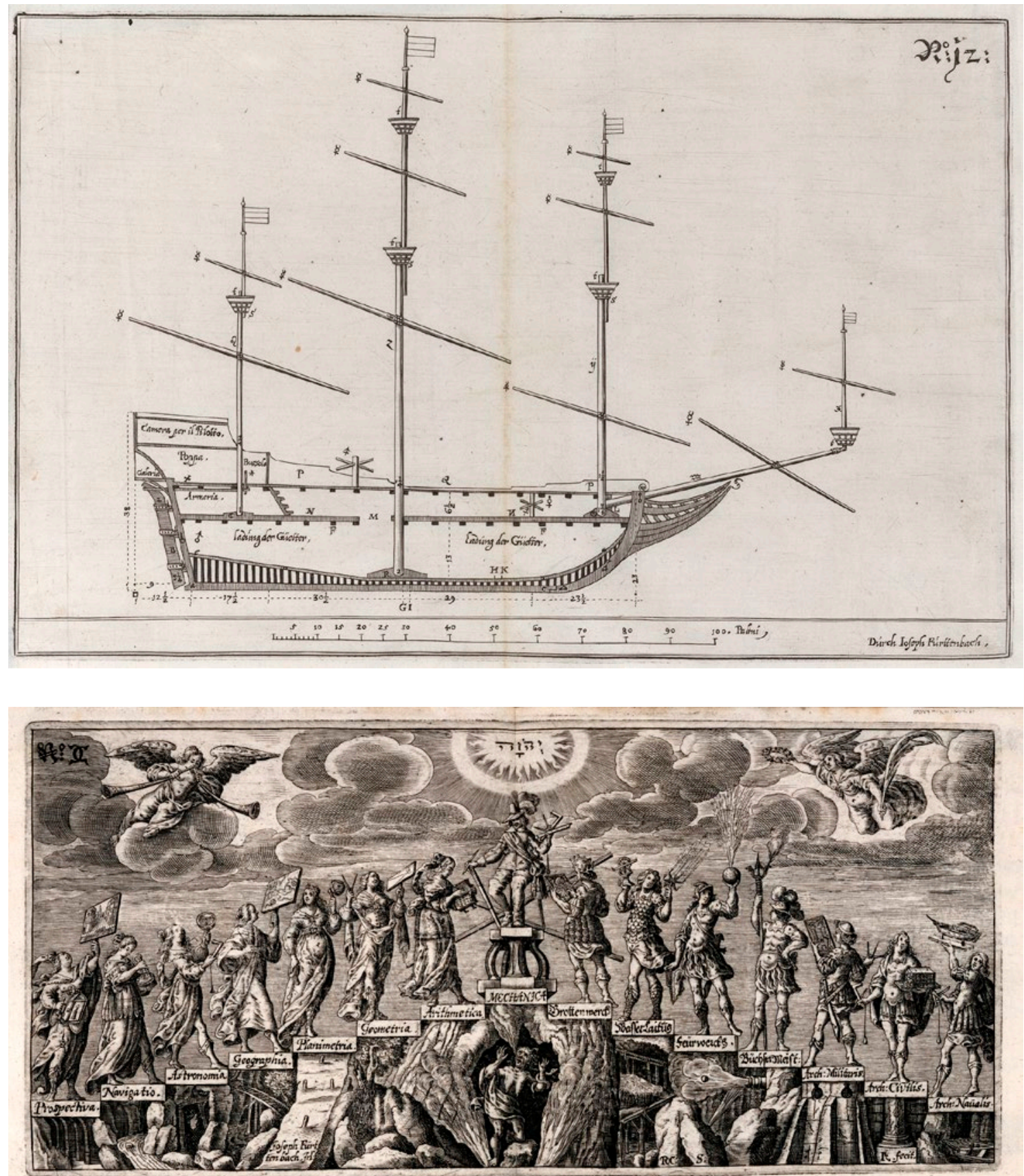


\section{Die Praxis des Exzerpierens}

„Excerpta sind denckwürdige Sachen oder Reden, welche in ein dazu verordnetes Buch eingetragen werden, damit wir sie von der Vergessenheit erretten, und bey vorfallender Gelegenheit zu unserm und anderer Vortheil, wieder hervor such und gebrauchen können" heißt es in J. F. Bertrams Discours Von der Klugheit zu Excerpiren von 1727.

Ein solches Exzerptbuch, das zum Sammeln und Kompilieren von Informationen zu bestimmten Themen dient, führte auch Uffenbach unter dem Titel Ausgezogene Schriftstellen aus Büchern so zur Erläuterung der Naturlebre, Mathematic und künstlichen Handarbeit etwas beytragen [Uff 9]. Es enthält mehr als 130 Abschriften und Zeitungsausschnitte von Artikeln, die er teils mit erklärenden Federzeichnungen versehen hat. Aus der Fülle von Berichten und Neuigkeiten in Publikationen wie den sogenannten Breslauischen Sammlungen - Sammlung Von Natur-und Medicin-Wie auch bierzu gebörigen Kunst- und Literatur-Gescbicbten -, eine der ältesten deutschsprachigen medizinischen Zeitschriften, schrieb Uffenbach stets die seinem Universalinteresse entsprechenden Artikel heraus. Zu den Themen gehörten neben den neuesten technischen Erfindungen auch Innovationen im Kunsthandwerk, Beschreibungen von Kuriositäten und exotischen Tierarten bis hin zu Anleitungen zur Ungezieferbeseitigung - ein buntes Konglomerat, das einen Einblick in Uffenbachs Wissbegier gewährt.

Einige der in seinem Exzerptbuch beschriebenen Objekte befanden sich in ähnlicher Form tatsächlich in seiner Instrumentensammlung, wie ein ledernes Schlauchboot oder eine auf dem Kasten einer Kutsche zu befestigende Camera Obscura, die auf einem darunter befindlichen Tisch im Innenraum für die Reisenden die umliegenden Gebäude projizieren konnte.

Nadja Kehe

Johann Friedrich von Uffenbach, Ausgezogene Schriftstellen aus Büchern, o. O. 1733-1767, SUB, 2 Cod. Ms. Uffenbach 9, p. 27, Zeichnung von Scblauchbooten und p. 164., Zeichnung einer Camera Obscura. 

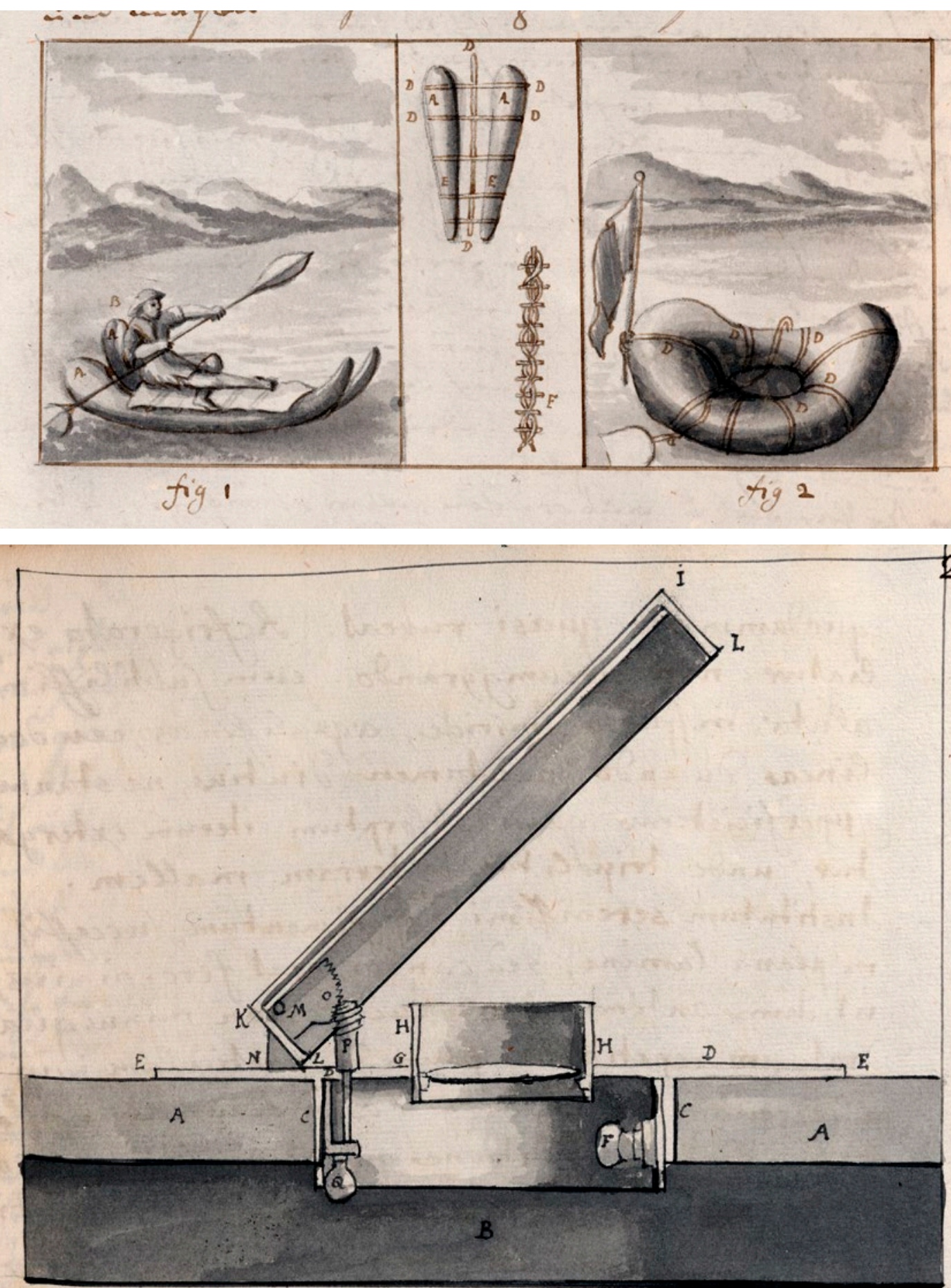

2: 


\section{Das Proportionalinstrument}

Das Manuskript Einleitung zu einer neuen Perspectiv [Uff 41] des deutschen Mathematikers Christian Ludwig Gersten (1707-1762) beschreibt eine neue Methode des perspektivischen Zeichnens unter Verwendung des sogenannten Proportional Instruments, auch bekannt als Reduktionsoder Proportionalzirkel. Beauftragt vom Landgrafen Ernst Ludwig von Hessen-Darmstadt (1667-1739) sollte Gersten eine neue und einfache Technik zur künstlerischen Anfertigung perspektivischer und proportionierter Zeichnungen entwickeln. In der hierzu ab 1735 erarbeiteten Handschrift wird schrittweise erläutert, wie ein Haus, ausgehend von Grund- und Aufriss, in Proportion und Perspektive zu setzen ist.

Das dabei verwandte Proportional Instrument war nicht nur für Künstler von praktischem Nutzen, sondern auch für Feldmesser, Seeleute, Artillerieoffiziere und Kriegsingenieure. Es war in vielzähligen Varianten bis ins 19. Jahrhundert hinein in Gebrauch. Als universelles Symbol der angewandten Mathematik und als Sammelobjekt hielt es auch Einzug in fürstliche Kunstkammern und in Instrumentensammlungen bürgerlicher Liebhaber wie Uffenbach, der selbst zahlreiche Zirkel, Winkelmessgeräte und Proportionalzirkel sowie Ellipsenzeichengeräte besaß.

Gerstens Manuskript blieb unveröffentlicht. Er trug das Werk wohl bei sich, als er im März 1762 nach Frankfurt am Main aufbrach, wo er Uffenbach begegnet und ihm bei dieser Gelegenheit das Manuskript ausgehändigt haben könnte. In dessen Sammlung befinden sich neben weiteren gedruckten Werken von Gersten auch zahlreiche Standardwerke der Perspektive, Optik und Mathematik anderer Autoren.

Jacqueline Gwiasdowski

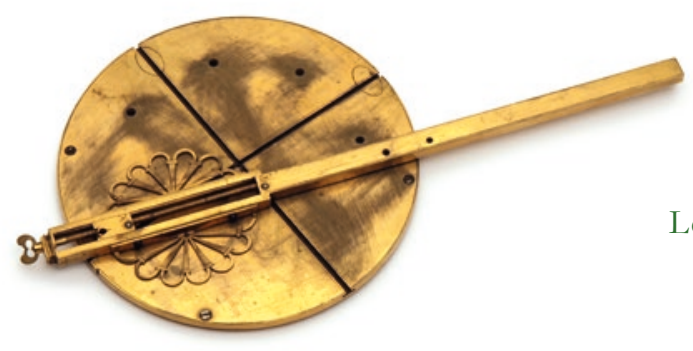

Ellipsenzeichengerät, 1. H. 18. Jh., Städt. Mus., Inv. Nr. 1909/68.

Christian Ludwig Gersten, Einleitung zи einer neuen Perspectiv, o. O. 1736-1746, SUB, 8 Ms. Cod. Uffenbach 41.

Levinus Hulsius: Tractat Der Mechanischen Instrumenten Levini Hulsii 3: Beschreibung und Unterricht deß Jobst Burgi Porportional-Circkels, 1607, Frankfurt a. M., 4 Bibl. Uff 192, 1 (3). 

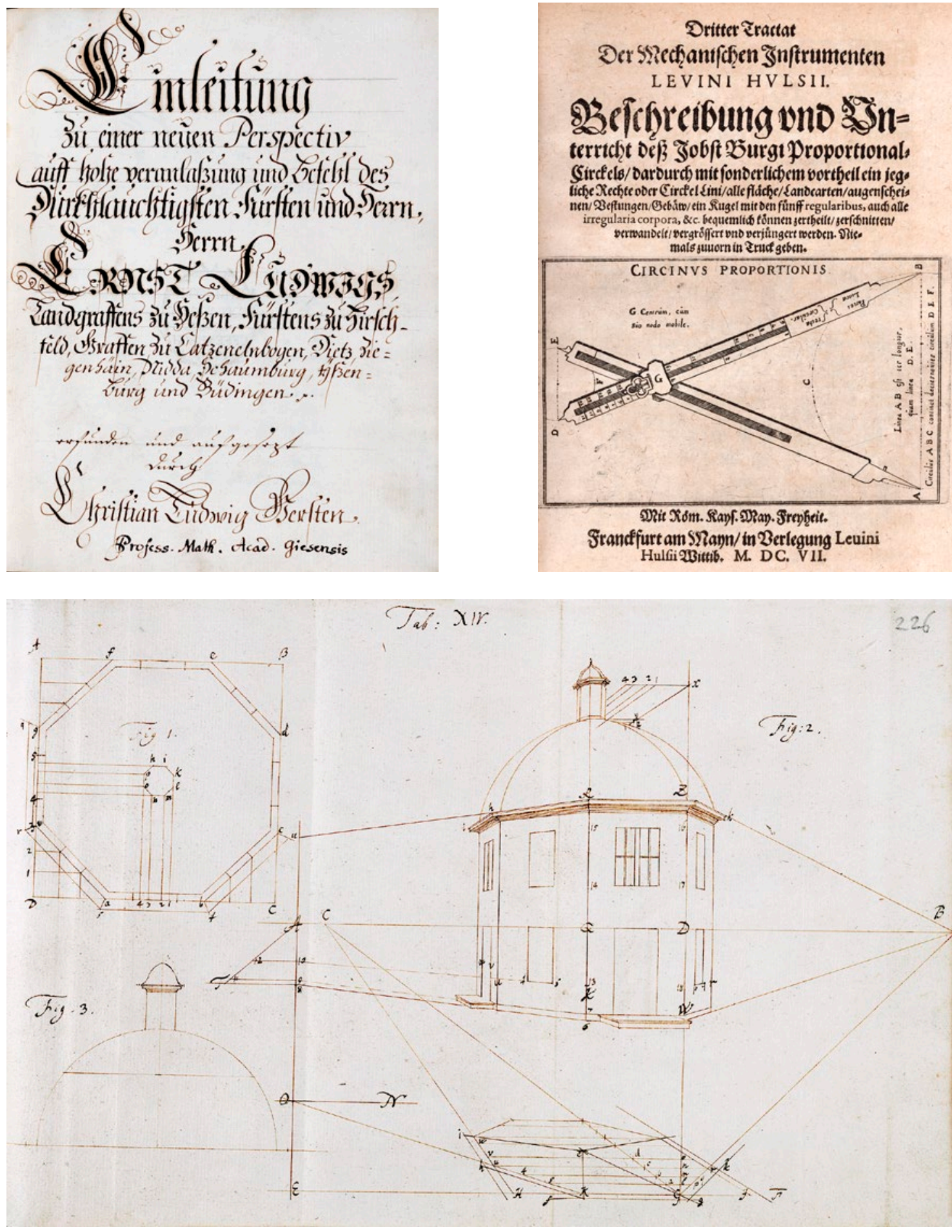


\section{Uffenbachs Sonnenuhren}

Die Vielfalt von Sonnenuhren, ihre Größe und Anwendungsbereiche, faszinierten den gebildeten Laien im 18. Jahrhundert. Besonders Instrumente, die das Große der Sternen- oder Planetenbewegung im Kleinen abzubilden oder sichtbarzumachen vermochten, wie Sonnenuhren, erregten stets großes Interesse.

Der technisch-naturwissenschaftlich orientierte Uffenbach teilte diese Begeisterung und besaß mehrere Universalsonnenuhren, die er zum Ablesen von Datum und Uhrzeit an verschiedenen Orten aufstellen konnte. Sonnenuhren waren selbst im ausgehenden 18. Jahrhundert ein aktuelles Thema: Johann Wilhelm David Korth (1783-1861) behandelt in einer der umfangreichsten Enzyklopädie von Johann Georg Krünitz (1728-1796) ausführlich die Thematik der Sonnenuhren.

Uffenbachs zeittypische Begeisterung belegen auch über 70 Schriften zur Theorie und Praxis der Sonnenuhr auf Deutsch, Italienisch, Französisch und Latein in seinem Besitz. Unter den Texten waren nicht nur Drucke, sondern auch handschriftliche Kopien von Sonnenuhrtraktaten, so wie die Beschreibung eines bölzernen universal Sonnenubren instruments [Uff 37], ein Werk Erich Philipp Ploennies' (1672-1751). Darin wird die Herstellung einer Sonnenuhr erläutert. Obwohl Uffenbach 1724 vom Autor die Genehmigung erhielt, die Beschreibung handschriftlich zu kopieren, findet sich unter den erhaltenen Objekten seiner Instrumentensammlung keine Sonnenuhr, die nach der Anleitung Ploennies' gebaut sein könnte. Einzig ein tragbarer Sonnenuhrring, der vom Amsterdamer Instrumentenbauer Dirk Metz (tätig 1730-1767) eigens für Uffenbach angefertigt wurde, befindet sich noch heute im Städtischen Museum Göttingen.

Annika Zinger

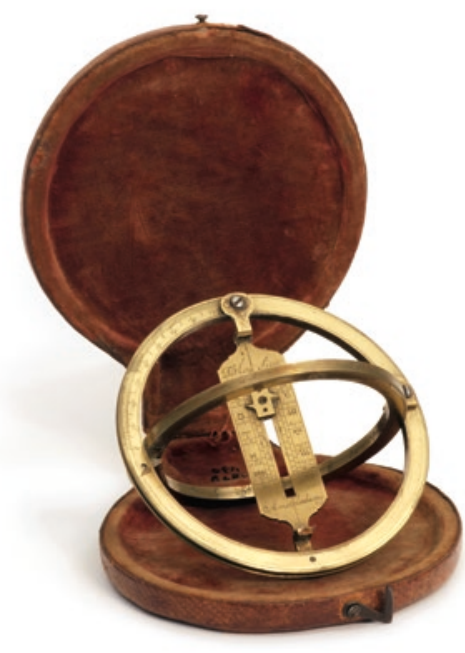

Dirk Metz, Ringsonnenubr mit Etui, 1. H. 18. Jh., Städt. Mus., Inv. Nr. 1898/430. Joseph Furttenbach d. J., Von Sonnenubren, Augsburg 1652, SUB, 4 Bibl. Uff 710. 


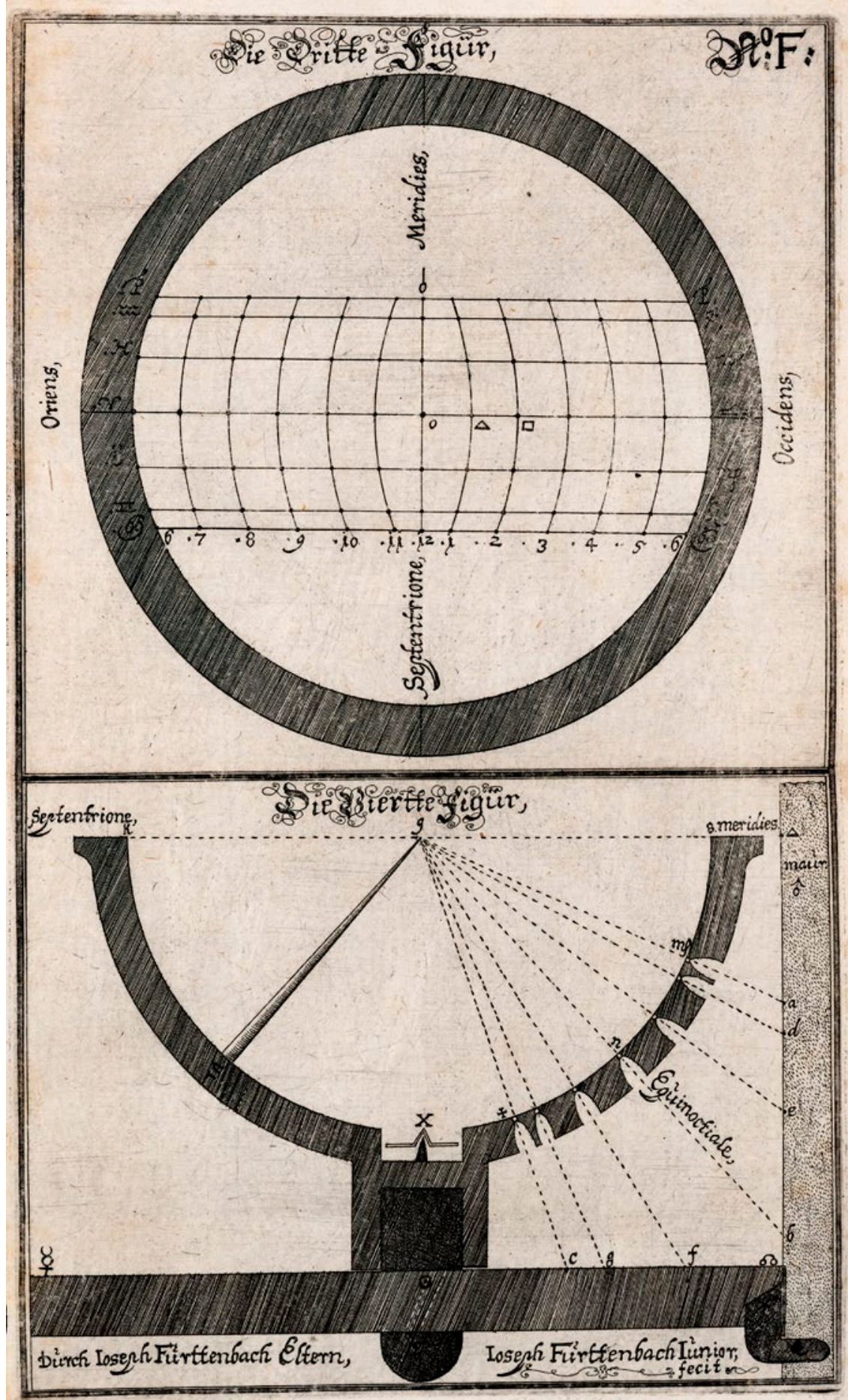




\section{Wasserspiele und ihre Maschinerien}

Brunnen, Grotten oder Wasserspeier faszinierten Betrachter des 18. Jahrhunderts, besonders aufgrund der stets unsichtbaren, doch noch rätselhaft erscheinenden Technik, die Wasser unter Druck zu setzen vermochte und in bis dahin ungekannte Höhen aufsteigen ließ. Auch Uffenbach begeisterte sich dafür und begutachtete auf seinen Reisen zahlreiche Wasserspiele sowie deren Maschinen und technische Konzepte, worüber er detailreich in seinen Tagebüchern berichtete. Zudem besaß er bedeutende und wichtige Werke über Wasserkunst und Hydraulik. Reich illustrierte Bücher, wie Georg Andreas Böcklers (um 1617-1687) Architectura Curiosa Nova (1670) oder Jacob Leupolds (1674-1727) Theatri Machinarum (1727) vermittelten Grundlagen und Technik der Wasserkunst.

Uffenbach besuchte 1709 die noch nicht fertiggestellten Wasserspiele in Kassel, die Giovanni Francesco Guerniero (um 1665-1745) ab 1701 anlegte, eine Anlage mit Kaskaden und mehreren Bassins, die später vom krönenden Herkules bis ins Tal hinab reichte. Beim Besuch der Herrenhäuser Wassermaschine 1728 erschloss sich Uffenbach auch im Gespräch mit dem Hofarchitekten Johann Christian Böhm (1678-1730) deren Funktionsweise nicht. Im Nachhinein ließ er sich sieben teils großformatige Zeichnungen von der Wassermaschine anfertigen, einer allein durch die Strömungskraft des Flusses Leine angetriebenen Anlage, die Wasser mittels Druckpumpen direkt zur großen Fontäne beförderte. Neben erläuternden Texten vervollständigten Klapptäfelchen die Zeichnungen, um einen Blick ins Innenleben der Maschine zu ermöglichen.

Mithilfe dieser Zeichnungen sowie anhand eines Modells stellte Uffenbach die Maschine am 15. September 1729 in seiner wissenschaftlichen Gesellschaft vor und verglich sie mit anderen europäischen Wassermaschinen. Auf seiner zweiten großen Reise durch Frankreich besuchte er im September 1715 im französischen Marly die Wassermaschine, die er bereits von Kupferstichen kannte.

Lara Siegers

Johann Christian Böhm, Profil von der Herrenbäuser Waßer Machine obne die aufgelegte Zeichnung der Pumpenanlage, SUB, Cod. Ms. philos. 26d. Nicolas de Fer, Les beautès de la France, Paris 1708, SUB, 2 Bibl. Uff 21, Wassermaschine von Marly. 

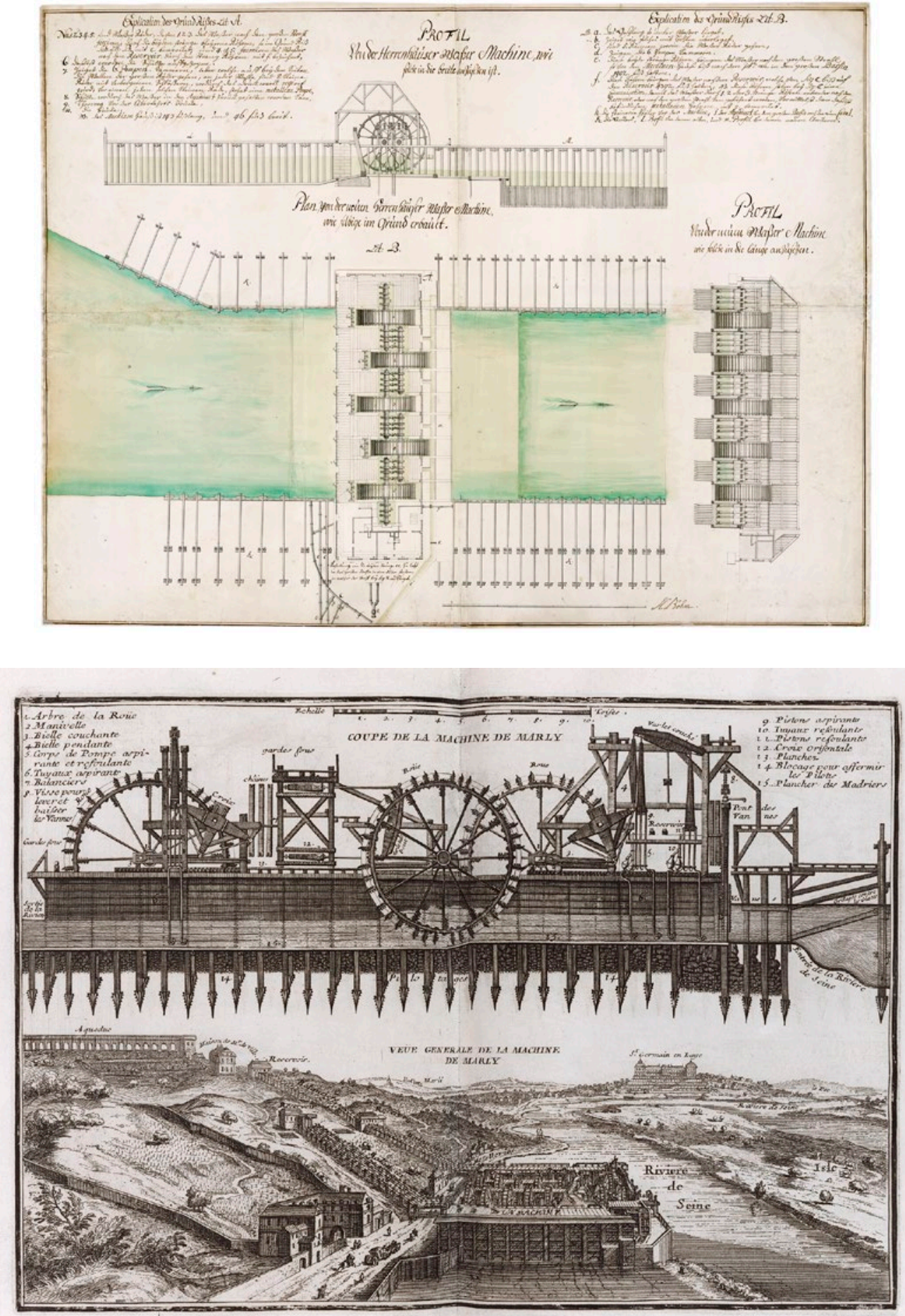


\section{Der Weg des Lichts}

Der Astronom Johann Beyer (1673-1751) richtete in den 1720er Jahren die erste Sternwarte Hamburgs in seinem eigenen Haus ein, wo er auch eigene Modelle, Maschinen und Instrumente präsentierte. Der Katalog seiner Erfindungen führt Objekte wie Camerae obscurae, Erd- und Himmelsgloben, Quadranten, Ringkugeln, Teleskope und ein Modell des kopernikanischen Systems auf. Uffenbach scheint mit Beyers Produktionen besonders vertraut gewesen zu sein, denn seine Bibliothek enthält neben dem Katalog selbst insgesamt sechs kurze Anleitungen zu Objekten, die der Hamburger Astronom hergestellt und verkauft hat.

In einer Sitzung der wissenschaftlichen Gesellschaft am 9. März 1736 stellte Uffenbach auch eine von Beyer entwickelte Universalsonnenuhr vor. Das von Beyer 1724 geschaffene Modell des menschlichen Auges hat die Besonderheit, die Eigenschaften und Bewegungen des Organs zu imitieren. Anstelle der Netzhaut hat sie eine Mattscheibe und kann auch als Camera obscura verwendet werden, wenn der Beobachter einen kleinen Spiegel dahinter platziert. Beyer wurde hier wahrscheinlich vom zweiten Band der Elementa Matheseos Universae (1715) des Gelehrten Christian Wolff (1679-1754) inspiriert, der darin eine ähnliche Konstruktion vorschlägt. Diese „Kunstaugen“ gab es in Europa ab der zweiten Hälfte des 17. Jahrhunderts vermehrt. Sie wurden vor allem in London, Paris und Nürnberg hergestellt und gehandelt sowie europaweit zur wissenschaftlichen Demonstration und Lehre eingesetzt. Daneben enthält Uffenbachs Bibliothek wichtige Abhandlungen zu diesem Gebiet, beispielsweise Oculus (1619) und Rosa Ursina (1629) des deutschen Jesuiten Christoph Scheiner (1573-1650).

Valérie Kobi

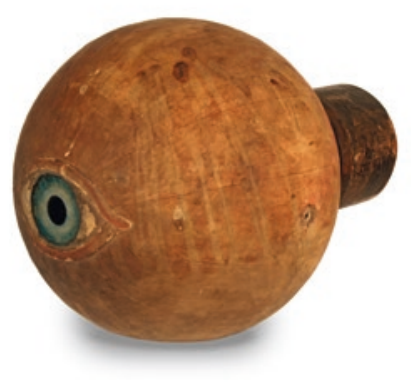

Johann Beyer, Modell eines menschlichen Auges, Städt. Mus., Inv. Nr. 2014/71.

Christian Wolff, Elementa Matheseos Universae, Magdeburg 1715, SUB, 4 Bibl. Uff 303. 


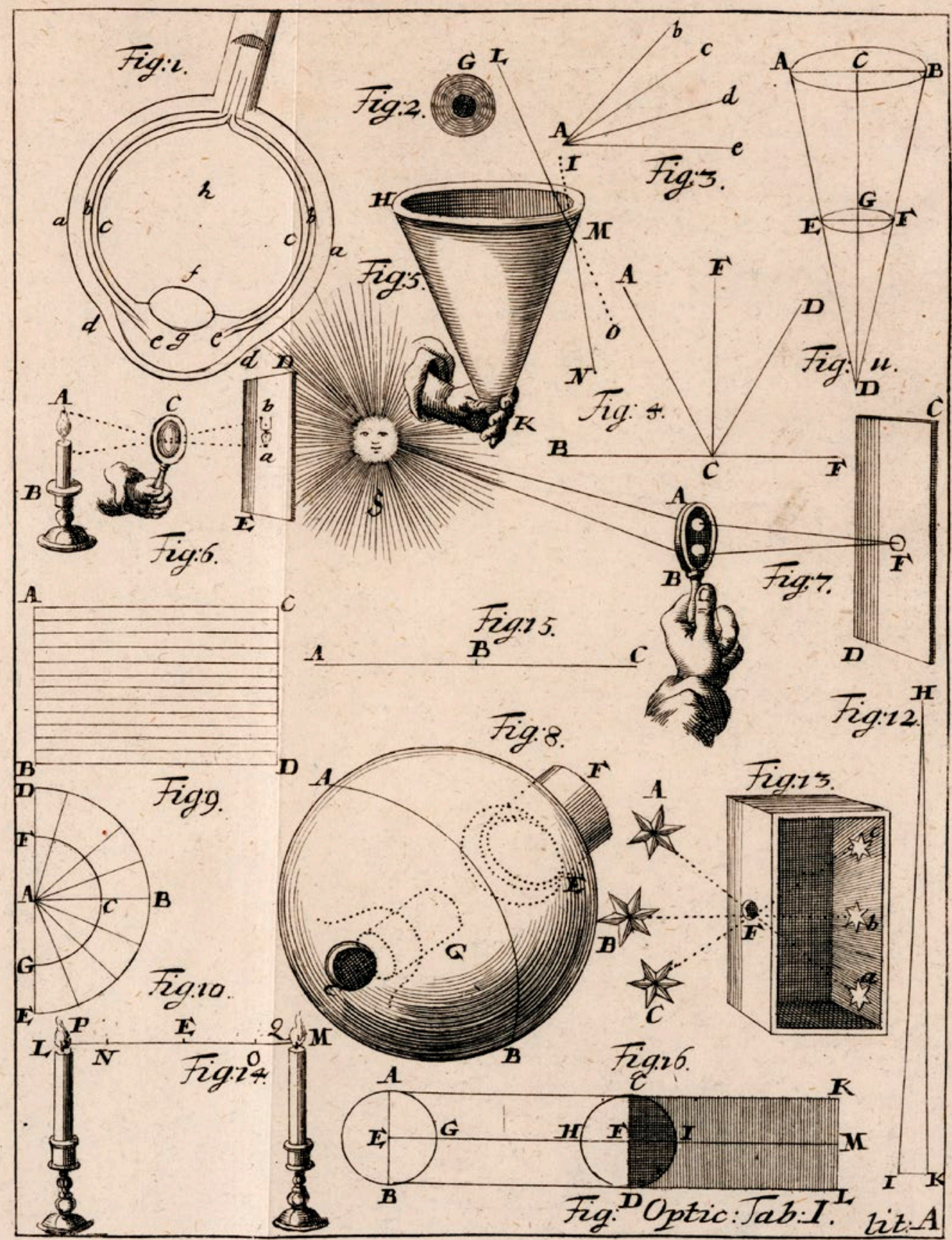




\section{Verzerrte Bilder}

Anamorphosen sind Zerrbilder, die aus dem richtigen Blickwinkel oder mithilfe eines Spiegels entzerrt und dadurch erkennbar werden. Uffenbach besaß diverse Anamorphosen in seiner Sammlung optischer Instrumente, darüber hinaus eine Reihe von zugehörigen Spiegeln. Ebenfalls in seinem Inventar aufgeführt sind zwei Maschina anamorphotica des deutschen Ingenieurs Jacob Leupold (1674-1727), welche für zylindrische und konische Figuren bestimmt sind. Auch wenn Leupolds Text zur Erläuterung dieser Maschinen mit dem Titel Anamorphosis mechanica nova (1713) in Uffenbachs Bibliothek nicht vorhanden zu sein scheint, konnte sich der Gelehrte auf Joachim Ernst Schefflers (gest. 1751) Theatri Machinarium Supplementum (1739) beziehen, welches nahezu identisch die von Leupold 1713 zur Verfügung gestellten Tafeln wiedergibt. Uffenbachs großes Interesse an der empirischen Herangehensweise lässt vermuten, dass er diese Instrumente tatsächlich selbst zur Fertigung von Anamorphosen verwendet hat.

Unter den Anamorphosen in Uffenbachs Sammlung befindet sich eine verzerrte Abbildung seines Familienwappens, was auf eine persönliche Ausarbeitung hinweisen könnte. Die in der Renaissance erfundenen Anamorphosen gehörten im 17. Jahrhundert zu den Kuriositäten, die in den Wunderkammern gesammelt wurden, während sie sich im 18. Jahrhundert zu regelrechten Anschauungsobjekten entwickelten, die unter anderem für den Unterricht in Geometrie zur Demonstration des Reflexionsgesetzes nützlich wurden.

Uffenbachs Bibliothek beweist die Bedeutsamkeit, die er diesem Themenbereich beigemessen hat, da sie die einflussreichsten Abhandlungen zu diesem Wissensgebiet besitzt, wie Giacomo Barozzi da Vignolas (1507-1573) Le due regole della prospetiva pratica (1583), Salomon de Caus' (1576-1626) La perspective, avec la raison des ombres et miroirs (1612), Jean-Louis Vaulezards (tätig 1630-1644) Perspective cilindrique et conique (1630), Athanasius Kirchers (1602-1680) Ars Magna Lucis et Umbrae (1646), Jean-François Nicérons (1613-1646) La perspective curieuse (1663) oder Jean Du Breuils (1602-1670) zweite Ausgabe von La perspective pratique (1679). In einigen dieser Schriften wird sehr genau beschrieben, wie anamorphotische Bilder zu zeichnen sind.

Valérie Kobi

Johann Friedrich von Uffenbach, Anamorphosen, 18. Jh., Städt. Mus.

Ein die Pauke schlagendes Kind, Inv. Nr. 2011/137.3.

Globus, Inv. Nr. 2011/137.5.

Vogel im Käfig, Inv. Nr. 2011/137.10.

Sitzender Hund, einen Teller präsentierend, Inv. Nr. 2011.137.15. 

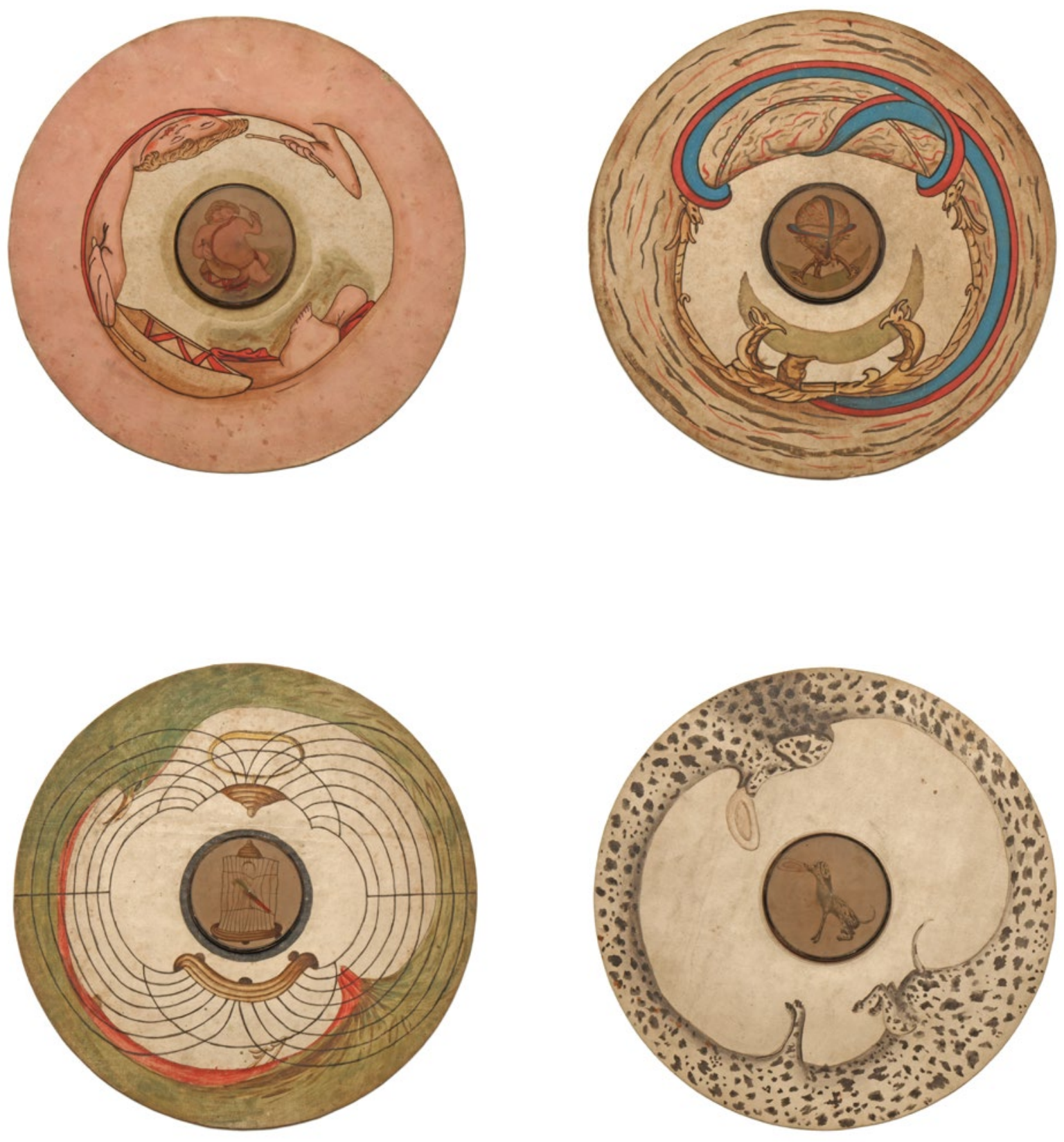


\section{Schriften und Instrumente zum Feldmessen}

Die Kunst des Feldmessens findet heute wie schon seit der Antike und auch im 18. Jahrhundert Anwendung. Gegenwärtig meist mit Lasertechnik durchgeführt, nutzte man zur Zeit Uffenbachs Instrumente wie Messstäbe, Messketten, Sextanten und Quadranten, also Winkelmesser mit Peilvorrichtung, um Wiesen, Äcker, Berge und Gewässer zu vermessen. Angewandt wurden Feldmessverfahren für die Bestimmung von Flächen und deren Grenzen im Kleinen wie im Großen, zur Sicherung von Rechtsansprüchen, bei kartographischen Unternehmen, aber auch für zeichnerische Aufnahmen von Gebäuden. Grundlegende Technik war die Triangulation, also die Bestimmung von Längen durch Winkelpeilung von zwei Messpunkten auf einer Basislänge. Die durch dieses Verfahren erzielten Maße lieferten Entfernungen, Höhen, räumliche Positionierungen und Flächenmaße.

Als stabile Unterlage, auf der Zeichenplatte und Winkelmessgerät montiert wurden, verwendete der Landvermesser einen Messtisch. Die Basis dafür bildet ein Dreibeinstativ, das Uffenbach im eigenhändig kopierten Manuskript Kurtzer Unterricht von dem Feltmessen [Uff 24] von 1724 detailliert zeichnete. Die gesamte 82-seitige Anweisung mit beigefügtem Brief gibt Anweisungen des Stückhauptmanns und Baumeisters Helferich Müller (1686-1759) wieder. Darin erwähnt er ein Messgerät mit Kompass. Zwei Geräte dieses Typs haben sich in Göttingen erhalten.

Jennifer Furchheim / Arwed Arnulf

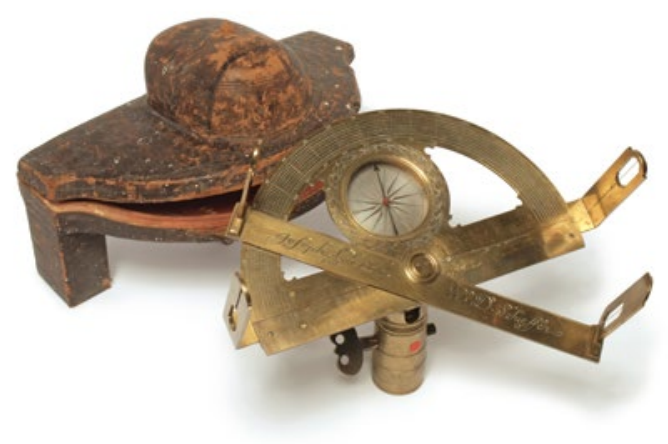

Joseph Czech, Astrolabium/Halbkreisgerät mit Etui, 1. H. 18. Jh., I. Phys. Inst., Inv. Nr. H742.

Benjamin Bramer, Kurtzer Bericht zu seinem Semicirculo, Ulm, Augsburg 1651, SUB, 4 Bibl. Uff 279:1 


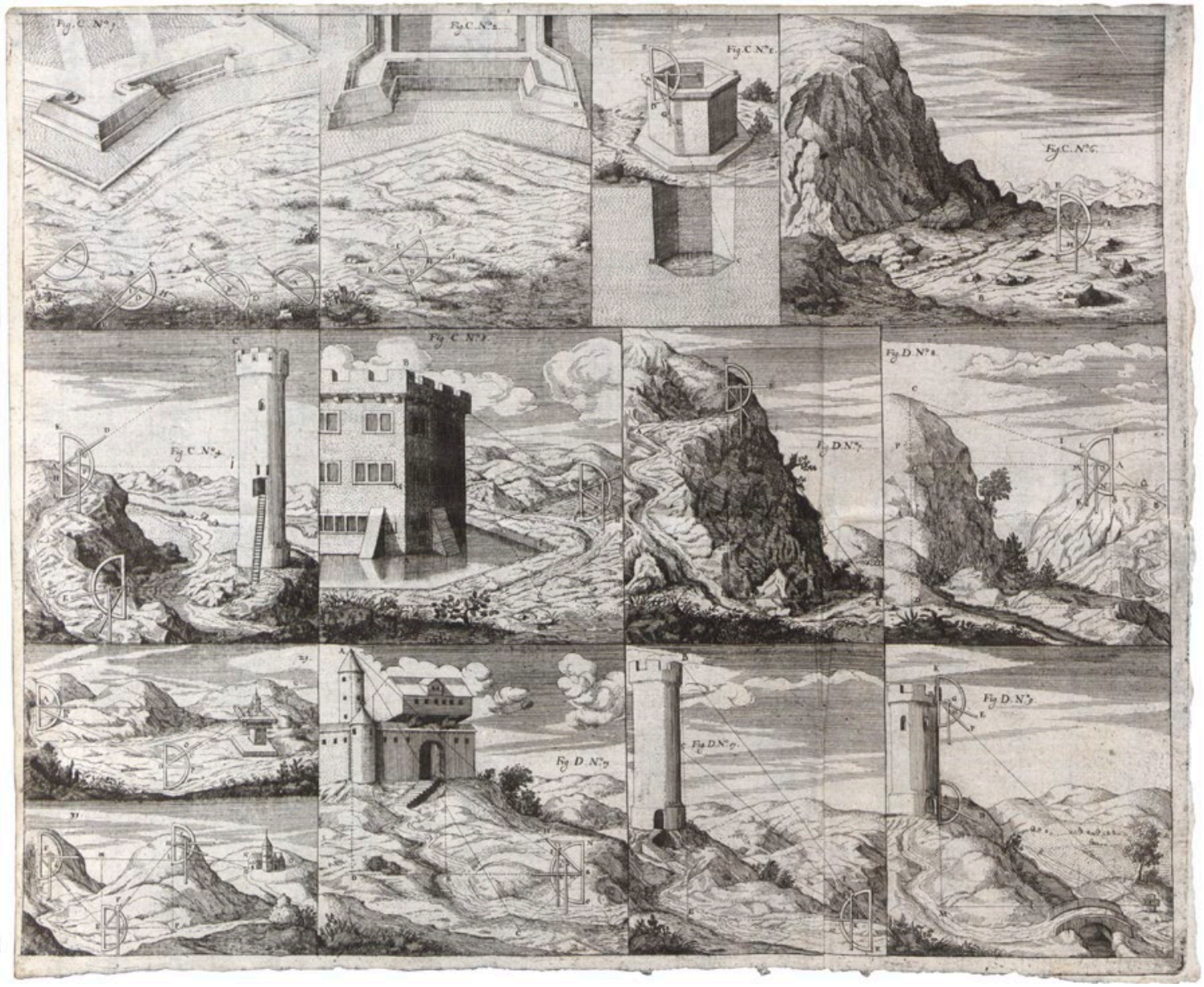




\section{Ingenieurwissenschaften: Artillerie und Festungsbau}

Das Aufkommen von Pulvergeschützen und Feuerwaffen in der Kriegsführung des 15. Jahrhunderts führte zu einer radikalen Veränderung im europäischen Festungsbau: Der bislang zumeist rechteckige Grundriss wurde zu einem Polygon ausgebaut, Bastionen und Rondelle ersetzten die mittelalterlichen Türme, die Burg- und Stadtmauern wurden niedriger und durch breite Wälle und Wassergräben verstärkt. Eine gesonderte Ausbildung zum Festungsbaumeister - seit dem 18. Jahrhundert in sogenannten Ingenieurschulen - ermöglichte das Erlernen der hierzu benötigten Mathematik- und Architekturkenntnisse. Ab dem 16. Jahrhundert erschien eine Vielzahl von Traktaten, die sich mit der Kunst des Fortifizierens beschäftigten und die bereits vorhandenen Theorien vertieften, erweiterten oder modifizierten.

Auch Uffenbach betätigte sich als Architekt und Ingenieur, beispielsweise beim Neubau der Alten Brücke in seiner Heimatstadt Frankfurt am Main. In seiner Sammlung besaß er neben Artillerielehrbüchern über 100 solcher fortifikatorischen und bautechnischen Werke - darunter die Schriften bekannter Festungsbaumeister wie Sébastien Le Prestre de Vauban (1633-1707), oberster Festungsbaumeister unter Ludwig XIV., und Menno van Coehoorn (1641-1704). Zu den interessantesten deutschsprachigen Büchern der Sammlung gehören das Kriegsbuch von Leonhardt Fronsperger (1520-1575), das Befestigungswerk von Albrecht Dürer (1471-1528), die Architectura Militaris von Adam Freitag (1608-1650) sowie die Ingenieursschul von Johannes Faulhaber (1580-1635).

Diesen Interessen entsprechend erhielt Uffenbach in Anbetracht seiner Schenkung nach Göttingen 1737 vom englischen König und Braunschweig-Lüneburgischen Kurfürsten Georg II. den Ehrentitel eines „Königlich Großbrittanisch Churfürstlich Braunschweigisch Lüneburgischen Artillerieobristenlieutenants“.

Weronika Herrenkind

Johannes Faulhaber, Tabula Fortificatoria, Ulm, SUB, 2 Bibl. Uff 518. Abraham Doprun (?), Modell einer Kanone, 1663, Städt. Mus., Inv. Nr. 1890/12. 

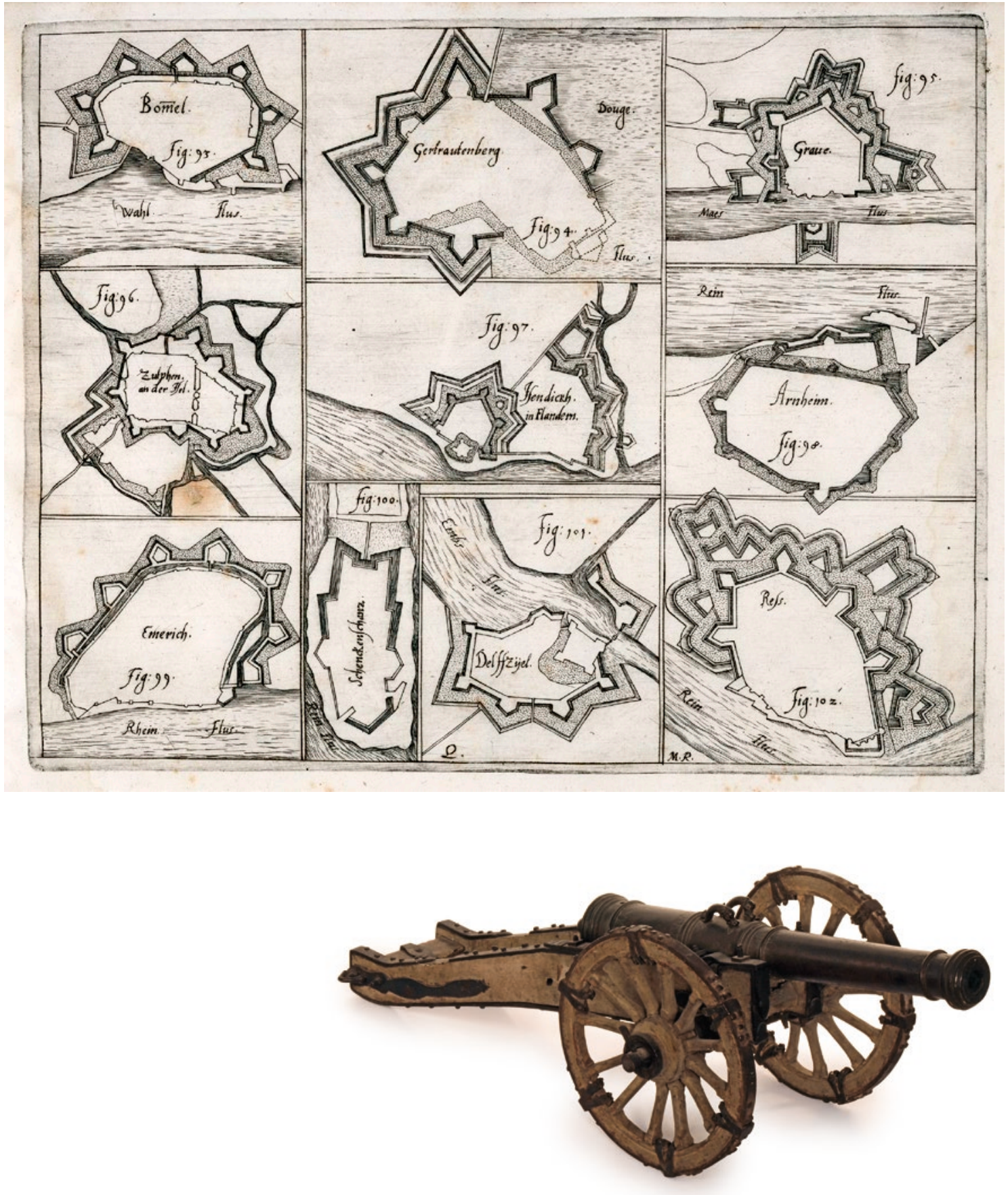


\section{Uffenbach als Feuerwerker}

Im 18. Jahrhundert unterschied man zwischen „Ernst- und Lustfeuerwerk“': Ersteres bezeichnet den Einsatz von Schwarzpulver zu militärischen Zwecken, letzteres steht für imposante Schaufeuerwerke im Rahmen von höfischen Festen. Für die Fabrikation der Feuerwerke stellte man aus Salpeter, Schwefel und Holzkohle das leicht entzündliche und hochexplosive Schießpulver her. Zunächst musste das Pulvergemisch 20 bis 24 Stunden gestampft, anschlieBend in Stücke gebrochen, gekörnt und gerundet werden. Anstelle von Schießpulver konnte auch das sogenannte Schmelzzeug zur Herstellung von Raketen und Knallkörpern genutzt werden. Diese ebenfalls explosive Mischung bestand aus drei Teilen Schwefel, zwei Teilen Salpeter und einem Teil Mehlpulver, die in einer Pfanne über einem Ofen miteinander verschmolzen wurden.

Feuerwerk und Artillerie betreffende Texte lieferten entsprechende Rezepte, erklärten Theorie und Praxis. Zahlreiche davon befanden sich in Uffenbachs Bibliothek, so Heinrich Vogels (1671-1753) Kurzer Unterricht in der Artillerie-Wissenschaft, Zu Ernst- und Lust-Feuer-Werkeen, Joseph Furttenbachs d. Ä. (1591-1667) Halinitro-Pyrobolia und Georg Andreas Boecklers (1617-1687) Architecturae Militaris.

In einem großformatigen Graphikband sammelte Uffenbach Darstellungen der von ihm selbst durchgeführten Lustfeuerwerke. Das erste nachweisbare Spektakel veranstaltete er anlässlich des Namenstages der spanischen Königin Elisabeth (1692-1766), sein berühmtestes fand am 12. Februar 1742 zur Feier der Kaiserkrönung Karls VII. (1697-1745) in Frankfurt statt. Dem Anlass entsprechend sollte es von angemessener Größe sein, daher wurde es an diversen Standorten und an mehreren aufeinanderfolgenden Tagen abgebrannt. Als Schauplätze wurden die Wohnsitze der Botschafter, die Fürstenhöfe aber auch das Haus von Uffenbach selbst genutzt.

Pia Denkmann

O. A., Abbildungen derer Feuerwercke und Illuminationen, so 1741 und 1742 zu Franckfurt angestellt worden durch J. F. v. U., Augsburg, SUB, GR 2 Bibl. Uff 462. 

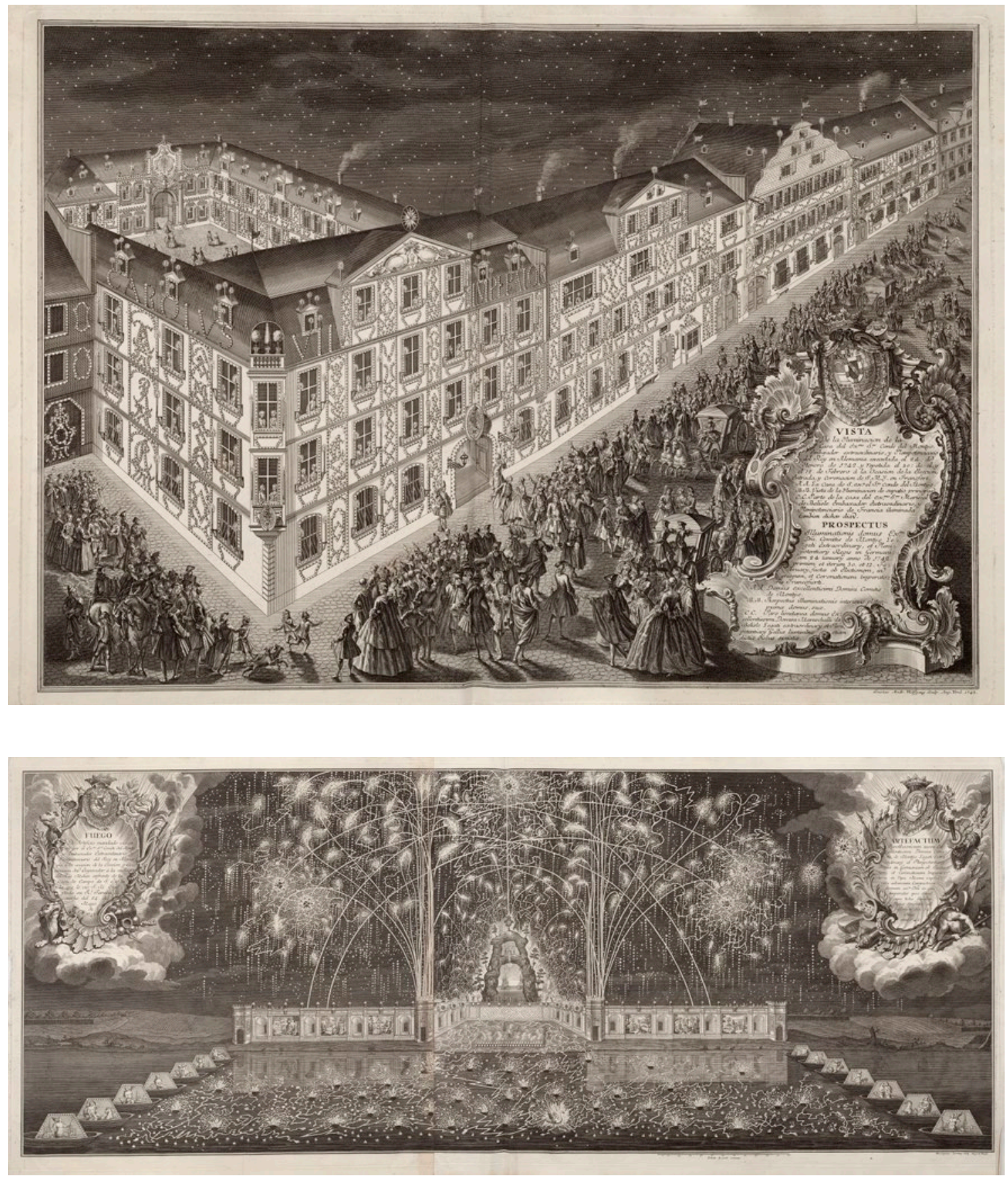


\section{Biografie}

1687 Geboren am 6. Mai in Frankfurt am Main

1704 Studium der Jurisprudenz in Gießen

$1706 \quad$ Wechsel an die Universität Halle

1709-1711 Reise mit seinem älteren Bruder Zacharias Conrad durch Niederdeutschland, die Niederlande und England (Tagebücher)

1712-1714 Studium in Straßburg, Abschluss

1714-1716 Gelehrtenreise durch die Schweiz, Italien, Frankreich und die Niederlande (Tagebücher)

1716 Rückkehr Frankfurt am Main, Am Großen Kornmarkt 13

$1717 \quad$ Heirat mit Anna Elisabeth Lindheimer

1718 Reise durch die Niederlande (Tagebuch)

1725 Gründung der Frankfurter Gesellschaft

1728 Reise ins Braunschweig-Lüneburgische (Tagebuch)

1731 Reise durch die Pfalz (Tagebuch)

1736 Stiftung seiner Sammlung an die Universität

Göttingen

1740 Umzug ins Palais Auf der Zeil, Frankfurt am Main

1744 Wahl zum Ratsmitglied der Freien Reichsstadt Frankfurt am Main

$1751 \quad$ Wahl ins Schöffenamt

$1755 \quad$ Heirat mit Maria Magdalena von Bertram

1769 Gestorben am 10. April in Frankfurt am Main

$1770 \quad$ Stiftung kommt nach Göttingen 


\section{Literaturverzeichnis}

\section{Manuskripte aus Uffenbachs Sammlung}

Uff 4, I-IV

2 Cod. Ms. Uffenbach 4

Johann Friedrich Armand von Uffenbach/Zacharias Konrad von Uffenbach: Fratris germani J. F. ab Uffenbach diarii itinerarii tom. I(-IV). [Ausführliches Tagebuch über die Reisen im Elsass, in der Schweiz, in Italien, Frankreich und den Niederlanden], o. O. [Frankfurt a. M.] 1716-1734.

Uff 8

2 Cod. Ms. Uffenbach 8

J. F. A. v. Uffenbach: Kupfer Vol. zu allen Theilen der Reisz Diariorum, o. O. 1680-1720.

Uff 9

2 Cod. Ms. Uffenbach 9

J. F. A. v. Uffenbach: Ausgezogene Schriftstellen aus Büchern, so zur Erläuterung der Naturlehre, Mathematic und künstlichen Handarbeit etwas beytragen, angefangen 1733, о. O. [Frankfurt a. M.] 1733-1767.

Uff 13 , I-IV

2 Cod. Ms. Uffenbach 13

J. F. A. v. Uffenbach: Wochentliche Sammlung der in Nützlichen NebenStunden angestelten Untersuchungen der Natur und Kunst, welche zu einer vernünftigen Gemüths-Ergötzung diejenige Gesellschaft veranlasset, deren Denckspruch ist: Quo simplicius eo perfectius, 5 Bde., Frankfurt a. M. 1726-1727.

Uff 18

2 Cod. Ms. Uffenbach 18

J. F. A. v. Uffenbach: Der von Londinen zugleich geliebte und ungeliebte Pharasmanes König von Iberien in einem Sing-Spiel (in 3 Handlungen), o. O. 1720.

Uff 20 I und II

2 Cod. Ms. Uffenbach 20

J. F, A. v. Uffenbach: Commercium epistolicum J. Fr. Armandi ab Uffenbach I.II, 2 Bde., o. O. [Frankfurt a. M.] o. J. [ca. 1768].

Uff 24

8 Cod. Ms. Uffenbach 24

J. F. A. v. Uffenbach: Kurtzer Unterricht von dem Feltmessen aufgesetzt von [Helfrich] Müller, Hessen-Darmbstättischen Stückhauptmann und Baumeister, so er mir 1724 Juny zur Abschrifft communicirt, J.F. v. Uffenbach, o. O. 1724.

Uff 25 , I-IV

8 Cod. Ms. Uffenbach 25

J. F. A. v. Uffenbach/Z. K. v. Uffenbach: Gemeinschaftlich geführtes Tagebuch über die Reisen durch Niederdeutschland und England, 4 Bde., o. O. o. J.
Uff 29, I-IV

8 Cod. Ms. Uffenbach 29

J. F. A. v. Uffenbach: Elsaßer und Schweitzer

Reis-Diarium von Franckfurt biß Turin exclusive.

Ausführliches Tagebuch über die Reisen im Elsass, in der Schweiz, in Italien, Frankreich und den Niederlanden, 4 Bde., o. O. o. J.

Uff 33

8 Cod Ms. Uffenbach 33

J. F. A. v. Uffenbach: Kurtze Reise Beschreibung oder Tagbuch einer Spazierfarth durch die Hessische in die Braunschweig Lüneburgische Lande, welche anno 1728 im August obhabender Geschäfften wegen gethan, o. O. nach 1728 bzw. 1731.

Uff $36 \mathrm{a}$

2 Cod. Ms. Uffenbach 36 a

J. F. A. v. Uffenbach: [Alphabetisches Verzeichnis aller Mahler, Bildhauer und Kupferstecher]. Beilagen, Frankfurt a. M. u. a., um 1736.

Uff 37

8 Cod. Ms. Uffenbach 37

J. F. A. v. Uffenbach: Beschreibung eines hölzernen universal Sonnenuhren Instruments, welches ein jeder entweder selbst machen oder doch [...] sich leicht angeschaffen kann [...], o. O. 1724.

Uff 39

8 Cod. Ms. Uffenbach 39

J. F. A. v. Uffenbach: Encaustische Mahlerey [...] von J[ohann] H[einrich] Müntz, 1760 London, aus dem Engeländischen übersetzet, o. O. um 1764.

Uff 40

8 Cod. Ms. Uffenbach 40

J. F. A. v. Uffenbach: Alphabetisches Verzeichnüs derer auslandischer Bäume und Hölzer [...], o. O. 1729-1736.

Uff 41

8 Cod. Ms. Uffenbach 41

Christian Ludwig Gersten: Einleitung zu einer neuen Perspectiv [...] erfunden und aufgesetzt durch Christian Ludwig Gersten Profess. math. akad. Giesensis, o. O. nach 1735 .

Uff 46

8 Cod. Ms. Uffenbach 46

J. F. A. v. Uffenbach: Tagebuch einer Vergnügungsreise durch die Niederlande (Juli und August 1718), Düsseldorf/Utrecht u. a., o. O. nach 1728.

Uff 47

8 Cod. Ms. Uffenbach 47

J. F. A. v. Uffenbach: Kurtzes Verzeichnüs derer Mathematischer Physicalischer und Kupffer Bücher wie auch des Vorraths einiger hiezu gehöriger Instrumenten mein, o. O. o. J.

Uff 49

8 Cod. Ms. Uffenbach 49

Friedrich Brentel: Mahlen und Illuminir Büchlein von Fridrich Brentel († 1651) dem Ältern, auff 
instendiges Begehren seinem guten Freund zusamen geschriben a. 1642, o. O. 1642.

Uff 50

8 Cod. Ms. Uffenbach 50

J. F. A. v. Uffenbach: Monogrammata [...] derer Mahler und Kupferstecher, so noch ungedeutet oder unbekannt sind, o. O. vor 1736.

\section{Drucke aus Uffenbachs Bibliothek}

2 Bibl. Uff. 3

Salomon Kleiner: Wahrhafte Vorstellung beyder Hoch$=$ Gräfl. Schlösser Weissenstein ob Pommersfeld und Geibach [...], Augsburg 1728.

2 Bibl. Uff. 21

Nicolas de Fer: Les beautès de la France, Paris 1708.

4 Bibl. Uff. 28

Jean Du Breuil: La perspective pratique, Paris 1679.

4 Bibl. Uff. 36

Sebastiano Serlio: Tutte l'opere d'architettura, Venedig 1584.

8 Bibl. Uff. 48

Jean-Louis Vaulezard: Perspective cilindrique et conique, Paris 1630.

2 Bibl. Uff. 50

Salomon de Caus: La perpective, avec la raison des ombres et miroirs, London 1612.

2 Bibl. Uff. 82 Jean-François Nicéron: La perspective curieuse, Paris 1663.

2 Bibl. Uff. 92

Christoph Scheiner: Rosa Ursina, Bracciano 1629.

2 Bibl. Uff. 99

Giacomo Barozzi da Vignola: Le due regole della prospetiva pratica, Rom 1583.

4 Bibl. Uff. 99

Galileo Galilei: Dialoghi sopra i due massimi sistemi del mondo [...], Leiden 1699.

2 Bibl. Uff. 152

Leonhardt Fronsberger: Kriegsbuch (Teil 1+2), Frankfurt a. M. 1573.

2 Bibl. Uff. 153

Leonhardt Fronsberger: Kriegsbuch (Teil 3), Frankfurt a. M. 1573.

2 Bibl. Uff. 167

Adam Freitag: Architectura Militaris Nova et aucta, [...], Amsterdam 1665.

2 Bibl. Uff. 183

Albrecht Dürer: Etliche vnderricht, zu befestigung der Stett, Schloß, und flecken, Nürnberg 1527.

2 Bibl. Uff. 188

Albrecht Dürer: Opera Alberti Dvreri. Das ist/ Alle Bücher des weitberühmbten und künstreichen Mathematici und Mahlers Albrechten Durers von Nürenberg, Arnheim 1604.
4 Bibl. Uff. 193

Christoph Scheiner: Oculus, Innsbruck 1619.

2 Bibl. Uff. 216

Athanasius Kirchner: Ars Magna Lucis et Umbrae, Rom 1646.

4 Bibl. Uff. 268

Joseph Furttenbach: Mechanische ReißLaden, Augsburg 1644.

4 Bibl. Uff. 279

Benjamin Bramer: Kurtzer Bericht zu seinem Semicirculo, Ulm/Augsburg 1651.

4 Bibl. Uff. 303

Christian von Wolff: Elementa Matheseos Universae, Magdeburg 1715.

2 Bibl. Uff. 309

Johann Christian Schumann: Alchimedon, Dresden 1680.

2 Bibl. Uff. 345

Joachim von Sandrart: Teutsche Academie der Edlen Bau- Bild- und Mahlerey-Künste, Nürnberg, Frankfurt a. M. 1675.

4 Bibl. Uff. 408

Oseas Schadeaus: Summum Argentoratensium Templum, Straßburg 1617.

4 Bibl. Uff. 418

Karel van Mander: Het Schilder Boek, Amsterdam 1618.

2 Bibl. Uff. 439

Johann Jacob Schüber: Sciagraphia Artis Tignariæ, Oder nutzliche Eröffnung zu der sichern fundamentalen Holtz-Verbindung, Nürnberg 1736.

8 Bibl. Uff. 441 [Nicht mehr vorhanden; Ersatzexemplar: DD2003 A 204]

Franz Ernst Brückmann: Die Neu-erfundene Curieuse Fliegen-Falle, o. O. 1735.

2 Bibl. Uff. 442

Johann Jacob Schübler: Neu-inventiert sehr curieusen Frantzösischen Betten, Augsburg ca. 1735.

2 Bibl. Uff. 458

Joachim Ernst Scheffler: Theatri Machinarium Supplementum, Leipzig 1739.

2 Bibl. Uff. 462

Anonym: Abbildungen derer Feuerwercke und Illuminationen, so 1741 und 1742 zu Franckfurt angestellt worden durch J. F. v. U., Augsburg o. J.

2 Bibl. Uff. 467

Anonym: Representaion de la gallerie de S. Girardon. a Paris, o. O. o. J.

2 Bibl. Uff. 472

Johann Gabriel Doppelmayr: Atlas Coelestis, Nürnberg 1742.

8 Bibl. Uff. 506

Peter Ambrosius Lehmann: Die vornehmsten Europæischen Reisen, Hamburg 1706. 
4 Bibl. Uff. 517

Johannes Faulhaber: Ingenieurs-Schul, 4 Bde., Frankfurt a. M. und Ulm 1630-1633.

2 Bibl. Uff. 518 Johannes Faulhaber, Tabula Fortificatoria, Ulm o. J.

8 Bibl. Uff. 519

Philipp von Zeesen: Beschreibung der Stadt Amsterdam, Amsterdam 1664.

8 Bibl. Uff. 523 Arnold Houbraken: Groote Schouburgh, Antwerpen 1718.

2 Bibl. Uff. 562

Johann Friedrich von Uffenbach: Der genesenen Vernunft zufällige Gedancken über alle sonn- und festägliche Evangelia, o. O. o. J.

4 Bibl. Uff. 601 Georg Christoph Petri von Hartenfels: Elephantographia curiosa, Erfurt 1723.

4 Bibl. Uff. 633 Johann Georg Keyßler: Neüeste Reise durch Teütschland, Böhmen, Ungarn, die Schweitz, Italien, und Lothringen [...], 2 Bde., Hannover 1740/41.

4 Bibl. Uff. 670 Johann Christoph Keller (Hrsg.): Geschichte der gemeinen Stubenfliege, Nürnberg 1764.

4 Bibl. Uff. 710 Joseph Furttenbach: Von Sonnenuhren, Augsburg 1652 .

8 Bibl. Uff. 786 Johann David Köhler: Anweisung für Reisende Gelehrte, Frankfurt a. M. und Leipzig 1762.

8 Bibl. Uff. 797 Johann Casper Füssli: Geschichte und Abbildung der besten Mahler in der Schweitz, 2 Bde., Zürich 1755.

\section{Weiterführende Literatur zu Uffenbach und seiner Sammlung}

Anonym: Catalogus von Original-Handzeichnungen, Gemählden und Statuen, nebst einigen Naturalien, wie auch optischen und technischen Maschinen, welche der wohlseel. Herr Johann Friedrich von Uffenbach hinterlassen, [...], Frankfurt a. M. o. J. [1771].

Anonym: Catalogus von Original-Handzeichnungen, Gemählden, Pretiosis und Silbergeschirr, welche des wohlseel. Herrn Johann Friedrich Armand von Uffenbachs [...] leztlich wohlseel. verstorbene Frau Wittib hinterlassen [...], Frankfurt a. M. o. J. [1775].

Max Arnim: Johann Friedrich Armand v. Uffenbachs Schenkung an die Göttinger Universitäts-Bibliothek (1736-1770), in: Beiträge zur Göttinger Bibliotheksund Gelehrtengeschichte, Göttingen 1928, S. 20-39.

Max Arnim (Hrsg.): Johann Friedrich Armand von Uffenbach's Tagbuch einer Spazierfarth durch die
Hessische in die Braunschweig-Lüneburgischen Lande (1728), Göttingen 1928.

Max Arnim (Hrsg.): Johann Friedrich v. Uffenbachs Reise durch die Pfalz im Jahre 1731, Mannheim 1928.

Max Arnim (Hrsg.): Pharasmanes. Ein Singspiel mit 15 Bühnenbildern von Johann Friedrich von Uffenbach, Berlin 1930.

Arwed Arnulf: Jenseits der Kennerschaft. Intentionen gelehrten Graphiksammelns, in: Aachener Kunstblätter 67(2018/19), 2021, S. 35-74.

Hermann Bode (Hrsg.): Nachrichten über Pariser Bibliotheken. Aus einem Reisetagebuch des Johann Friedrich Armand von Uffenbach, Göttingen 1961.

Konrad Franke: Zacharias Conrad von Uffenbach als Handschriftensammler. Ein Beitrag zur Kulturgeschichte des 18. Jahrhunderts, Frankfurt a. M. 1965.

Wilhelm Meyer (Hrsg.): Verzeichnis der Handschriften im Preussischen Staate: Die Handschriften in Göttingen, Bd. I 3, 3: Universitäts-Bibliothek: Nachlässe von Gelehrten, Orientalische Handschriften, Handschriften im Besitz von Instituten und Behörden, Register zu Band 1-3, Berlin 1894.

Dietrich Meyerhöfer: Johann Friedrich von Uffenbach: Sammler - Stifter - Wissenschaftler, (Diss. Univ. Göttingen), Göttingen 2020.

Thomas Nickol (Bearb.): Georg Christoph Lichtenberg. Gesammelte Schriften. Historisch-kritische und kommentierte Ausgabe, hrsg. von der Akademie der Wissenschaften zu Göttingen, Bd. 6: Vorlesungen zur Naturlehre - Instrumentenverzeichnis, Göttingen 2017.

Ernst Polaczek: Das Strassburger Tagebuch des Johann Friedrich von Uffenbach aus Frankfurt (17121714), in: Elsaß-Lothringisches Jahrbuch 1, Berlin/ Leipzig 1922, S. 68-122.

Eberhard Preussner: Die musikalischen Reisen des Herrn von Uffenbach. Aus einem Reisetagebuch des Johann Friedrich A. von Uffenbach aus Frankfurt a. M. 1712-1716, Kassel 1949.

Johann Georg Schelhorn (Hrsg.): Herrn Zacharias Conrad von Uffenbach Merkwürdige Reisen durch Niedersachsen, Holland und Engelland, 3 Bde., Ulm 1753-1754.

Anne-Katrin Sors: Tieck, Fiorillo und Uffenbach - Zum Einfluß niederländischer und deutscher Kunst auf die frühe Romantik an der Göttinger Universität nebst sammlungsgeschichtlichen Funden zum Erwerb des Arhardtschen Nachlasses, in: Niederdeutsche Beiträge zur Kunstgeschichte NF 4, 2019, S. 161-171.

Gerd Unverfehrt (Hrsg.): Zeichnungen von Meisterhand. Die Sammlung Uffenbach aus der Kunstsammlung der Universität Göttingen, Göttingen 2000. 



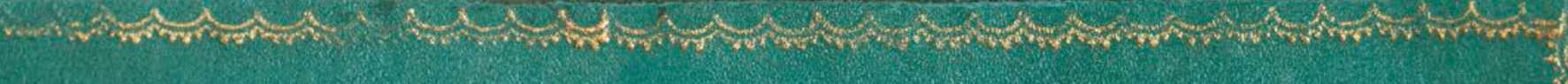

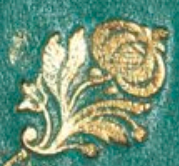

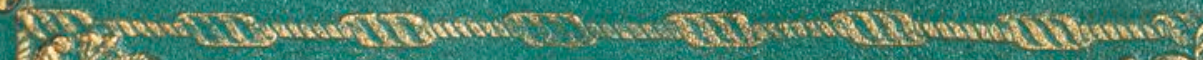
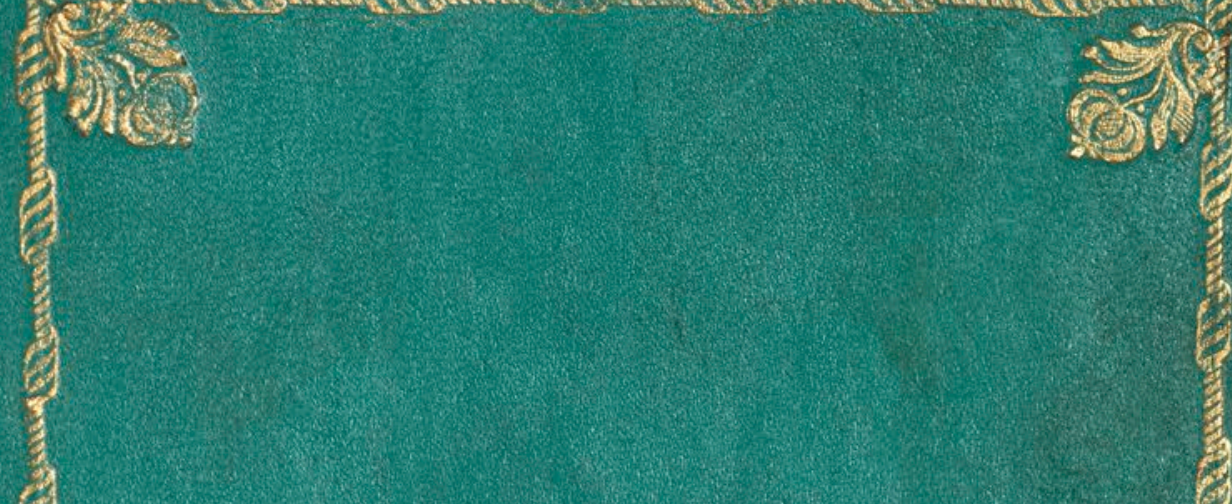

(3)
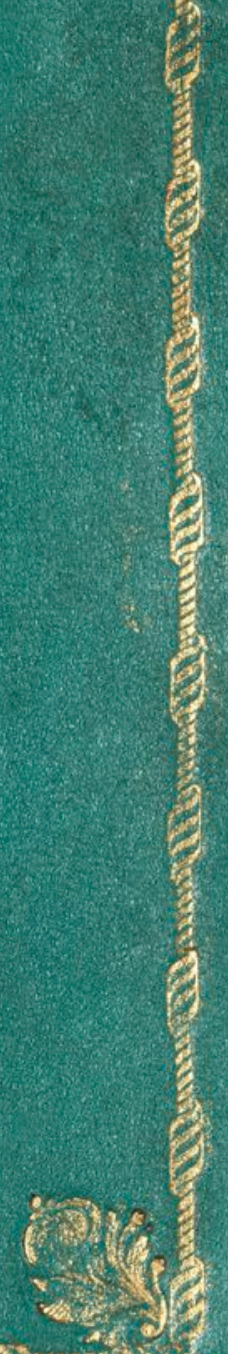

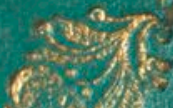

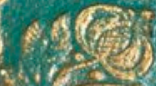

(8)

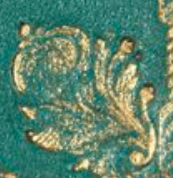

Them 6.

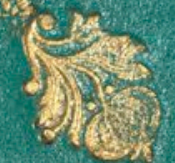

